\title{
Helena França
}

\section{METODOLOGIA DE IDENTIFICAÇÃO E QUANTIFICAÇÃO DE ÁREAS QUEIMADAS NO CERRADO COM IMAGENS AVHRR/NOAA}




\section{Helena França}

\section{METODOLOGIA DE IDENTIFICAÇÃO E QUANTIFICAÇÃO DE ÁREAS QUEIMADAS NO CERRADO COM IMAGENS AVHRR/NOAA}

Tese apresentada ao Instituto de Biociências da Universidade de São Paulo, para a obtenção de Título de Doutor em Ciências, na Área de Ecologia.

Orientador: Dr. Alberto Setzer

São Paulo 


\section{AGRADECIMENTOS}

Agradeço às Instituições que viabilizaram a realização deste trabalho: Instituto de Biociências da Universidade de São Paulo (IB/USP); Instituto Nacional de Pesquisas Espaciais (INPE); Fundação de Amparo à Pesquisa do Estado de São Paulo (FAPESPProc. 97/07695-0).

Meus sinceros agradecimentos ao Dr. Alberto Setzer, pela orientação, discussões, confiança e incentivo à realização desta pesquisa.

E também a todos pesquisadores e funcionários que me auxiliaram nas diversas fases deste trabalho, em ordem alfabética:

MsC Adriana Mattedi (LAC/INPE); Alessandra de Pádua (DSA/INPE); MsC Alfredo da Costa Pereira; MsC Anibal Evaristo Fernandes (DSR/INPE); Dr. Bernardo Rudorff (DSR/INPE); MsC Camilo Daleles (DSR/INPE); Cláudia Martins (DSA/INPE); MsC Eymar Lopes (DPI/INPE); Gonzalo Valenzuela (DSA/INPE) ; Heber Reis Passos (LMO/INPE); Júlio Aragão (LTID/INPE); Dr. Leopoldo Magno Coutinho (IB/USP); Marilene Alves (LMO/INPE); Dra. Marisa Bittencourt (IB/USP); Paulino Rodrigues (DSR/INPE); Ricardo A. Braga (DSA/INPE); Rovedy Busquim (DSR/INPE); MsC Sergio Pereira (DSA/INPE); Dra. Thelma Krug (OBT/INPE); Valéria Pelodan (LTID/INPE); Dra. Vania Pivello (IB/USP); Dr. Waldir Mantovani (IB/USP).

Agradeço ainda, aos meus amigos e familiares: Halina; Lucas; Marisa; Renato; Sérgio; Sarah; Tatiana; Regina; e Lilian. 


\section{RESUMO}

Desenvolveu-se nesse trabalho uma metodologia para identificar e quantificar quinzenalmente a área queimada na região contínua do Cerrado brasileiro a partir de imagens diárias do sensor AVHRR (Advanced Very High Resolution Radiometer) do satélite NOAA-14 (National Oceanic and Atmospheric Administration), utilizando as bandas $1(0,6 \mu \mathrm{m}), 2(0,9 \mu \mathrm{m}), 3(3.7 \mu \mathrm{m})$ e IVDN (Índice de Vegetação de Diferença Normalizada). A variação temporal de características das áreas queimadas e outras superfícies, obtida de mosaicos quinzenais das imagens AVHRR, foi a base para elaborar um algoritmo de identificação de "cicatrizes" de queimadas. Os resultados foram validados e ajustados com dados de alta resolução espacial obtidos em imagens TM/Landsat (Thematic Mapper). A análise estatística de regressão linear entre os dados de queimadas obtidos pela aplicação do algoritmo nos mosaicos AVHRR e aqueles das imagens TM gerou duas equações para estimar a área queimada no Cerrado com $r^{2}=0,8$ e 0,7 . Com a aplicação da metodologia desenvolvida, estimou-se em $\sim 429.000 \mathrm{~km}^{2}$ a área queimada (entre $404.000 \mathrm{~km}^{2}$ e $455.000 \mathrm{~km}^{2}$ com intervalo de confiança a $95 \%$ ) no período de $01 /$ maio/98 a 30/abril/99, correspondendo a $19 \%$ (18 a $20 \%$ ) da área total estudada. A relação entre focos de queimadas obtidos do AVHRR/NOAA-12 e área queimada permitiu cálculos preliminares de área queimada no Cerrado no período de $01 /$ maio/99 a 31/outubro/00. Os dados TM mostraram que as queimadas pequenas, menores que $0,5 \mathrm{~km}^{2}$, embora muito numerosas ( $53 \%$ do total), respondem por apenas $\sim 2 \%$ da área queimada. Por outro lado, as queimadas grandes, maiores que $10 \mathrm{~km}^{2}$, são poucas $(8 \%)$, mas responsáveis por cerca de $74 \%$ da área queimada no Cerrado. Os resultados desse trabalho mostraram pela primeira vez que é possível estimar regularmente a área queimada no Cerrado com erro inferior a $15 \%$ no cálculo anual a partir dos dados diários do AVHRR. Tais estimativas poderão subsidiar estudos sobre o papel ecológico do fogo no Cerrado, planejamento ambiental em nível regional, localização das áreas críticas com ocorrências mais freqüentes de queimadas, implantação de planos de uso, manejo e fiscalização do uso do fogo em escala regional, cálculos de emissões de queimadas, etc. 


\begin{abstract}
This work presents the development of a methodology to identify and quantify the surface burnt in the Brazilian contiguous Cerrado on a bi-weekly basis using daily images of the AVHRR (Advanced Very High resolution Radiometer) sensor on-board the NOAA-14 (National Oceanographic and Atmospheric Administration) satellite after its bands $1(0,6 \mu \mathrm{m}), 2(0,9 \mu \mathrm{m})$ and $3(6,7 \mu \mathrm{m})$, as well as the NDVI (Normalized Difference Vegetation Index). The temporal variation of the burnt areas and of other surface covers in bi-weekly AVHRR mosaics was the basis for an algorithm to identify the "scars" from vegetation fires. The results were validated and adjusted with high resolution data from TM-Landsat (Thematic Mapper). The statistical analysis of linear regression between the fire data obtained with the use of the algorithm and those of the TM produced two equations to estimate burnt area in the Cerrado, with $\mathrm{r}^{2}=0.8$ and 0.7. Applying the methodology developed, $429,000 \mathrm{~km}^{2}$ burned in the period of May/01/98 to April/04/99 (range of 404,000 to $455,000 \mathrm{~km}^{2}$ for the $95 \%$ confidence interval), corresponding to $19 \%$ (18 to $20 \%$ ) of the total study area. The relation between active fires obtained with AVHRR/NOAA-12 and the burnt area supplied preliminary estimates of burnt area in the Cerrado from May/01/99 to Oct/31/00. The TM data showed that small scars, with less than $0.5 \mathrm{~km}^{2}$, although numerous ( $53 \%$ of the total), account for just $\sim 2 \%$ of the burnt area. Large scars, with more than $10 \mathrm{~km}^{2}$, correspond to a small number ( $8 \%$ ), but to $74 \%$ of the Cerrado burnt area. The results of this work showed for the first time that it is possible to estimate on a regular basis the Cerrado yearly burnt area with an error smaller than $15 \%$, using daily AVHRR data. These estimates should provide important information to understand the ecological role of fire in the Cerrado, identify areas with higher fire frequency, help environmental planning at regional levels, and plan soil use and control, as well as provide subsidies in biomass burning emission studies. Data from new sensors in satellites to be made available in 2001 should improve even further the methodology developed.
\end{abstract}




\section{ÍNDICE}

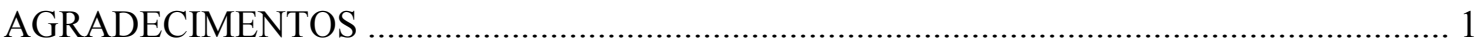

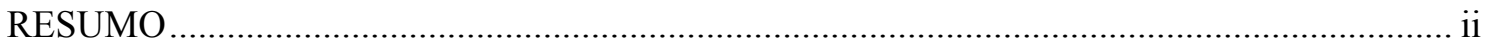

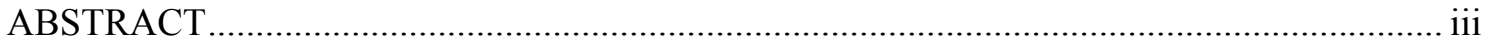

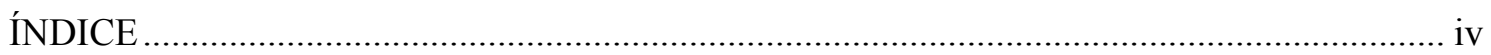

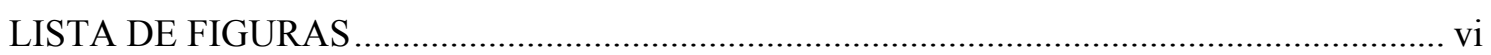

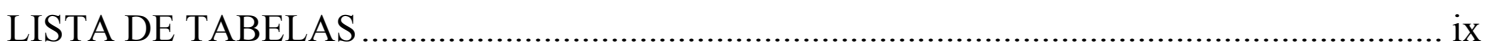

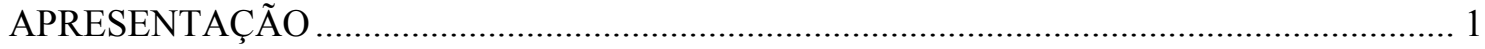

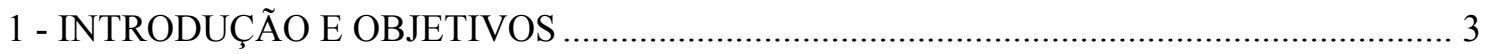

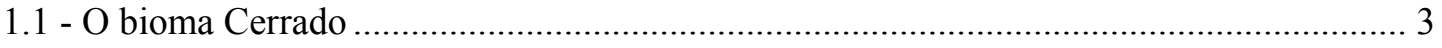

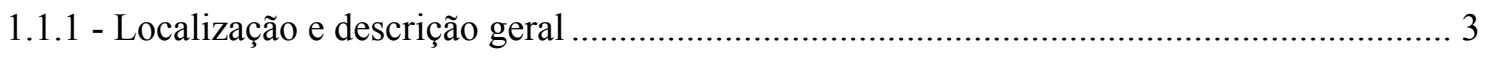

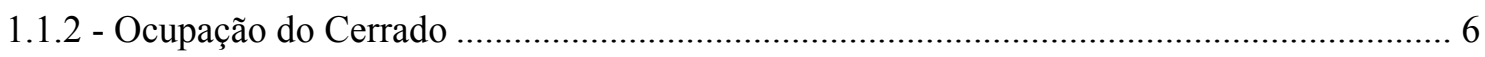

1.2 - Quantificações de queimadas nos Cerrado.................................................................. 9

1.3 - As queimadas no Cerrado e emissões de carbono, gases-traço e material particulado .. 13

1.4 - Características espectrais das queimadas ...................................................................... 19

1.5 - Identificação e estimativas de áreas queimadas com imagens orbitais ........................... 22

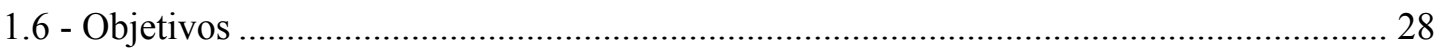

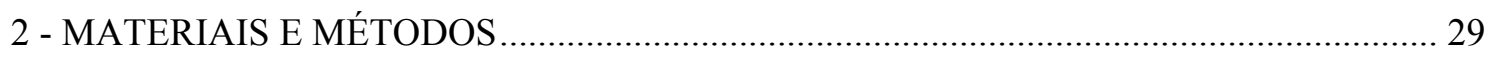

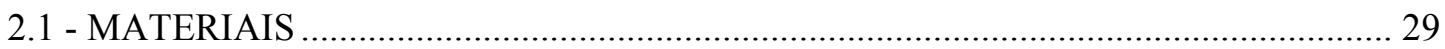

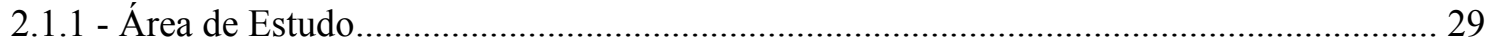

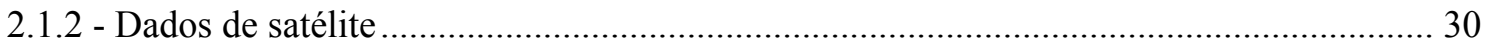

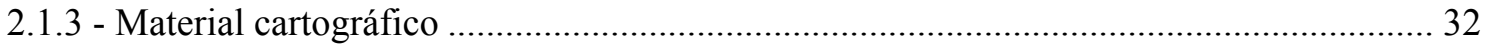

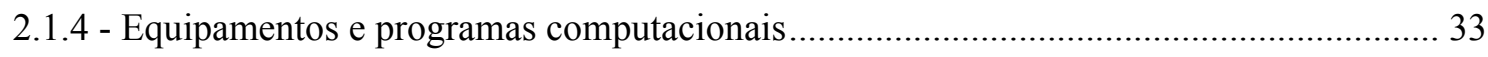

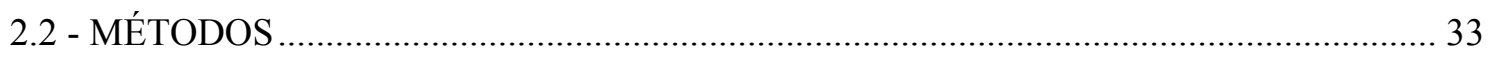

2.2.1 - Regravação das imagens AVHRR/NOAA-14 _.............................................................. 34

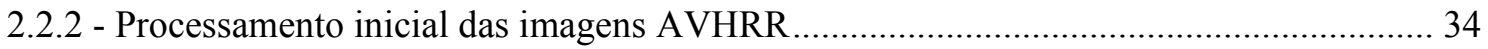

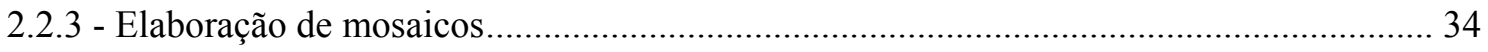

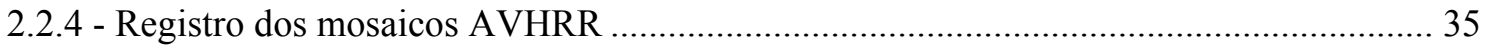

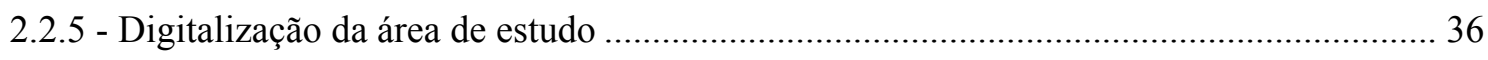

2.2.6 - Variação temporal do IVDN e dos valores digitais das bandas 1, 2 e 3 do AVHRR ...... 36

2.2.7 - Elaboração do algoritmo de avaliação de áreas queimadas ............................................. 37

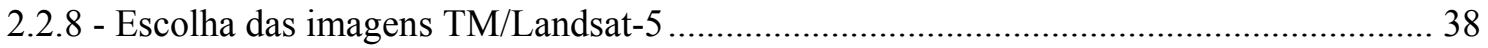


2.2.9 - Registro das imagens TM/Landsat 39

2.2.10 - Interpretação das imagens TM/Landsat............................................................ 39

2.2.11 - Elaboração adicional de mosaicos AVHRR/NOAA-14 ....................................... 41

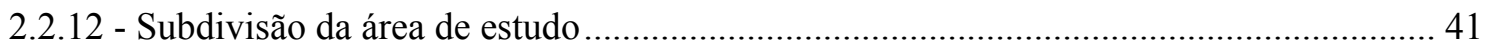

2.2.13 - Aplicação do algoritmo de avaliação de áreas queimadas .......................................... 42

2.2.14 - Comparação dos dados AVHRR com os dados TM.................................................43

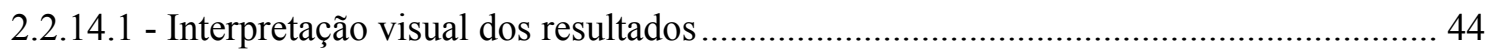

2.2.14.2 - Estimativas de áreas queimadas por células .............................................. 45

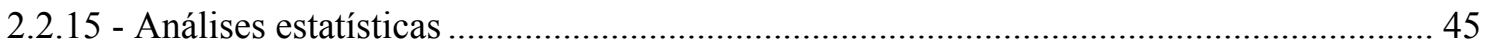

2.2.16 - Estimativas de áreas queimadas para o Cerrado .................................................... 50

2.2.17 - Relação entre os dados AVHRR/NOAA-14 e AVHRR/NOAA-12 ............................ 52

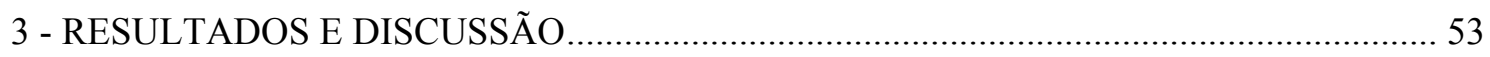

3.1 - Mosaicos AVHRR/NOAA-14 e registro ........................................................... 53

3.2 - Variação temporal dos números digitais e do IVDN nos mosaicos AVHRR .............. 58

3.3 - Algoritmo de identificação de área queimada .................................................... 63

3.4 - Delimitação das áreas queimadas nas imagens TM/Landsat .................................... 66

3.5 - Avaliação de área queimada nas imagens TM/Landsat ............................................ 70

3.6- Caracterização das queimadas a partir das imagens TM/Landsat ................................ 71

3.7 - Uso do algoritmo para identificar queimadas nas regiões de Mato Grosso, Goiás e Bahia

3.8 - Resultados da interpretação visual dos dados ............................................... 82

3.9 - Aplicação do algoritmo de identificação de queimadas para todo Cerrado .................. 84

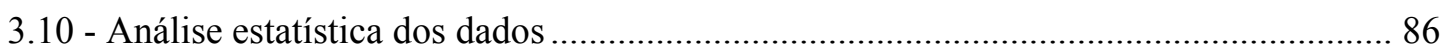

3.10 .1 - Teste de Kolmogorov-Smirnov para duas amostras ................................................. 86

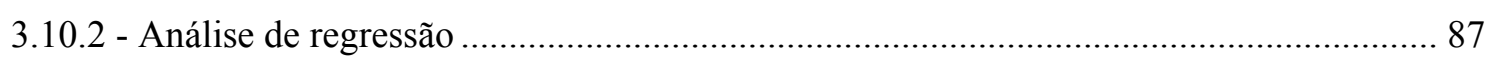

3.11 - Estimativas quinzenais de áreas queimadas no Cerrado ...................................... 100

3.12 - Relação das estimativas de áreas queimadas obtidas nos mosaicos com focos de queimada do AVHRR-NOAA-12 ...................................................................... 105

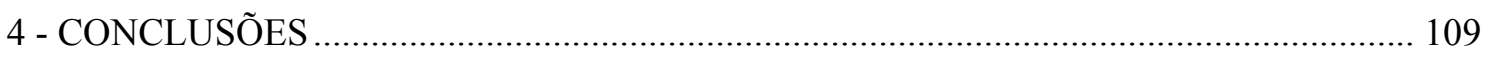

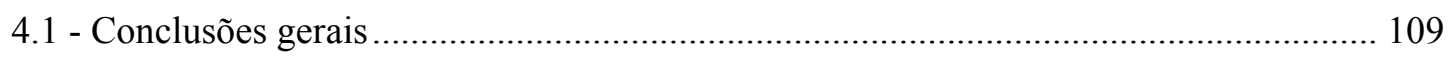

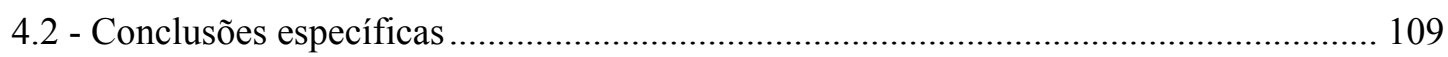

4.3 - Recomendações e trabalhos futuros .................................................................. 112

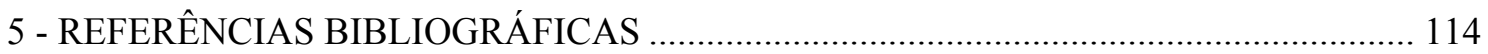

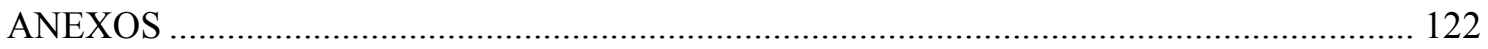




\section{LISTA DE FIGURAS}

Figura 1.1 - Evolução do número de focos de queimadas detectados pelo NOAA-12 em 1998, 1999 e 2000; CPTEC (2000).

Figura 1.2 - Ocorrência de focos de fogo detectados pelo NOAA-12 em agosto e setembro de 1998 (CPTEC, 2000).

Figura 1.3 - Número de focos de fogo detectados pelo NOAA-12 em Mato Grosso, Goiás e Tocantins em 1998; baseado em CPTEC (2000).

Figura 1.4 - Contribuição das queimadas nas emissões globais de gases traços e material particulado para a atmosfera; baseada em Andreae et al. (1996).

Figura 1.5 - Imagens TM Landsat do cerrado mato-grossense de 01/agosto/98 (a) e 17/agosto/98 (b), mostrando (1) o rápido início da rebrota da vegetação e o (2) desaparecimento das marcas de uma queimada em menos de 16 dias.

Figura 2.1 - Área contínua do Cerrado determinada a partir do Mapa de Vegetação do Brasil; baseado em IBGE (1993).

Figura 2.2 - Regiões Cerrado 1 e Cerrado 2 com localização das imagens TM/Landsat: A - Mato Grosso (225/70); B - Goiás (221/70); C - Bahia (220/68).

Figura 3.1 - Mosaico AVHRR/NOAA-14 com limite do Cerrado, banda 1; 2ª quinzena de julho/98.

Figura 3.2 - Mosaico AVHRR/NOAA-14 com limite do Cerrado, banda 2; 2 $2^{\mathrm{a}}$ quinzena de julho/98. 55

Figura 3.3 - Mosaico AVHRR/NOAA-14 com limite do Cerrado, banda 3; 2 $2^{\mathrm{a}}$ quinzena de julho/98. 56

Figura 3.4 - Mosaico AVHRR/NOAA-14 com limite do Cerrado, IVDN; $1^{\text {a }}$ quinzena de agosto/98.

Figura 3.5 - Variação quinzenal dos números digitais nos mosaicos das bandas 1,2 e 3 e do IVDN na área $21, \mathrm{MT}, 1^{\circ} 07^{\prime} 18^{\prime \prime} \mathrm{S}$ e $53^{\circ} 23^{\prime} 20.38^{\prime \prime} \mathrm{W}$; ocorrência de queimada na $8^{\mathrm{a}}$ quinzena (agosto/98).

Figura 3.6 - Variação quinzenal dos números digitais nos mosaicos das bandas 1,2 e 3 e do IVDN na área $19, \mathrm{MG}, 17^{\circ} 42^{\prime} 44.31^{\prime \prime S}$ e $45^{\circ} 14^{\prime} 35.90^{\prime \prime} \mathrm{W}$; ocorrência de queimada na $8^{\mathrm{a}}$ quinzena (agosto/98).

Figura 3.7 - Variação quinzenal dos números digitais nos mosaicos das bandas 1,2 e 3 e do IVDN na área $25, \mathrm{MT}, 1^{\circ} 41^{\prime} 54.2^{\prime \prime} \mathrm{S}$ e $59^{\circ} 29^{\prime} 8,6^{\prime \prime} \mathrm{W}$; sem ocorrência de queimada.

Figura 3.8 - Variação quinzenal dos números digitais nos mosaicos das bandas 1,2 e 3 e do IVDN na área 5, BA, $12^{\circ} 35^{\prime} 1.9^{\prime \prime} \mathrm{S}$ e $45^{\circ} 59^{\prime} 4.0^{\prime \prime} \mathrm{W}$; área agrícola com ocorrência de reflexo na banda 3.

Figura 3.9 - Variação quinzenal dos números digitais nos mosaicos das bandas 1,2 e 3 e do IVDN na área $12, \mathrm{TO}, 12^{\circ} 24^{\prime} 49,2^{\prime \prime S}$ e $50^{\circ} 48^{\prime} 32.6^{\prime \prime} \mathrm{W}$; ocorrência de queimada na $7^{\mathrm{a}}$ quinzena (julho/98).

Figura 3.10 - Variação quinzenal dos números digitais nos mosaicos das bandas 1, 2 e 3 e do

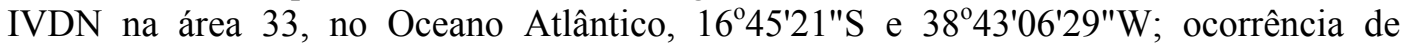
reflexos na banda 3 
Figura 3.11 - Queimadas ocorridas em Mato Grosso no período 01 a 17/agosto/98, segundo interpretação das imagens TM/Landsat 225/70; nuvens estão em azul.

Figura 3.12 - Queimadas ocorridas em Goiás no período de 21/agosto a 06/setembro/98, segundo interpretação das imagens TM/Landsat 221/70. 68

Figura 3.13 - Queimadas ocorridas em Bahia no período de 14 a 30/agosto/98, segundo interpretação das imagens TM/Landsat 220/68

Figura 3.14 - Número de polígonos e área das queimadas ocorridas no período de 01 a 17/agosto/98 na região de Mato Grosso (TM 225/70).

Figura 3.15 - Número de polígonos e área das queimadas ocorridas no período de 21/agosto a 06/setembro/98 na região de Goiás (TM 221/70).

Figura 3.16 - Número de polígonos e área das queimadas ocorridas no período de 14 a 17/agosto/98 na região de região da Bahia (TM 220/68).

Figura 3.17 - Número de polígonos e área das queimadas ocorridas nas regiões de Mato Grosso, Goiás e Bahia (TM 225/70; 221/70; 220/68), em períodos de 16 dias durante a estação seca de 1998.

Figura 3.18 - Freqüência relativa das áreas queimadas nas três áreas de estudo combinadas. ... 76

Figura 3.19 - Freqüência relativa acumulada das áreas queimadas nas três áreas de estudo combinadas.

Figura 3.20 - Aplicação do algoritmo de identificação de queimadas nos mosaicos AVHRR, região de Mato Grosso, 01 a 16/agosto/98. 78

Figura 3.21 - Aplicação do algoritmo de identificação de queimadas nos mosaicos AVHRR, região de Goiás, 21/agosto a 05/setembro/98.

Figura 3.22 - Aplicação do algoritmo de identificação de queimadas nos mosaicos AVHRR, região da Bahia, 14 a 30/agosto/98.

Figura 3.23 - Estimativas de áreas queimadas obtidas das imagens TM/Landsat e da aplicação do algoritmo de identificação de queimadas nos mosaicos AVHRR/NOAA-14. Notar discrepância na Bahia, devido a reflexos na banda 3 do AVHRR. 82

Figura 3.24 - Exemplo da visualização da classificação das queimadas nos mosaicos AVHRR (em vermelho), juntamente com os contornos das queimadas obtidos das imagens TM; região correspondente ao quadrante superior direito da imagem TM de Mato Grosso. .... 83

Figura 3.25 - Exemplo de aplicação do algoritmo nos mosaicos de agosto/98 mostrando queimadas, queimadas anteriores, reflexos em rios, nuvens e solos agrícolas.

Figura 3.26 - Dispersão dos erros padronizados para os dados originais das regiões de Mato Grosso e Goiás (Cerrado 1). 89

Figura 3.27 - Dispersão dos erros padronizados para os dados originais da região da Bahia (Cerrado2). 89

Figura 3.28 - Dispersão do erros padronizados para os dados transformados das regiões de Mato Grosso e Goiás (Cerrado 1); os outliers, posteriormente removidos, estão assinalados.

Figura 3.29 - Dispersão dos erros padronizados para os dados transformados da região da Bahia (Cerrado1); o outlier, posteriormente removido, está assinalado. 
Figura 3.30 - Regressão linear com os dados transformados da área queimada nos mosaicos AVHRR $(\mathrm{km})$ e nas imagens TM $(\mathrm{km})$ nas regiões de Mato Grosso e Goiás - Cerrado 1.

Figura 3.31 - Regressão linear com os dados transformados da área queimada nos mosaicos AVHRR $(\mathrm{km})$ e nas imagens TM $(\mathrm{km})$ na região da Bahia - Cerrado 2. 96

Figura 3.32 - Intervalo de confiança para os dados de regressão das regiões de Mato Grosso e Goiás - Cerrado 1

Figura 3.33 - Intervalo de confiança para os dados de regressão da Bahia - Cerrado 2........... 98

Figura 3.34 - Reta de regressão e intervalos de confiança para dados de área queimada do AVHRR e TM nas regiões de Mato Grosso e Goiás — Cerrado 1.................................... 99

Figura 3.35 - Reta de regressão e intervalos de confiaça para dados de área queimada do AVHRR e TM na região da Bahia - Cerrado 2. 99

Figura 3.36 - Área queimada quinzenalmente no Cerrado no período de maio/98 a abril/99 estimada com os mosaicos AVHRR/NOAA-14.

Figura 3.37 - Freqüência acumulada relativa da área queimada no Cerrado nas quinzenas do período de maio/98 a abril/99. 104

Figura 3.38 - Modelo linear de regressão entre focos de queimadas detectados pelo AVHRR/NOAA-12 e área queimada estimada nos mosaicos AVHRR/NOAA-14......... 106

Figura 3.39 - Estimativas preliminares de área queimada no Cerrado no período maio/99 a outubro/00, obtidas dos dados AVHRR/NOAA-12. 


\section{LISTA DE TABELAS}

Tabela 1.1 - Número de polígonos e área queimada no cerrado por classes de tamanho, conforme PNUD ( 2000).

Tabela 2.1 - Classes de vegetação utilizadas para delimitar a área de estudo; baseada em IBGE (1993).

Tabela 2.2 - Parâmetros orbitais e espectrais do AVHRR-NOAA; adaptado de Kidwell (1995 e 1998).

Tabela 2.3 - Localização das áreas amostrais nos mosaicos AVHRR/NOAA-14.

Tabela 3.1 - Número de imagens utilizadas nos mosaicos AVHRR, de pontos de controle e erro de registro.

Tabela 3.2 - Total de área queimada entre duas passagens consecutivas do TM/Landsat em três regiões do Cerrado, na estação seca de 1998.

Tabela 3.3 - Número de polígonos e área queimada por classes de tamanho na região de Mato Grosso.

Tabela 3.4 - Número de polígonos e área queimada por classes de tamanho na região de Goiás.

Tabela 3.5 - Número de polígonos e área queimada por classes de tamanho na região da Bahia.

Tabela 3.6 - Número de polígonos de queimadas e área queimada por classe de tamanho nas três áreas de estudo.

Tabela 3.7 - Estimativas brutas de áreas obtidas nos mosaicos através do algoritmo de identificação de queimadas nas regiões de Mato Grosso, Goiás e Bahia............................ 81

Tabela 3.8 - Totais brutos de áreas queimadas obtidos das imagens TM e dos mosaicos AVHRR.

Tabela 3.9 - Quantidade de polígonos de queimadas identificados nas imagens TM e sua correspondência nos mosaicos AVHRR.

Tabela 3.10 - Área queimada obtida dos polígonos das imagens TM e sua correspondência com os mosaicos AVHRR.

Tabela 3.11 - Resultados do teste de Kolgomorov-Smirnov para pares de amostras. 87

Tabela 3.12 - Dados brutos de área queimada por célula, obtidos dos mosaicos AVHRR (coluna $\mathrm{X}, \mathrm{em} \mathrm{\textrm {km } ^ { 2 }}$ ) e das imagens TM (coluna $\mathrm{Y}, \mathrm{km}^{2}$ ), colocados em ordem crescente segundo área de $\mathrm{Y}$.

Tabela 3.13 - Valores transformados de X e Y, erro e erro médio padronizado para a região de Mato Grosso e Goiás (Cerrado 1); os outliers foram suprimidos. 90

Tabela 3.14 - Valores transformados de X e Y, erro e erro médio padronizado para a região da Bahia (Cerrado 2); o outlier foi suprimido.

Tabela 3.15 - Análise de regressão para a região Cerrado 1 (MT/GO) ……................................ 94

Tabela 3.16 - Teste t-student para a região Cerrado 1 (MT/GO) .................................................. 94

Tabela 3.17 - Análise de regressão para a região Cerrado 2 (BA).............................................. 94 
Tabela 3.18 - Teste t-student para a região Cerrado 1 (BA). 94

Tabela 3.19 - Análise de regressão com reta passando pela origem, para a região Cerrado 1 (MT/GO). 95

Tabela 3.20 - Teste t-student com reta passando pela origem, para a região Cerrado 1(MT/GO). 95

Tabela 3.21 - Análise de regressão com reta passando pela origem, para a região Cerrado 2 (BA) 95

Tabela 3.22 - Teste t-student com reta passando pela origem, para a região Cerrado 2 (BA).... 95

Tabela 3.23 - Resultados da aplicação do teste de Kolmogorov-Smirnov. 97

Tabela 3.24 - Estimativas quinzenais de $Y_{1}^{\prime}$ e $Y_{2}^{\prime}{ }_{2}$ de todo o Cerrado no período de 15/maio/98 a 30/abril/99. 101

Tabela 3.25 - Resultados da simulação de Monte Carlo para obtenção da área total quinzenal $\left(m Y_{t}\right)$.

Tabela 3.26 - Número de focos de queimada ativa detectados pelo AVHRR/NOAA-12 no Cerrado e área queimada estimada nos mosaicos AVHRR/NOAA-14. 105

Tabela 3.27 - Estimativa preliminar de área queimada no Cerrado a partir do número de focos de queimada detectados pelo AVHRR/NOAA-12. 107 


\begin{abstract}
APRESENTAÇÃO
Embora a ocorrência de fogo no cerrado seja um evento natural, sua atual utilização, principalmente como técnica de manejo de pastagens e de abertura de frentes agrícolas, principalmente, é freqüente e generalizada. Os efeitos do fogo no cerrado têm sido objeto de estudos acadêmicos desde a década de 40. Demonstrou-se sua importância na ciclagem de nutrientes, na fenologia da vegetação, e nas adaptações das plantas aos seus efeitos, porém sempre em estudos de escalas locais. O desenvolvimento de tecnologias espaciais de observação da Terra, a partir da década de 70, possibilitou dimensionar a ocorrência de queimadas em nível global. Mas, foi somente na década 80, com a preocupação da comunidade científica com os possíveis efeitos das queimadas no clima do planeta, que a questão ganhou importância. Imagens de satélites mostraram milhares de focos de queimadas ocorrendo diariamente nas savanas africanas, e também na Amazônia e Cerrado do Brasil. Desde então, o tema queimadas tornou-se assunto polêmico no país e ganhou importância internacional. As emissões de queimadas, em particular, dos gases-traços e seus possíveis efeitos climáticos passaram a ser uma das principais preocupações da comunidade científica. Porém, a questão das queimadas vai muito além, pois deve-se avaliar seus efeitos na manutenção da biodiversidade, na conservação dos solos, na ciclagem de nutrientes, na redução da radiação fotossinteticamente ativa na superfície da Terra, no comprometimento da saúde humana e na provável redução da produção agrícola, etc.

As únicas estimativas existentes acerca da ocorrência de queimadas no Cerrado são as contagens de focos de fogo por satélites que, no entanto, não indicam a extensão das queimadas no bioma, deixando assim de responder uma das principais questões ambientais. Neste contexto, este trabalho teve como principal objetivo desenvolver uma metodologia para estimar de forma rápida, relativamente precisa, e de baixo custo, a extensão da superfície queimada no Cerrado, e assim dar suporte a estudos em ecologia, principalmente aqueles que tenham a conservação do Cerrado como prioritária. Cabe também esclarecer que a realização deste trabalho procurou contribuir para o avanço do
\end{abstract}


conhecimento sobre efeitos do fogo no Cerrado, criando insumos para grupos nacionais já estabelecidos nesta área.

Para tanto, utilizaram-se, as imagens diárias do satélite meteorológico NOAA. Esses dados possuem características desejáveis para o estudo queimadas: alta repetitividade, área de abrangência quase continental, e capacidade de identificar focos ativos e também cicatrizes de queimadas. Por outro lado, procurou-se avaliar e minimizar aquela que seria sua maior limitação: a resolução espacial limitada a $1,1 \mathrm{~km}^{2}$.

Inicialmente, apresenta-se uma descrição sucinta da área de estudo e um breve histórico da ocupação de Cerrado; mostra-se também os trabalhos já existentes sobre a quantificação das queimadas no bioma e uma revisão técnica de utilização de imagens de sensores orbitais para estimar área queimada. Descreve-se, em seguida, o material e a metodologia utilizada e, finalmente, são apresentados e discutidos os resultados obtidos. 


\section{1 - INTRODUÇÃO E OBJETIVOS}

\section{1 - O bioma Cerrado}

\subsection{1 - Localização e descrição geral}

O Cerrado localiza-se, em sua maior parte, no Planalto Central do Brasil, e sua área contínua abrange integralmente o estado de Goiás e o Distrito Federal, grande parte dos estados de Mato Grosso do Sul, Tocantins, Minas Gerais, Mato Grosso e Piauí e porções menores da Bahia, Maranhão, Ceará, Rondônia, São Paulo. Áreas disjuntas são encontradas no Amapá, Pará, Roraima e São Paulo. A região do Cerrado localiza-se entre $3^{\circ}$ e $24^{\circ}$ de latitude Sul e entre $42^{\circ}$ e $65^{\circ}$ de longitude Oeste, excluindo alguns enclaves. No entanto, cerca de $70 \%$ de sua área situa-se entre $10^{\circ}$ e $20^{\circ}$ de latitude, numa região dominada por amplos planaltos (Dias, 1996; IBGE, 1993).

Há divergências nas estimativas da área total abrangida por esse bioma. Azevedo e Adámoli (1988) avaliaram, a partir dos dados do Projeto Radam de 1973, esta área, incluindo, também, a vegetação de transição com outros biomas e áreas disjuntas, em cerca de 2,4 milhões de $\mathrm{km}^{2}$. Pereira (1992) estimou a área contínua total do bioma em cerca de 2,2 milhões de $\mathrm{km}^{2}$, incluindo as áreas de Tensão Ecológica (transição), a partir do Mapa de Vegetação do IBGE (1988). Com base nos resultados de Azevedo e Adámoli (1988), Dias (1996) avaliou a área do bioma em aproximadamente 2,04 milhões de $\mathrm{km}^{2}$. De qualquer forma, as dimensões do Cerrado fazem dele o segundo maior bioma do Brasil, ocupando cerca de $25 \%$ do território nacional.

O termo "cerrado" tem diversos usos e significados na literatura, e sua utilização tem gerado controvérsias e dificuldades de comparação de trabalhos. Neste trabalho, Cerrado grafado com inicial em maiúscula, refere-se ao bioma predominante no Brasil Central, conforme sugerido por Ribeiro e Walter (1998). 
O Cerrado ocorre em altitudes que variam de cerca de $300 \mathrm{~m}$ a mais de $1.600 \mathrm{~m}$, mas metade de sua área situa-se entre 300 e $600 \mathrm{~m}$, e somente cerca de 5\% ocorre acima de 900 m (Ribeiro e Walter, 1998; Dias, 1996).

O clima dominante da região é tropical-quente-subúmido (Aw). Ao sul do bioma e nos locais mais altos, acima de $1.200 \mathrm{~m}$ de altitude, pode ocorrer o clima Cwa tropical de altitude. A temperatura de região se mantém elevada durante a primavera e o verão, quando registram-se médias mensais de $26^{\circ}$ a $28^{\circ} \mathrm{C}$ no norte, $24^{\circ}$ a $26^{\circ} \mathrm{C}$ no centro e sul, e inferiores a $24^{\circ} \mathrm{C}$ nas altitudes mais elevadas. No inverno, a temperatura média do mês mais frio é superior a $18^{\circ} \mathrm{C}$ e, com exceção das terras altas, na maior parte da região do Cerrado não há nenhum mês cuja média mensal seja inferior a $20^{\circ} \mathrm{C}$. No entanto, as médias das temperaturas mínimas diárias podem variar entre $6^{\circ}$ e $16^{\circ} \mathrm{C}$, conforme a latitude e a altitude do local, e mínimas absolutas de $0^{\circ} \mathrm{C}$ não são raras (Nimer e Brandão, 1989; Ribeiro e Walter, 1998).

O total anual de chuvas no Cerrado varia de 600 a $2.200 \mathrm{~mm}$, mas em $65 \%$ da área, a precipitação oscila entre 1.200 e $1.800 \mathrm{~mm}$. No entanto, apesar dos altos valores anuais, as chuvas se concentram nos meses de verão, e durante o inverno quase não chove, definindo, dessa forma, duas estações distintas: chuvosa e seca. O regime de chuvas no cerrado apresenta alta regularidade estacional, com $50 \%$ da precipitação anual ocorrendo em apenas três meses. No entanto, ocorre razoável variabilidade interanual do total precipitado. Aproximadamente $60 \%$ do bioma está sujeito a pequenos e irregulares períodos de seca durante a estação chuvosa, fenômeno conhecido como "veranico" (Dias, 1996; Cochrane et. al, 1988; Nimer e Brandão, 1989).

Os Latossolos ocorrem em cerca de $46 \%$ do bioma, predominando nas chapadas com topografia plana ou suave-ondulada. Solos do tipo Areia Quartzosas ocupam em torno de $15 \%$ da região, e geralmente ocorrem em relevo plano ou suave ondulado. Solos Podzólicos Vermelho-Amarelo e Vermelho-Escuro representam, juntos, $15 \%$ do Cerrado, ocupando a porção inferior das encostas, onde o relevo apresenta-se ondulado ou forte-ondulado. Plintossolos são solos hidromórficos, suscetíveis ao alagamento temporário, e representam em torno de $9 \%$ da área total do bioma, ocorrendo em relevo plano e suave ondulado. Solos litolíticos, associados a afloramentos de rochas, são 
encontrados em aproximadamente 7\% do Cerrado, e normalmente ocorrem em áreas bastante acidentadas, com relevo ondulado até montanhoso. Solos concrecionários, cambissolos, gleys húmicos, terras roxas e outros também ocorrem, mas em áreas inferiores a 3\% do bioma (Reatto et al., 1998; Dias, 1996). Nessas estimativas não foi incluído o Pantanal mato-grossense.

Aproximadamente $90 \%$ dos solos de cerrado são distróficos, com baixa fertilidade e com elevada acidez e toxidez devido a alta concentração de óxidos de alumínio e ferro. A maior parte desses solos é profunda e bem drenada e tem a capacidade de reter temporariamente as águas das chuvas, liberando-as lentamente para as nascentes dos riachos e veredas durante a estação seca (Dias, 1996).

A vegetação do bioma Cerrado apresenta grande diversidade de fisionomias que podem ser incluídas em três grandes grupos: florestas, savanas e campos. As florestas correspondem às áreas com predominância de espécies arbóreas, com formação de dossel; savana refere-se à vegetação com árvores e arbustos espalhados sobre um estrato graminoso, sem formação de dossel contínuo; campo designa áreas com predomínio de espécies herbáceas e algumas arbustivas, mas sem árvores (Ribeiro e Walter, 1998). A vegetação predominante no bioma, ao menos originalmente, é a de cerrado no sentido amplo em suas várias manifestações fisionômicas: floresta (cerradão), savana (cerrado sentido restrito e Parque de Cerrado) e campestre (campo limpo e campo sujo). No entanto, ocorrem no bioma, também, várias fitofisionomias de floresta, savana e campo que não são de cerrado no sentido amplo.

Assim, encontramos na região do Cerrado, grandes variações em latitude e altitude, bem como em precipitação anual e na duração da seca que, somadas à diversidade de solos e à complexidade da geologia, geomorfologia e da vegetação, conferem ao bioma enorme diversidade de ambientes que, constituindo um imenso mosaico de paisagens naturais (Dias, 1996). 


\subsection{2 - Ocupação do Cerrado}

A abundância de partículas de carvão em sedimentos antigos sugere que o Cerrado tem longa história de convívio com o fogo. Os indícios mais antigos de queimadas — anteriores a 20.000 anos AP — indicam que elas precederam a ocupação humana da região, apontando para ocorrências naturais de fogo. As evidências de queimadas no período de 10.500 a 3.500 anos AP no Brasil Central, por outro lado, podem ser associadas à ocupação humana, pois, principalmente a partir de 5.000 anos AP, são abundantes os indícios antrópicos (Vicentini e Laboriau, 1996; Laboriau et al., 1997).

Nos dois primeiros séculos de ocupação portuguesa no Brasil, a região central foi pouco explorada e não foi, de fato, colonizada. Somente a partir do início do Séc. XVIII, com a descoberta de ouro e pedras preciosas, ocorreram os primeiros assentamentos de povoados na região que vai de Cuiabá ao oeste do atual estado de Goiás. Aliada à exploração mineral, desenvolveu-se a economia de subsistência na região. Esgotado o ouro, a economia permaneceu restrita às culturas de subsistência e à pecuária bovina extensiva, e assim permaneceu até meados do presente século. Durante todo esse período, as queimadas possivelmente foram utilizadas no processo de desmatamento que precedia o de plantação, e no manejo das pastagens. No entanto, não há dados sobre a dimensão e a localização das áreas ocupadas e alteradas, nem da freqüência e extensão destas queimadas (Aragão, 1990).

A partir da década de 50, iniciou-se uma expansão agrícola realmente significativa, juntamente com a construção da cidade de Brasília, e da malha rodoviária ligando a região central ao norte e sudeste do país. Na década de 70 , a região oeste do Cerrado passou a integrar, efetivamente, a economia nacional, com a construção de rodovias que ligaram Cuiabá a Brasília e ao sudeste brasileiro. É nessa época, também, que foram implantados grandes projetos governamentais com o objetivo de ocupar e integrar a Amazônia e o Centro-Oeste à economia nacional. Dentre esses projetos, destacou-se o Programa para o Desenvolvimento do Cerrado - POLOCENTRO -, criado em 1975, e que impulsionou a expansão da agricultura comercial na região. Estima-se que entre 1975 e 1980, o POLOCENTRO tenha sido responsável pela 
incorporação direta de cerca de 2,4 milhões de hectares à agricultura. Esse programa previa que $60 \%$ da área explorada pelas fazendas fosse cultivada com lavouras que produzissem principalmente alimentos, sendo o restante destinado à pastagens plantadas. O resultado, no entanto, foi o contrário: a área reservada à lavoura foi suplantada por aquela destinada às pastagens, e a lavoura foi predominantemente tomada pela soja (WWF, 1998).

No período 1970-1985, a área ocupada por estabelecimentos agrícolas na região Centro-Oeste, aumentou em 41\%, passando de cerca de 82 para quase 116 milhões de hectares (IBGE, 1975; IBGE, 1984; IBGE, 1987). Porém, a área alterada nas fazendas da região sofreu um incremento ainda maior, cerca de 30,6 milhões de hectares $151,5 \%$ - e a área de terras abertas, mas não utilizadas, chamadas "em descanso" passou de 7,5 para 10,3 milhões de hectares no mesmo período (WWF, 1998). Em 1995, a área total de estabelecimentos na Região Centro-Oeste foi estimada em quase 125 milhões de hectares (IBGE, 1998).

As principais culturas do Cerrado, por ordem de área plantada são: soja, milho, arroz, feijão, café e mandioca. Em 1985, elas representavam cerca de 74\% da área total cultivada no Cerrado, aproximadamente 6 milhões de hectares. Nos cinco anos seguintes, o aumento de área dessas culturas foi da ordem de 11\% (WWF, 1998).

No entanto, apesar da acelerada expansão das áreas de lavoura, elas representam menos de 1/8 da área ocupada por pastagens naturais e plantadas, segundo dados do Censo agropecuário de 1996 (IBGE, 1998). O rebanho bovino na Região Centro-Oeste vem aumentando consideravelmente nas últimas décadas, passando de 17 para 60 milhões de cabeças no período 1970-1996. Segundo o IBGE (1998), a área ocupada por pastagens naturais ou plantadas era de 74 milhões de hectares na Região Centro-Oeste em 1996, incluindo-se também, o estado de Tocantins. Outras estimativas de área de pastagem para todo o bioma indicam que mais de 90 milhões de hectares são utilizados como pastagens naturais, totalizando cerca de 40\% do Cerrado (Haridasan, 1996; Filgueiras e Wechsler, 1996). 
Com a expansão das atividades agropecuárias e o crescimento das áreas urbanas nas últimas três décadas, a cobertura vegetal do cerrado passou a ser alterada com a mesma rapidez e hoje, a devastação desse bioma é muito maior do que o da Amazônia (Coutinho, 1990b). Dias (1990) estimou que em 1985, o bioma já teria perdido 37\% da sua cobertura primitiva, a qual teria sido substituída por paisagens antrópicas: pastagens plantadas; culturas temporárias; culturas perenes, especialmente eucalipto, pinheiro, manga e café; represamentos; áreas urbanas e áreas degradadas abandonadas, como desmatamentos, garimpos, áreas decapeadas, pastos e roças abandonadas, voçorocas, depósitos de lixo, etc. Os $63 \%$ que ainda estariam cobertos por paisagens naturais também estão, em sua maior parte, submetidos a diferentes intensidades de uso: $76 \%$ dessa área é utilizada como pastagem nativa para criação de gado de corte e exploração de carvão vegetal. Apenas $7 \%$ da região do Cerrado estaria assegurada como paisagem natural preservada.

Em estudo mais recente, Mantovani e Pereira (1998) estimaram o grau de integridade da vegetação de cerrado brasileiro, sentido amplo, em todo o bioma, mediante interpretação de 164 imagens do satélite TM/Landsat, escala 1:250.000, em sua maioria do período 1992-93. Obtiveram, desse estudo, os seguintes resultados: $35 \%$ da vegetação de cerrado encontrava-se fortemente antropizada, ou seja, com solo exposto, culturas agrícolas e florestais, pastagens plantadas, área urbanizada ou com reservatórios artificiais de água; 35\% estava mediamente antropizada, correspondendo, principalmente, aos campos nativos utilizados como pastagem; 30\% do cerrado ainda não antropizado. Constatou-se também, que a distribuição das áreas com e sem antropização não é homogênea no interior do bioma. As maiores áreas contínuas de vegetação de cerrado não antropizado estão no sudoeste do Piauí, na divisa entre Tocantins e Goiás e na região sudoeste de Tocantins. Por outro lado, as regiões mais fortemente antropizadas localizam-se nos Estados de São Paulo, Paraná, Mato Grosso do Sul, Goiás e Minas Gerais. 
A prática de queimadas no Cerrado está associada principalmente à expansão das fronteiras agrícolas, à conversão de florestas e savanas em pastagens e à renovação de cultivos agrícolas e, principalmente, de pastagens. Dessa forma, o conhecimento préhistórico e histórico da ocupação do Cerrado associada a essas atividades pode ser relacionada ao uso do fogo nesse bioma e suprir a falta de informações específicas sobre ocorrência de queimada de origem antrópica.

\section{2 - Quantificações de queimadas nos Cerrado}

Os cerrados brasileiros são sistematicamente expostos a queimadas acidentais ou intencionais, relacionadas sobretudo ao manejo de pastos e cultivos agrícola e a expansão das fronteiras de ocupação humana no bioma. Queimadas naturais, provocadas por raios, também ocorrem, mas são bem menos freqüentes (Ramos-Neto, 2000; Pivello e Coutinho, 1992), e concentram-se no período úmido (Ramos-Neto, 2000). Segundo Coutinho (1990a), a queima de pastagens é tradicionalmente repetida a cada três anos, em média. No entanto, tem-se verificado a diminuição do intervalo entre queimadas para um ou dois anos, relacionada às pressões de ocupação e à substituição da economia de subsistência pela ecocômicas de mercado, com a implantação de grandes projetos agropecuários no Cerrado.

A maioria das queimadas no Cerrado ocorre na estação seca, compreendida no período maio - outubro para a maior parte do Cerrado, mas o pico de ocorrências de queimadas é em agosto e setembro e são causadas principalmente pelo manejo de pastagens com fogo (Coutinho, 1990a e 1990b).

Até a metade da década de 80, não havia registros sistemáticos que dimensionassem o uso do fogo em todo o Cerrado. A partir dessa data, iniciou-se no Brasil, através do INPE (Instituto Nacional de Pesquisas Espaciais), o monitoramento diário de queimadas abrangendo praticamente todo o país, com os dados dos satélites meteorológicos da série NOAA (National Oceanic and Atmospheric Administration). Esses dados permitiram não só quantificar a ocorrência de focos de fogo, mas também localizá-los geograficamente (Setzer et al., 1992; Setzer, 1993). A Figura 1.1 mostra a evolução do número de focos detectados pelo sensor do satélite NOAA-12 no país, 
durante as estações secas de 1998 a 2000, evidenciando sua maior ocorrência nos meses de agosto e setembro. As Figuras 1.2 e 1.3 mostram a distribuição espacial das queimadas no país, nos meses de agosto e setembro de 1998, segundo dados fornecidos também pelo satélite NOAA-12. A Figura 1.4 mostra o número de focos detectados pelo NOAA-12 no período de junho a novembro de 1998 nos estados de Tocantins, Goiás e Mato Grosso, nos quais predominam vegetação de cerrado, mostrando novamente, o máximo de número de focos de fogo nos meses de agosto e setembro. Particularidades desse e de outros sistemas sensores e suas aplicações em estudos de queimadas serão discutidas adiante.

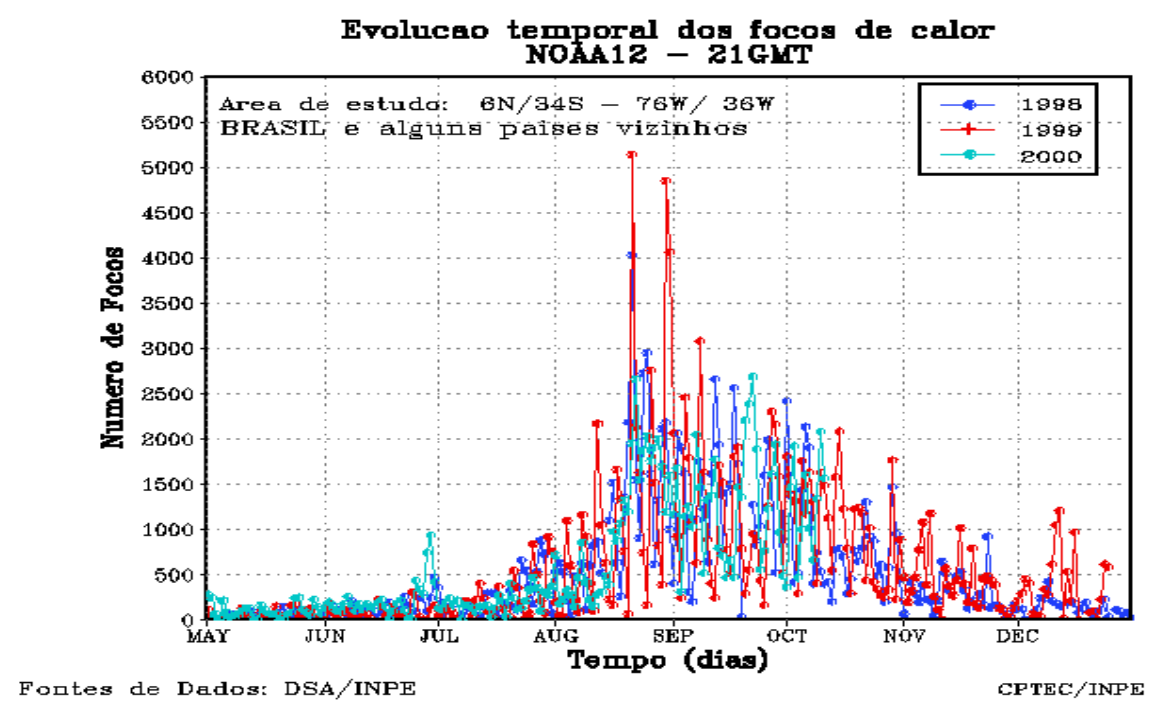

Figura 1.1 - Evolução do número de focos de queimadas detectados pelo NOAA-12 em 1998, 1999 e 2000; CPTEC (2000).

Os dados de focos de queimadas, no entanto, não fornecem informações diretas sobre a extensão da área queimada. Para estabelecer relações desse tipo, é necessário calibrar os dados de focos com estimativas de áreas queimadas obtidas de sensores de alta resolução (Arino et al.; 2000; Eva, 2000). Possivelmente, a primeira estimava de área queimada para todo o bioma foi feita por Pereira e Setzer (1996) e Pereira (1992), baseada em regressões de dados de focos de queimadas obtidos pelo NOAA com aqueles interpretados de imagens de satélite de alta resolução - TM/Landsat. Estimouse que cerca de $196.000 \mathrm{~km}^{2}$ de Cerrado queimaram no período 08 de junho a 12 de setembro de 1988. Identificaram-se também, as regiões do Cerrado com maior 
concentração de queimadas no período: sul do Maranhão, centro-leste de Tocantins, centro-oeste da Bahia, centro-sul de Goiás e centro-oeste e centro-leste de Mato Grosso.
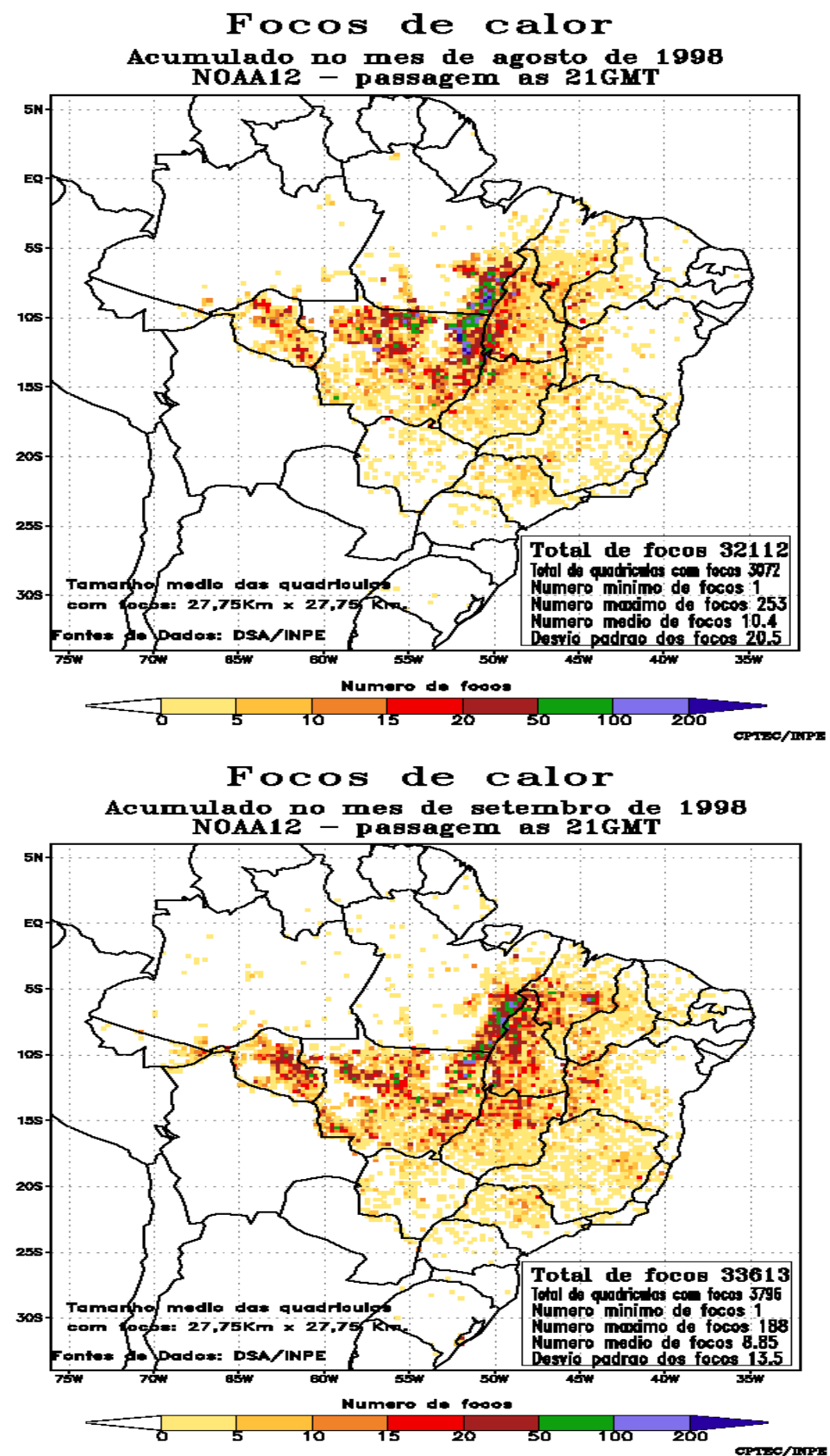

Figura 1.2 - Ocorrência de focos de fogo detectados pelo NOAA-12 em agosto e setembro de 1998 (CPTEC, 2000). 

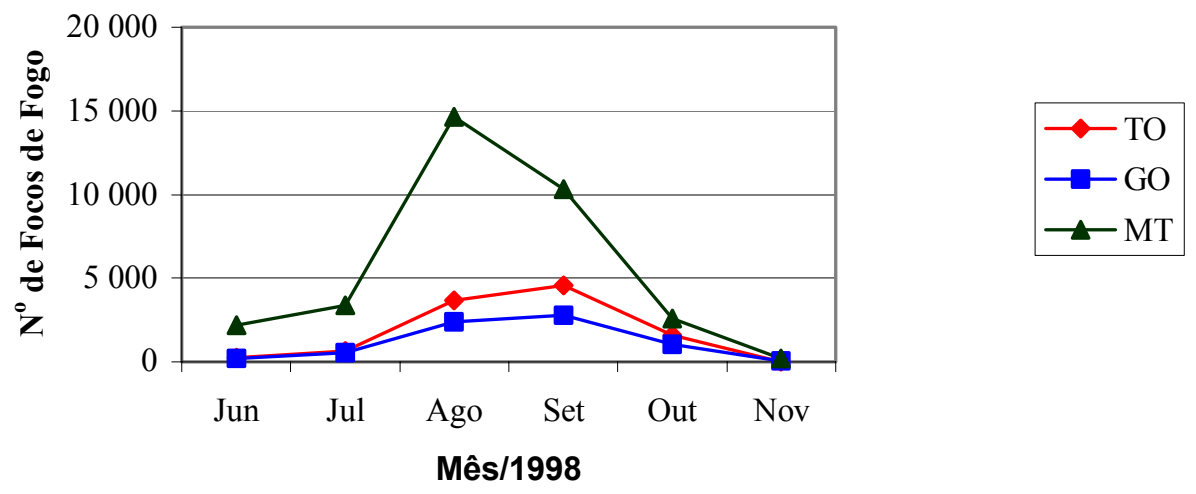

Figura 1.3 - Número de focos de fogo detectados pelo NOAA-12 em Mato Grosso, Goiás e Tocantins em 1998; baseado em CPTEC (2000).

Em estudo recente do PNUD (2000), estimou-se a área queimada no Cerrado em 1999, para efeito de cálculos de emissões relacionadas ao aquecimento global. Foi feita interpretação visual de 59 cenas TM/Landsat — 39 das quais do mês de julho — das 103 que foram listadas para recobrir o Cerrado. Posteriormente, incluiu-se a interpretação de 69 cenas adicionais que também continham áreas de cerrado. Três análises distintas foram feitas para estimar a área queimada para todo o Cerrado, sendo duas delas baseadas também em número de focos de queimada do NOAA-12. As estimativas obtidas foram: $315.545 \mathrm{~km}^{2}, 187.224 \mathrm{~km}^{2}$ e $119.865 \mathrm{~km}^{2}$, conforme o método utilizado, mas a segunda estimativa foi considerada a mais confiável. Desse estudo resultou também classificação das queimadas no Cerrado por tamanho, conforme interpretação das imagens TM — Tabela 1.1.

Tabela 1.1 - Número de polígonos e área queimada no cerrado por classes de tamanho, conforme PNUD ( 2000).

\begin{tabular}{ccccc}
$\begin{array}{c}\text { Classes de tamanho das } \\
\text { queimadas }\left(\mathbf{k m}^{2}\right)\end{array}$ & $\begin{array}{c}\text { No de polígonos e } \\
\text { \% do Total }\end{array}$ & $\begin{array}{c}\text { Área total queimada } \\
\text { do total. }\end{array}$ \\
\hline$<0,5$ & 1.909 & $(32 \%)$ & 482,4 & $(2 \%)$ \\
$0,5-1,99$ & 2.168 & $(36 \%)$ & $2.321,2$ & $(11 \%)$ \\
$2,00-5,99$ & 1.160 & $(19 \%)$ & $3.958,5$ & $(19 \%)$ \\
$6,00-9,00$ & 315 & $(5 \%)$ & $2.391,3$ & $(12 \%)$ \\
$>9,99$ & 444 & $(8 \%)$ & $11.724,5$ & $(56 \%)$ \\
\hline
\end{tabular}


Outras estimativas de área queimada no Cerrado, infelizmente existem apenas para casos isolados, abrangendo área pequenas, como o Parque Nacional das Emas, GO, cujas extensões de queimadas foram quantificadas para o período 1973-1995 por França e Setzer (1997 e 1999) e, posteriormente por Ramos-Neto (2000), para o período 19951999.

\section{3 - As queimadas no Cerrado e emissões de carbono, gases-traço e material particulado}

Queima de biomassa tem importante contribuição nas emissões globais de carbono e outros gases-traço, além de material particulado (Crutzen e Andreae, 1990; Andreae et al., 1996). A Figura 1.4 mostra a participação relativa das emissões de queimadas em relação às emissões de todas fontes em conjunto.

Estimativas globais apontam para a taxa de $8.700 \mathrm{Tg}$ matéria seca/ano, em decorrência de queimadas, da qual $87 \%$ tem origem nos trópicos. A contribuição das savanas tropicais nesse montante é da ordem de 42\%, ou cerca de $3.690 \mathrm{Tg}$ matéria seca/ano (Crutzen e Andreae,1990). A maior parte das queimadas em savana (65\%) ocorre no continente africano; a contribuição anual da América tropical é estimada em $770 \mathrm{Tg} \mathrm{ms}$, ou 21\%. Dessa forma, estima-se que a queima de biomassa em savanas da América do Sul representem $\sim 9 \%$ da queima de biomassa total no mundo.

Medidas da concentração de $\mathrm{CO}_{2}$ em diferentes regiões do Brasil mostraram variações sazonais. Valores mais elevados nos meses de agosto a outubro na região Centro-Oeste, foram atribuídos ao elevado número de queimadas nessa época do ano. Em Porto Nacional, TO, por exemplo, a concentração de $\mathrm{CO}_{2}$ medida em abril de 1993 foi 347 ppmv, passando para 380 ppmv em setembro. Esse aumento foi atribuído às queimadas (Pavão, 1994).

Embora as queimadas nas savanas sejam apontadas como a principal fonte de emissão de $\mathrm{CO}_{2}$ (Hao et al., 1990), não se pode, a princípio, atribuir a elas o aumento da concentração desse gás na atmosfera em nível global, pois entre 1 e 5 anos depois da queimada, o $\mathrm{CO}_{2}$ é reincorporado a esta vegetação, durante sua rebrota (Andreae, 1991; Iacobellis, et al., 1994). Experimentos no Cerrado, indicaram que a re-absorção do 
carbono liberado em queimadas ocorre em cerca de dois anos em campo sujo. Em fisionomias mais densas, o tempo de reposição é maior, podendo chegar a quatro anos em cerrado sentido restrito. Portanto, para avaliar o papel do Cerrado no balanço mundial de carbono, deve-se levar em conta o efeito do regime de queimadas nas diferentes fisionomias da vegetação (Miranda e Miranda, 2000; Silva et al.; 1996). Além disso, deve-se avaliar as emissões de carbono decorrentes da mudança de uso do solo, que tem substituído a vegetação do Cerrado por monoculturas. No entanto, mesmo quando a rebrota da vegetação garante que não há aumento líquido de $\mathrm{CO}_{2}$ na atmosfera decorrente de queimadas, deve-se levar em conta que outros gases-traços emitidos — , em particular $\mathrm{CO}, \mathrm{CH}_{4}, \mathrm{MNHC}, \mathrm{NO}_{\mathrm{x}}$, e $\mathrm{N}_{2} \mathrm{O}$ - contribuem para a elevação da temperatura global (Lashof, 1996). Esse autor estima que dentre os gases emitidos por queimadas, o $\mathrm{CO}$ é o de maior impacto na elevação da temperatura global e o $\mathrm{CH}_{4}$ aparece em segundo lugar.

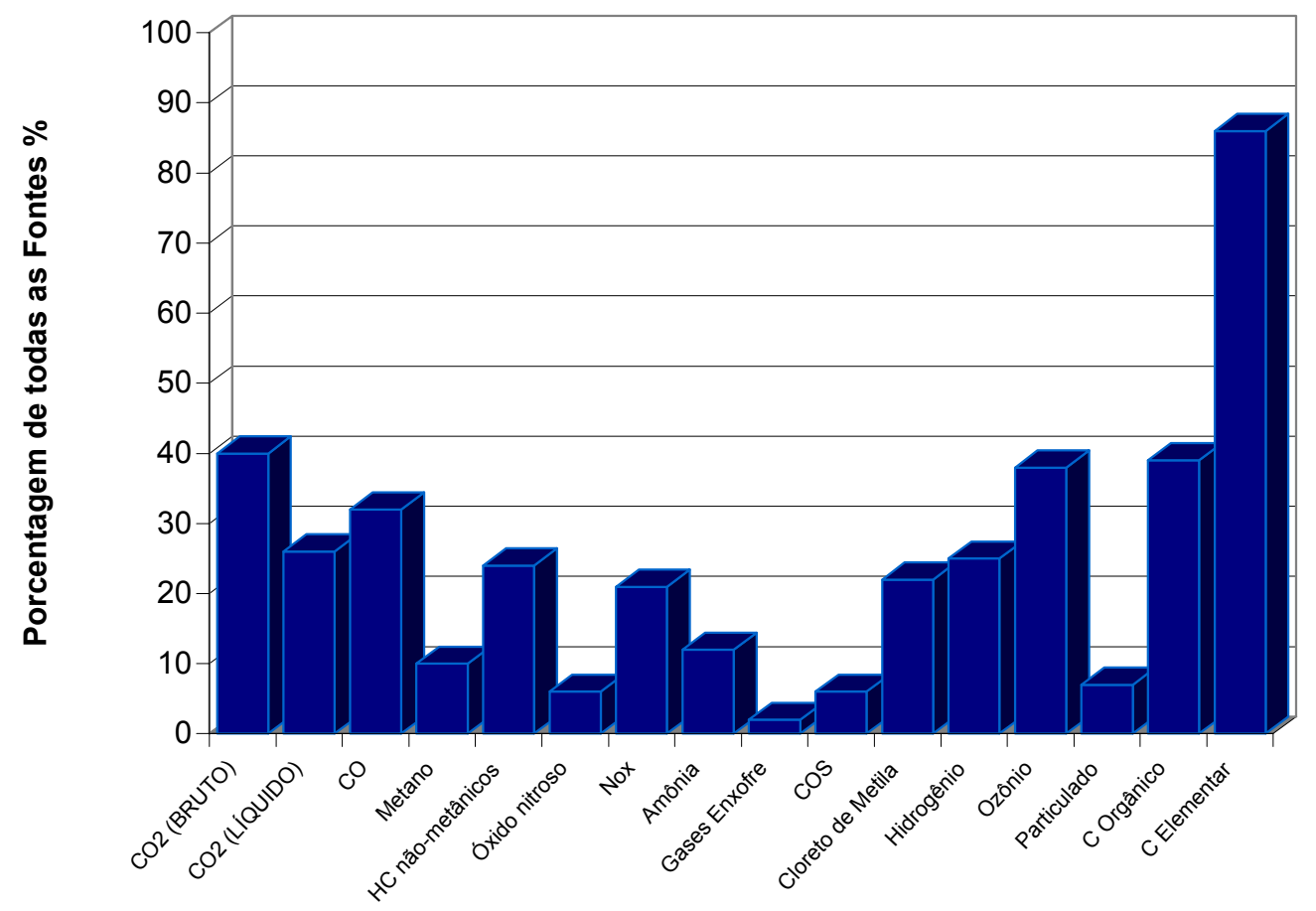

Figura 1.4 - Contribuição das queimadas nas emissões globais de gases traços e material particulado para a atmosfera; baseada em Andreae et al. (1996). 
Além do $\mathrm{CO}_{2}$, uma complexa mistura de outros gases e partículas é adicionada à atmosfera, durante a queima de biomassa. Esses gases resultam da combustão incompleta de compostos de carbono, originando, principalmente, $\mathrm{CO}$ (monóxido de carbono) e $\mathrm{CH}_{4}$, (metano), e de componentes que contém outros nutrientes, tais como $\mathrm{SO}_{2}$ (dióxido de enxofre), derivados de aminoácidos e proteínas.

$\mathrm{O} \mathrm{CH}_{4}, \mathrm{CO}$ e $\mathrm{NO}_{\mathrm{x}}$ emitidos durante a queima de biomassa são envolvidos em reações químicas na troposfera, causando elevação do nível de ozônio (Kaufman et al. 1992).

Estima-se que as queimadas nas regiões tropicais sejam responsáveis por cerca $32 \%$ da emissão global de CO para a atmosfera (Andreae, 1991). A quantidade desse gás emitida numa queimada depende das características do fogo: queimadas rápidas, com bom suprimento de oxigênio e que atingem temperaturas elevadas, produzem pouco $\mathrm{CO}$, enquanto queimadas ineficientes produzem grande quantidade desse gás, como produto da combustão incompleta (Andreae, 1991). Medidas de concentração de $\mathrm{CH}_{4}$ e $\mathrm{CO}$ emitidos durante uma queimada no cerrado foram cerca de 5 a 10 vezes inferiores àquelas encontradas em incêndios florestais na América do Norte. Esse resultado pode indicar que a contribuição da queima do estrato graminoso do cerrado na produção de $\mathrm{CO}$ e $\mathrm{CH}_{4}$ é menor do que o esperado. Tal fato foi atribuído ao alto fator de combustão da vegetação do cerrado - cerca de $97 \%$ (Kaufman et al. 1992). No entanto, muitos autores apontam as queimadas nas regiões tropicais como a maior fonte de emissão de CO no mundo (Rodriguez et al., 1991). Zepp et al. (1996) afirmam que pouco se conhece a respeito dos efeitos da ação antrópica nas savanas sobre as emissões de CO. Medidas de concentração de CO na superfície, em Cuiabá, MT, feitas no período 1987-1988, mostraram variações sazonais, com máximos em torno de 0,65 ppmv, coincidindo com a época das queimadas. Durante os meses chuvosos, no entanto, a concentração de $\mathrm{CO}$ permaneceu em níveis próximos a 0,1 ppmv, semelhantes aos mesmos medidos em Natal, RN, local onde as variações sazonais foram negligenciáveis e a influência de queimadas é, provavelmente, muito pequena (Kirchhoff, 1991). Watson et al. (1991) também encontraram variações sazonais na concentração de CO no Brasil, com valores máximos medidos na estação seca. 
$\mathrm{CH}_{4}$ é um gás que contribui no efeito estufa, na formação de $0_{3}$ (ozônio) na troposfera e também interfere no ciclo do $0_{3}$ na estratosfera. A queima de biomassa é apontada como fonte importante de metano na atmosfera, responsável por cerca de $10 \%$ das emissões de origem antropogênicas desse gás (Andreae, 1991; Andreae et al., 1992; Andreae et al., 1996). Kirchhoff et al. (1996) encontraram concentrações de $\mathrm{NH}_{4}$ em Cuiabá, MT, e Porto Nacional, TO, muito superiores àquelas obtidas em Natal, RN. Verificou-se também, variação sazonal do teor desse gás na troposfera, com aumento de concentração coincidindo com a época das queimadas em Cuiabá e Porto Nacional.

O aumento da concentração de ozônio na troposfera, um dos poluentes atmosféricos mais fitotóxicos (Krupa e Kickert, 1989) e que contribui para o aquecimento global, também está relacionado com a queima de fitomassa. Estima-se que $38 \%$ do ozônio emitido para a atmosfera tenha origem em queimadas (Andreae, 1991; Andreae et al., 1992). As concentrações desse gás nos trópicos tendem a ser menores do que nas latitudes médias, exceto nas estações secas, quando aumenta a emissão de precursores de $\mathrm{O}_{3}$, derivados da queima de biomassa. Na América do Sul, os valores observados de $\mathrm{O}_{3}$ durante a primavera, atingem níveis tão elevados quanto aqueles observados durante o inverno nas latitudes médias, nas regiões industrializadas. A exposição prolongada de plantas à alta concentração de ozônio provoca alterações graves em vários processos fitofisiológicos levando, no caso de cultivos agrícolas, à diminuição da produção (Rudorff, 1993). Vários experimentos relatam os efeitos desse gás na vegetação (Rudorff, 1993; Jacobson e Hill, 1970; Hueter et al., 1974; Krupa e Kickert, 1989), mas não há informações dessa natureza acerca de plantas nativas do cerrado. Os exemplos seguintes referem-se a algumas das espécies mais cultivadas na região, segundo resultados apresentados por Hueter et al. (1974): plantas de soja (Glycine max) expostas à concentração de 100 ppb de $\mathrm{O}_{3}, 8 \mathrm{~h} /$ dia, 5 dias/semana, durante 3 semanas, tiveram perda de fitomassa fresca da ordem de 21 a $24 \%$, e exposições mais prolongadas (6h/dia, durante 133 dias) reduziram em 55\% a produção de sementes e em $65 \%$ a fitomassa fresca; no milho (Zea mays), exposto à $100 \mathrm{ppb}$ de $\mathrm{O}_{3}, 6 \mathrm{~h} /$ dia, durante 64 dias, observou-se 45\% de redução no peso dos grãos, e em concentração de 120 ppb, 5,5h/dia, durante 60 dias, levou a 90\% de inibição da germinação; no feijão (Phaseolus vulgaris), concentrações crescentes de 150 a 300 ppb de $\mathrm{O}_{3}$ durante 14 dias, com 
exposições variando de 0,5 a 6h/dia, provocaram de 8 a 76\% de diminuição de fitomassa foliar. Diminuição de $15 \%$ na produção de grãos e de $11 \%$ da fitomassa seca em cultivos de trigo foram observados por Rudorff (1993) quando as plantas ficaram expostas a variações cíclicas das concentrações de $0_{3}$ (de 20 a 120 ppb), 7h/dia, 5 dias/semana, durante quase 4 meses. Aumentos de concentrações de $\mathrm{O}_{3}$ nas camadas da atmosfera próximas à superfície, em conseqüência de queimadas nos cerrados, foram constatadas por Kirchhoff et al. (1996) e Kirchhoff e Pavão (1996) e Kaufman et al. (1992). Em setembro de 1994, p. ex., as médias diárias da concentração de $0_{3}$ oscilaram entre 30 e $70 \mathrm{ppb}$ em Cuiabá, com picos em torno de 100 ppb. No mesmo período do ano seguinte, as concentrações mantiveram-se semelhantes, mas em agosto registrou-se, no mesmo local, um pico de $140 \mathrm{ppb}$. Durante a época de queimadas, o ozônio se mantém em concentrações elevadas na baixa atmosfera, dentro de limites que comprovadamente causam sérios danos à vegetação comprometendo, possivelmente, a produção agrícola e a saúde pública. Faltam no entanto, trabalhos científicos que quantifiquem no Brasil, a influência das altas concentrações de $\mathrm{O}_{3}$ na vegetação nativa e na produção agrícola.

A transferência de nutrientes inicialmente contidos nas plantas de cerrado para a atmosfera em decorrência de queimadas, foi estimada em cerca de $95 \%$ de N, $51 \%$ do P, $44 \%$ do $\mathrm{K}, 52 \%$ do $\mathrm{Ca}, 42 \%$ do $\mathrm{Mg}$ e $59 \%$ do $\mathrm{S}$ numa área experimental de cerrado em São Paulo (Pivello e Coutinho, 1992). Mediu-se também o tempo de retorno desses elementos pela chuva, o qual foi estimado em três anos.

Queimadas na vegetação são também a maior fonte de partículas higroscópicas orgânicas e carbono grafítico presentes na atmosfera. As partículas higroscópicas aumentam o número de núcleos de condensação das nuvens e resultam em maior reflexão de luz solar para o espaço e, portanto, diminuem a quantidade de radiação solar que incide na superfície terrestre. Outro efeito da presença dessas partículas nas nuvens é a diminuição da precipitação em nuvens poluídas. $\mathrm{O}$ carbono grafítico produzido nas queimadas tem efeito oposto ao das partículas higroscópicas, pois aumentam a absorção de radiação solar pelas nuvens e pela atmosfera (Kaufman et al., 1992; Andreae, 1991). Como as nuvens são um dos principais reguladores do balanço de calor na Terra, 
qualquer modificação das propriedades delas, em larga escala, pode produzir grande impacto no clima global (Andreae, 1991; Lenoble, 1991). Artaxo et al. (1996a e 1996b) constataram altas concentrações de aerossol (média de $105 \mathrm{~g} / \mathrm{m}^{3}$, com picos de quase $300 \mu \mathrm{g} / \mathrm{m}^{3}$ ) nas regiões Amazônica e do Cerrado, sendo que 56\% dessa massa era proveniente de queimadas, com participação de $15 \%$ de carvão grafítico. Atenta-se aqui, que os Padrões Nacionais de Qualidade do Ar estipulam que a concentração de partículas inaláveis não deve ser excedido mais que uma vez por ano o valor de 150 $\mu \mathrm{g} / \mathrm{m}^{3}$ durante 24 horas. $\mathrm{O}$ aumento da concentração de aerossóis também foi medido sazonalmente por Holben et al. (1996a e 1996b) em várias regiões do país, mediante utilização de radiômetros espectrais. Constatou-se também, aumento da concentração de material particulado na atmosfera em função da queima de vegetação, inclusive na região do Cerrado.

Há registros da ocorrência de chuvas ácidas na América do Sul, África e Austrália não relacionadas às atividades industriais. Nesses casos, a acidez foi atribuída principalmente à presença de ácidos orgânicos e nítricos. Há evidências da emissão de ácido acético a partir de queimadas na vegetação, e da formação fotoquímica de ácidos acético e fórmico nas plumas de fumaça. Ácidos nítricos são produzidos a partir do $\mathrm{NO}_{\mathrm{x}}$ emitido nas queimadas e contribuem para a diminuição do $\mathrm{Ph}$ da água precipitada que pode ser inferior a quatro, conforme constatado freqüentemente na África. Substâncias ácidas presentes na atmosfera depositam-se no solo e nas plantas não só pela chuva, mas também por neblina e por deposição seca e podem afetar o ecossistema, pois provocam danos nas folhas e elevam a acidez do solo (Andreae, 1991).

Outro efeito das queimadas é a diminuição da incidência de radiação solar fotossinteticamente ativa $(0,4-0,7 \mu \mathrm{m})$ na superfície terrestre. Eck et al. (1998) estimaram em $45 \%$ a redução dessa radiação durante os meses de agosto e setembro em Rondônia; valores elevados, entre 20 e 36\%, também foram obtidos para Alta Floresta e Cuiabá no Mato Grosso. A redução da incidência de radiação foi atribuída à absorção pelos aerossóis emitidos pelas queimadas. 


\section{4 - Características espectrais das queimadas}

Com o lançamento dos primeiros satélites operacionais de sensoriamento remoto, na década de 70, evidenciou-se o uso de imagens orbitais no estudo das queimadas. Nos anos 80, a dimensão mundial de ocorrência de queimadas chamou a atenção da comunidade científica e da população em geral para as possíveis conseqüências do uso indiscriminado do fogo.

Há duas abordagens distintas no estudo de queimadas com dados orbitais. Numa, detecta-se fogo ativo, e na outra, identificam-se as cicatrizes das queimadas.

A identificação de focos ativos de queimadas é feita nas bandas termais, pois a vegetação em combustão geralmente atinge valores de temperatura em torno de $800 \mathrm{~K}$ e, nessa situação, o pico de emissão de energia radiante concentra-se em torno de 3,0 a 5,0 $\mu \mathrm{m}$, conforme as leis de Stefan-Boltzman e Wien (Robinson, 1991). Neste intervalo, a radiação emitida pela Terra é baixa, pois sua temperatura média é de cerca de $300 \mathrm{~K}$. Dessa forma, nas imagens obtidas na região de 3.0 a 5,0 $\mu \mathrm{m}$, os focos de fogo ativo são facilmente identificáveis, destacando-se das superfícies que estão em temperatura ambiente. Dentre os sistemas sensores operacionais disponíveis, os dados da banda 3 do AVHRR são os mais apropriados para a identificação de fogo ativo (Setzer et al., 1992; Pereira e Setzer, 1993; Setzer e Malingreau, 1996), conforme relacionado abaixo.

a) Faixa espectral apropriada. A banda 3, centrada em 3,7 $\mu \mathrm{m}$, está no intervalo espectral que corresponde ao pico de emissão de queima de vegetação.

b) Alta resolução temporal. Devido às características orbitais dos satélite NOAA, a mesma região é imageada uma vez a cada 12 horas. Essa freqüência pode, no entanto, ser maior, pois há no mínimo dois satélites NOAA em operação, simultaneamente, permitindo obtenção de imagens a intervalos ideais de 6 horas. Essa alta freqüência é adequada para monitoramento de alterações rápidas da superfície terrestre, como é o caso das queimadas. No presente, operam quatro satélites NOAA. 
c) Área de recobrimento. A extensão imageada é suficientemente grande para permitir a observação de dimensões continentais. Cada imagem corresponde a uma faixa no sentido longitudinal de cerca de $2.700 \mathrm{~km}$ de largura e $5.000 \mathrm{~km}$ no latitudinal.

d) Detecta frentes de fogo pequenas, de cerca de 30 a $50 \mathrm{~m}$ de comprimento por $1 \mathrm{~m}$ de largura, apesar da resolução espacial grosseira de, no mínimo 1,1km.

e) A radiação é transmitida pelas nuvens. A transmissão da radiação emitida pelas queimadas geralmente não é absorvida na fumaça e é detectada na banda 3 do AVHRR.

f) Baixo custo. Praticamente, o único custo envolvido é o de aquisição de uma estação receptora. Atualmente, adquire-se uma estação simples por cerca de U\$ 6.000 FOB.

Há, no entanto, algumas limitações na utilização de imagens AVHRR, banda 3, na detecção de queimadas (Setzer, 1993; Setzer e Malingreau, 1996):

a) A presença de nuvens de vapor d'água no momento da passagem do satélite impede a detecção de focos de fogo.

b) Queimadas ativas nos horários diferentes daqueles das passagens do satélite também não são detectadas.

c) Frentes de fogo menores do que $\sim 50 \mathrm{~m}$ ou sob dossel não são detectadas.

d) Reflexão solar em corpos de água e em alguns solos nus podem resultar em respostas, na imagem, idênticas às das queimadas. Esse problema é decorrente de uma determinada geometria sol-superfície-satélite e ocorre somente em épocas e locais específicos do ano.

A utilização de dados noturnos do AVHRR exclui a ocorrência de reflexos solares na banda 3. No entanto, o número de queimadas à noite é bem menor do que de dia. Esses problemas, bem como sugestões para minimizá-los são aprofundados em Setzer e Malingreau (1996). 
Muitos pesquisadores, no entanto, utilizam os dados da banda 3 em conjunto com a banda 4 para detectar focos ativos de fogo (Robinson, 1991). Os exemplos de aplicações de imagens AVHRR na detecção de queimadas ativas são inúmeros e tiveram origem com os trabalhos de Dozier (1981), Matson e Dozier (1981) e Matson et al. (1984), nos quais constatou-se que superfícies aquecidas, inclusive queimadas, eram evidenciadas na banda 3 desse sensor. Grandes incêndios florestais ocorridos em Borneo, em 1982 e 1983 foram detectados nas imagens termais do AVHRR/NOAA-7 (Malingreau et al., 1985). Matson e Holben (1987) e Pereira e Setzer (1986) e Pereira (1988) utilizaram imagens da banda 3 desse sensor na identificação de queimadas ativas na Amazônia brasileira. Outros exemplos de uso das bandas termais do AVHRR para a detecção e localização de incêndios na África são encontrados em Setzer et al. (1994), Langaas (1992), Kennedy et al.(1994). Aplicação de metodologias semelhantes são encontradas em Zherebtson et al. (1996). Dwyer, et al. (1998) propuseram um algoritmo para detecção de queimadas, em escala global, baseado nas bandas 3 e 4 do AVHRR; desse trabalho resultaram estimativas por continente, do total de focos detectados no período 1992-93, mostrando que $80 \%$ deles estavam nos trópicos, principalmente nas savanas africanas.

As marcas de queimadas permanecem identificáveis por vários dias e podem ser notadas por suas características espectrais (Arino et al., 2000). Na região do visível (0,4$0,7 \mu \mathrm{m}$ ), dependendo da concentração de clorofila, da intensidade do fogo e do tipo de vegetação, as marcas da queimada podem ter comportamentos opostos, resultando em cinzas brancas, quando a combustão da biomassa é completa, ou cinzas negras, quando combustão é incompleta em decorrência da deficiência de oxigênio (Arino et al., 2000). Conseqüentemente, as respostas espectrais podem ser opostas na região do visível: aumento ou diminuição da reflectância, conforme o caso. Vegetação apresenta alta reflectância na região espectral do infravermelho próximo $(0,7-1,1 \mu \mathrm{m})$. Depois de uma queimada, no entanto, verifica-se acentuado decréscimo de reflectância, o que torna essa faixa espectral bastante útil para a identificação de queimadas (Arino et al., 2000; Eva e Lambin, 1998). Na região de 1,1 a 3,0 $\mu \mathrm{m}$, não há também uma caracterização espectral padrão para cicatrizes de queimadas, e elas podem ter comportamentos opostos, 
conforme o ecossistema em questão. Na faixa termal do espectro eletromagnético, as cicatrizes de queimadas apresentam-se como áreas mais quentes do que as vizinhas. Esse fato deve-se ao aquecimento do solo exposto que absorve mais radiação solar por um lado e, a ausência de evapotranspiração do outro, mecanismo que transfere calor para a atmosfera (Eva e Labim, 1998; Arino et al., 2000). Eva e Lambin (1998), Barbosa et al. (1999) e Pereira (1999) consideram crucial a utilização do infravermelho médio (banda 3 do AVHRR) para identificar cicatrizes de queimadas nas regiões tropicais.

Índices de vegetação resultantes de combinações de bandas AVHRR também têm sido utilizados para identificar marcas de queimadas. Dentre eles, o IVDN Índice de Vegetação de Diferença Normalizada - foi bastante testado. O IVDN calculado pela razão (infravermelho próximo - visível)/(infravermelho próximo + visível) é um indicador da presença de biomassa fotossinteticamente ativa (Tucker, 1979; Malingreau, 1986) e pode variar de -1 a +1 . A remoção da cobertura vegetal pelo fogo provoca, em muitos casos, a redução do IVDN, e essa propriedade tem sido utilizada em alguns algoritmos de identificação de queimadas. No entanto, aplicação dessa técnica em regiões de savana é questionável, pois a maior parte das queimadas ocorre na vegetação senescente que já apresenta baixo IVDN.

\section{5 - Identificação e estimativas de áreas queimadas com imagens orbitais}

Sensores de alta resolução espacial (dezenas de metros) como o TM/Landsat são utilizados com freqüência para estimar áreas queimadas em regiões relativamente pequenas e para estudos de casos. Eva e Lambin (1998) apontam a resolução de 20 a $80 \mathrm{~m}$ como suficiente para determinar o padrão espacial das áreas queimadas. No entanto, quando se necessita de informação de regiões extensas (como o Cerrado, p. ex.), abrangendo toda a estação de queimadas, esses sensores tornam-se bastante inadequados, tanto no que diz respeito a amostragem temporal quanto a cobertura espacial. A freqüência temporal (16 dias para o TM, p. ex.), somada a probabilidade de ocorrência de nuvens, impossibilitam a observação contínua da dinâmica das queimadas em uma região. As queimadas observadas em imagens TM representam apenas os 
eventos que ocorreram nas semanas próximas ao de sua aquisição, e não devem ser extrapoladas para todo período de queimadas. Uma imagem adquirida no final do período da seca, p. ex., provavelmente não terá mais sinais de queimadas ocorridas no início da estação (Eva e Lambin, 2000). A cobertura espacial, por outro lado, impõe um grande número de imagens para uma análise regional. No caso do Cerrado, p. ex. o estudo de 1999 (PNUD, 2000), avaliou inicialmente, em 103 o número de imagens TM necessárias para recobrir o Cerrado (posteriormente, somaram-se outras). Mantovani e Pereira (1998) analisaram 163 imagens TM no estudo sobre integridade do Cerrado. Ademais, deve-se considerar o custo destas imagens, pois a cerca de U\$500 por imagem, só o gasto com esse material é de várias dezenas de milhares de dólares.

O desaparecimento das marcas das queimadas, comprometendo sua identificação nas imagens TM, é particularmente sério no Cerrado. É comum os indícios de queimadas desaparecerem em alguns dias ou semanas pela remoção das cinzas pelo vento ou chuva, pela rápida rebrota da vegetação, ou pela combinação desses fatores (França e Setzer, 1998 e 1999). Em áreas agrícolas, com uso de máquinas, essas mudanças podem ser ainda mais rápidas. A Figura 1.5 exemplifica a rápida transformação de marcas de queimadas no cerrado, no período entre duas passagens consecutivas do TM/Landsat. Tais transformações podem impedir sua identificação poucos dias depois de sua ocorrência.

Os sensores AVHRR/NOAA de baixa resolução espacial (1,1 km no nadir), por outro lado, têm alta freqüência de aquisição de dados (uma passagem a cada 12 horas), compatível, portanto, com a dinâmica das queimadas e transformação de suas cicatrizes. Imagens desse sensor, por outro lado, têm baixa resolução espacial, podendo levar à omissões de queimadas pequenas. Eva (2000) estimou em $40 \%$ a área mínima de queimada correspondente a um píxel de $1 \mathrm{~km}$, para que ele seja identificado como tal. $\mathrm{O}$ autor sugere que os dados de sensores de baixa resolução espacial sejam calibrados com aqueles provenientes de alta resolução. A partir de 1991, o sensor ATSR, a bordo dos satélites ERS-1, passou a ser utilizados para identificação de queimada. Esse sensor tem características semelhantes ao AVHRR, porém ciclo temporal de três dias. 


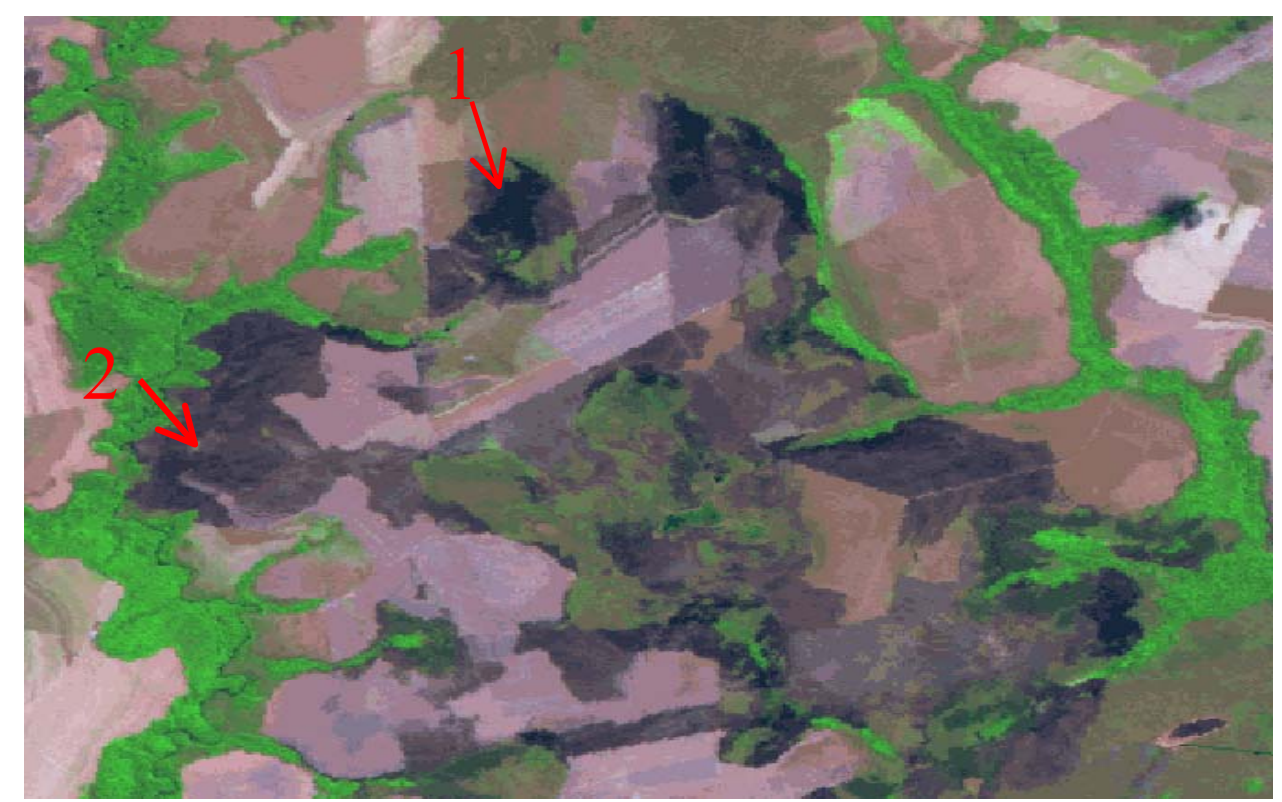

(a)

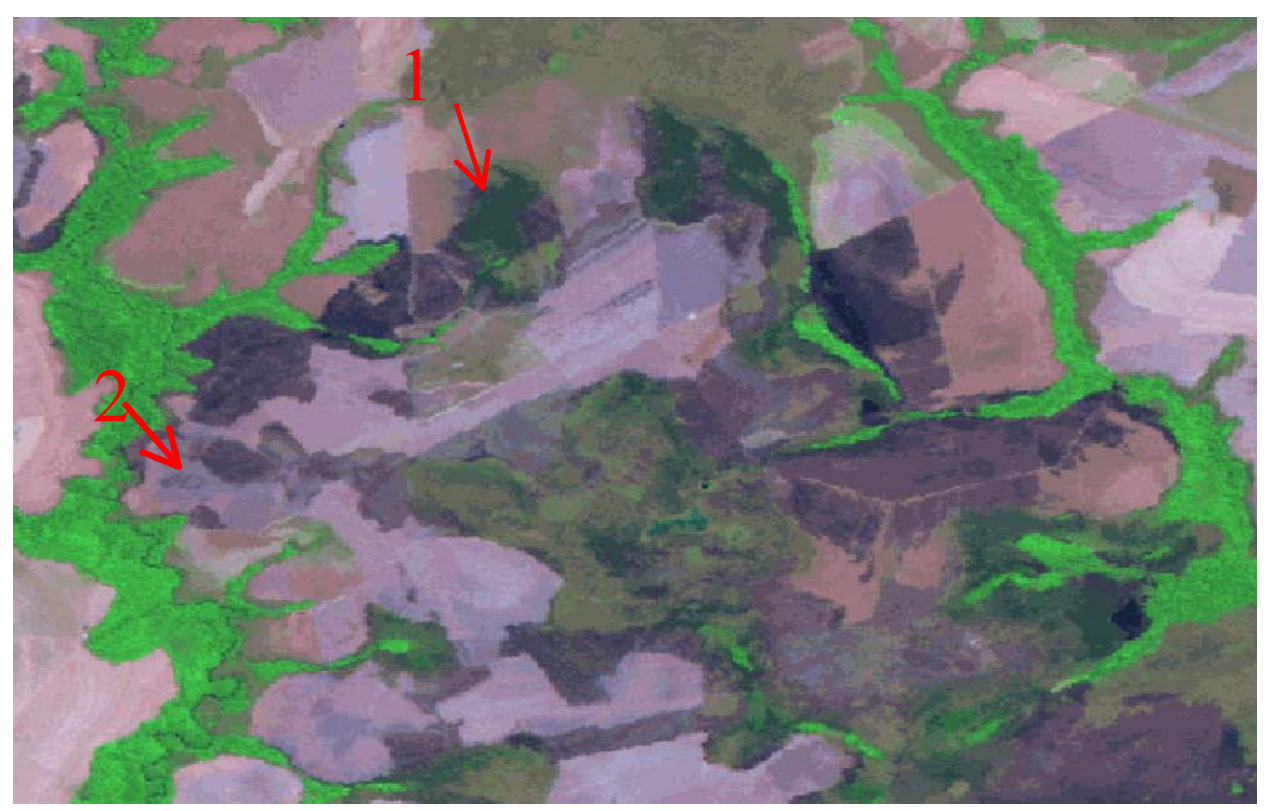

(b)

Figura 1.5 - Imagens TM Landsat do cerrado mato-grossense de 01/agosto/98 (a) e 17/agosto/98 (b), mostrando (1) o rápido início da rebrota da vegetação e o (2) desaparecimento das marcas de uma queimada em menos de 16 dias. 
Há na literatura inúmeros exemplos de utilização de dados orbitais para estimar áreas queimadas com sensores de alta resolução. Wightman (1973) mapeou queimadas ocorridas em 1972 no leste e sul da África com imagens do Landsat-1. Desher (1974) observou a progressão sazonal de incêndios em campos e savanas ao sul do Saara com imagens Landsat-1. Bruneau e Toan (1978) fizeram um estudo multitemporal de queimadas no norte da Tailândia com imagens Landsat de 1973 e 1975. Um incêndio em floresta implantada de Pinus elliotti, ocorrido no interior de São Paulo em 1973, foi mapeado por Chen et al. (1979) com imagens do Landsat-1. Hall et al. (1980) monitoraram uma área queimada de tundra, no Alasca, com imagens Landsat, dados de campo e aeronave, avaliando também a regeneração da cobertura vegetal. Tanaka et al. (1980) mapearam a extensão de um incêndio ocorrido em Etajima, Japão com imagens Landsat. Chuvieco e Congalton (1988) avaliaram os dados TM para fins de mapeamento de incêndios florestais na costa mediterrânea da Espanha. Santos e Aoki (1981) mostraram a possibilidade de detecção, mapeamento e avaliação da área queimada decorrente de um incêndio ocorrido em 1975 no cerrado do Parque Nacional de Brasília, utilizando classificação visual e automática das imagens Landsat digitais. Ponzoni et al. (1986) identificaram e mapearam a extensão de um incêndio ocorrido também no Parque Nacional de Brasília, em 1985. Shimabukuro et al. (1991) analisaram imagens digitais TM/Landsat para avaliar a área queimada depois de um incêndio de grandes proporções no Parque Nacional das Emas, em Goiás. França e Setzer (1998) mapearam as queimadas ocorridas no período 1973-1995 no Parque Nacional das Emas, utilizando uma seqüência temporal de 43 imagens Landsat.

Sensores de baixa resolução também têm sido utilizados para estimar áreas queimada. Incêndios de grandes proporções ocorridos na floresta boreal do Alasca entre 1990 e 1993 foram mapeados com IVDN derivado dos dados AVHRR (Kasischke et al., 1993 e Kasischke e French; 1995). Constatou-se que a comparação nos mosaicos quinzenais de máximos valores de IVDN pode identificar polígonos de queimadas superiores a 2000 ha. França (1994 e 2000) estimou a área queimada num incêndio de grandes proporções no Parque Nacional das Emas, GO, usando imagens da banda 3 do AVHRR e obteve estimativa 10\% inferior aquela feita em imagem TM/Landsat. 
A preocupação recente com as emissões de queimadas e seus possíveis efeitos no aquecimento global apontou a necessidade de estimar de forma regular e automática a extensão das áreas queimadas em todo o planeta. Foram propostos alguns algoritmos que utilizam dados de baixa resolução, principalmente do sensor AVHRR, com esse propósito, como exemplificado a seguir.

Certos algoritmos de identificação de queimadas são baseados no IVDN derivado dos dados AVHRR. Sua utilização apoia-se no princípio de que a remoção da cobertura vegetal pela queimada queimada produz queda desse índice, devido ao aumento da reflectância na faixa do visível, e diminuição na do infravermelho próximo. Fernandez et al. (1997) desenvolveram técnicas de mapeamento de áreas queimadas a partir de mosaicos de máximos valores IVDN, procurando identificar quedas nesse índice. Pereira (1999) avaliou a capacidade do IVDN e de outros índices de vegetação para discriminar áreas queimadas, validando os resultados com imagens TM; concluiu que o IVDN não é bom indicador de áreas queimadas na região mediterrânea, mas que o índice que usou a combinação por diferença normalizada das bandas 2 e 3 (com remoção da fração refletida) teve o melhor desempenho. O uso de dez bandas e índices diversos derivados do IVDN, foi proposto para identificar queimadas no continente africano em imagens diárias AVHRR com $5 \mathrm{~km}$ de resolução espacial num período de três anos (Barbosa et al., 1999); validação dos resultados foi com 08 imagens TM/Landsat, avaliou que os melhores indicadores de área queimadas derivaram de combinações das bandas 2 e 3 do AVHRR. Modelo de mistura espectral de pixel foi aplicado por Caetano et al. (1996) para mapeamento de áreas queimadas, utilizando imagens AVHRR das bandas 1, 2 e IVDN do AVHRR. Obtiveram-se as proporções de floresta, solo e queimada para cada píxel e gerou-se uma mapa somente com a classe queimada. Com a aplicação de técnicas de análise espacial nos dados de queimadas, obteve-se $91 \%$ de identificação de píxeis de queimada em relação à interpretação de imagens TM. Razafimpanilo et al. (1995) desenvolveram dois métodos de identificação de áreas queimadas, sendo o primeiro baseado na banda 2 do AVHRR e o segundo no IVDN. A banda 2 das imagens AVHRR também tem sido utilizada para mapear áreas queimadas na Austrália, embora sem descrição da metodologia empregada (DOLA, 2000). 
Dados do sensor ATSR 1 e 2 ( Along Track Scanning Radiometer) foram testados em alguns algoritmos de identificação de marcas de queimadas. Piccolini e Arino (2000), por exemplo, utilizam a diminuição da reflectância no infravermelho próximo $(0,87 \mu \mathrm{m})$ obtido do ATSR-2, como indicativo de remoção da cobertura vegetal, e o aumento da temperatura do solo, obtido da banda termal $(11,0 \mu \mathrm{m})$ como píxel de queimada. A validação com dados TM indicou relação de 1:1 entre as duas fontes de dados. Eva (2000) fez comparação de imagens em seqüência temporal entre as duas fontes de dados. A banda 1b do ATSR-1 $(1,6 \mu \mathrm{m})$ foi utilizada para calcular a radiância, e as bandas termais 2 e $3(11,0 \mu \mathrm{m}$ e $12,0 \mu \mathrm{m}$, respectivamente) foram empregadas conjuntamente para calcular a temperatura do solo. Na comparação com a imagem precedente, definiu-se o píxel de queimada quando se constataram simultaneamente a diminuição de $20 \%$ na radiância da banda 1 b e aumento de $4 \mathrm{~K}$ na temperatura. A regressão dos resultados com os dados TM indicaram forte relação entre eles.

Atualmente, a Agência Espacial Européia está elaborando um Atlas mundial de superfícies queimadas em 2000, com base em imagens ATSR-2 de 1 km de resolução espacial (ESA, 2000). 


\section{6 - Objetivos}

O principal objetivo deste trabalho foi desenvolver uma metodologia para identificar e quantificar quinzenalmente a superfície queimada na região contínua do Cerrado, utilizando imagens diárias do sensor AVHRR a bordo dos satélites meteorológico NOAA, bandas $1(0,58-0,68 \mu \mathrm{m}), 2(0,73-1,1 \mu \mathrm{m})$ e $3(3,55-3,93 \mu \mathrm{m})$, e de seu subproduto IVDN (Índice de Vegetação de Diferença Normalizada). Este desenvolvimento incluiu também a validação e o ajuste dos resultados com dados do sensor de alta resolução TM do satélite Landsat.

Como objetivos secundários, aplicando a metodologia desenvolvida, pretendeuse:

- estimar quinzenalmente a área queimada no Cerrado no período 01/maio/98 a 30/abril/99;

- relacionar as áreas estimadas com o número de focos de queimadas ativas detectados pelo AVHRR/NOAA-12;

- estimar a área queimada no Cerrado quinzenalmente no período de 01/maio/99 a 31/outubro/00, utilizando a relação obtida entre área queimada e quantidade de focos de fogo. 


\section{2 - MATERIAIS E MÉTODOS}

\section{1 - MATERIAIS}

\subsection{1 - Área de Estudo}

A área de estudo compreendeu toda a região contínua do bioma Cerrado, segundo interpretação feita nesta tese do Mapa de Vegetação do Brasil do IBGE (1993) - Figura 2.1. Essa área está compreendida entre $2^{\circ} 30^{\prime}$ e $26^{\circ} 00^{\prime}$ de latitude Sul e $41^{\circ} 45^{\prime}$ e $62^{\circ} 00^{\prime}$ de longitude Oeste, abrangendo quase a totalidade dos estados de Goiás, Tocantins e Mato Grosso do Sul, e partes dos estados de Mato Grosso, Maranhão, Piauí, Minas Gerais, Bahia, São Paulo e Paraná. Considerou-se como bioma Cerrado a união de todas as classes de "Savana" e de "Tensão Ecológica" especificadas pelo IBGE (1993) que indicassem o contato entre Savana e outros tipos de vegetação, conforme Tabela 2.1. Enclaves de "Floresta" ou "Savana Estépica" (caatinga) também foram incluídos no Cerrado. Por outro lado, excluíram-se, nesse estudo, áreas disjuntas de savana, como por exemplo, aquela localizada em Roraima. Ressalta-se que não houve exclusão de áreas antropizadas, como as utilizadas na agricultura e pastagens, as quais não mais se encontram recobertas por vegetação original de cerrado, pois dados atuais sobre suas delimitações não foram encontrados na literatura.

Tabela 2.1 - Classes de vegetação utilizadas para delimitar a área de estudo; baseada em IBGE (1993).

\begin{tabular}{ll}
\hline Savana & Tensão ecológica \\
\hline Sd - Florestada & SO - Savana/Floresta Ombrófila \\
Sa - Arborizada & SN - Savana/Floresta Estacional \\
Sp - Parque & SM - Savana/Floresta Ombrófila Mista \\
Sg - Gramíneo-lenhosa & ST - Savana/Savana Estépica \\
S - Atividades agrícolas & STN - Savana/Savana Estépica/Floresta Estacional \\
\hline
\end{tabular}




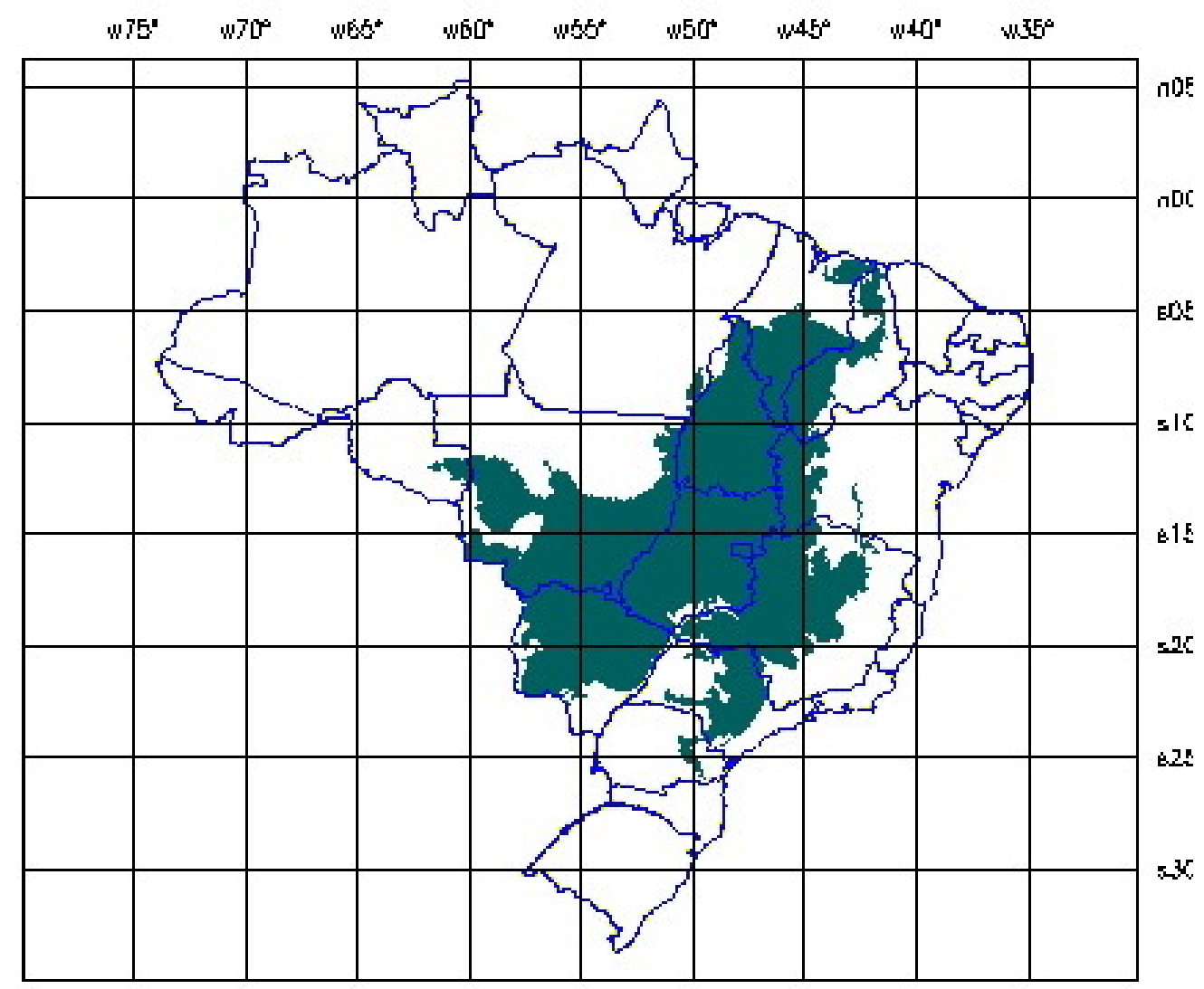

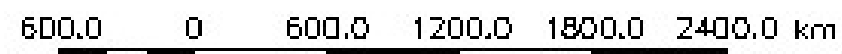

Figura 2.1 - Área contínua do Cerrado determinada a partir do Mapa de Vegetação do Brasil; baseado em IBGE (1993).

\subsection{2 - Dados de satélite}

Foram utilizadas imagens vespertinas AVHRR dos satélites NOAA-14 (Kidwell, 1995; Kidwell, 1998) para a elaboração de imagens-mosaico, a partir das quais se obtiveram estimativas de área queimada no Cerrado; as imagens TM do Landsat-5 foram usadas como "verdade de campo"; dados do AVHRR/NOAA-12 foram utilizados nas estimativas preliminares de áreas queimadas no Cerrado, no período maio/99 a outubro/00. 


\section{Dados AVHRR/NOAA}

- imagens diárias AVHRR/NOAA-14, bandas $1(0,58-0,68 \mu \mathrm{m}), 2(0,725-$ $1,10 \mu \mathrm{m})$ e $3(3,55-3.93 \mu \mathrm{m})$, resolução espacial de 1,1 km no nadir, 8 bits (256 números digitais), do período 01/maio/98 a 30/abril/99, gravadas pelas antenas do INPE localizadas em Cachoeira Paulista, SP e Cuiabá, MT - Tabela 2.2 . Foram utilizadas, sempre que disponíveis, duas imagens diárias contíguas. Das 631 imagens disponíveis para o período de interesse, 571 foram efetivamente processadas para a elaboração de mosaicos. O restante não foi aproveitado por motivos diversos, como alta cobertura de nuvens e falta de pontos de controle, excesso de ruídos ou ausência de linhas, erro no arquivo de parâmetros do satélite, etc.

- dados de detecção de queimadas ativas feita pelo processamento de duas imagens AVHRR/NOAA-12 diárias (do início da noite) pelo DAS/INPE referentes ao período agosto/98 a outubro/00. Esses dados são apresentados na forma de matrizes em que cada elemento corresponde à soma das queimadas ativas diárias detectadas em quadrículas de $0,5 \times 0,5$ graus de latitude e longitudes em 5 períodos fixos por mês: 01-07; 8-14; 15-21; 22-28; 29 ao último dia do mês.

- dados de detecção de queimadas feita pelo processamento de uma imagem diária do AVHRR/NOAA-12 pelo DAS/INPE, referentes ao período 01 a 31/maio/98.

\section{Dados TM/Landsat}

- imagens digitais TM/Landsat, órbita/ponto 225/70, bandas $3(0,63-0,69 \mu \mathrm{m})$, $4(0,76-0,90 \mu \mathrm{m})$ e $5(0,76-0,90 \mu \mathrm{m})$ de $01 /$ agosto/98 e 17/agosto/98.

- imagens digitais TM/Landsat, órbita/ponto 221/70, bandas $3(0,63-0,69 \mu \mathrm{m})$, $4(0,76-0,90 \mu \mathrm{m})$ e $5(0,76-0,90 \mu \mathrm{m})$ de $21 /$ agosto/98 e $06 /$ setembro/98.

- imagens digitais TM/Landsat, órbita/ponto 220/68, bandas $3(0,63-0,69 \mu \mathrm{m})$, $4(0,76-0,90 \mu \mathrm{m})$ e $5(0,76-0,90 \mu \mathrm{m})$ de $14 /$ agosto/98 e 30/agosto/98. 
As imagens relacionadas acima serão designadas nesse trabalho, pelo estado ao qual se referem, ou seja, Mato Grosso (MT), Goiás (GO) e Bahia (BA), respectivamente.

Tabela 2.2 - Parâmetros orbitais e espectrais do AVHRR-NOAA; adaptado de Kidwell (1995 e 1998).

\begin{tabular}{|c|c|c|}
\hline \multicolumn{2}{|l|}{ Ciclo de cobertura } & 9 dias \\
\hline \multicolumn{2}{|c|}{ Ângulo de imageamento } & $55,4^{\circ}$ \\
\hline \multicolumn{2}{|c|}{ Largura da faixa imageada } & $2.700 \mathrm{~km}$ \\
\hline \multicolumn{2}{|l|}{ Inclinação da órbita } & $98,8^{\circ}$ \\
\hline \multicolumn{2}{|l|}{ Altitude } & $833 \mathrm{~km}$ \\
\hline \multicolumn{2}{|l|}{ Período orbital } & 102 minutos \\
\hline \multicolumn{2}{|l|}{ Resolução no terreno } & $1,1 \mathrm{~km}$ (nadir) \\
\hline \multicolumn{2}{|l|}{ Quantização } & 10 bits \\
\hline \multicolumn{2}{|c|}{ Cruzamento com o Equador NOAA-12 } & $07 \mathrm{~h} 30$ (asc.) e $19 \mathrm{~h} 30$ (desc.) \\
\hline \multicolumn{2}{|c|}{ Cruzamento com o Equador NOAA-14 } & $13 \mathrm{~h} 30$ (asc.) e $19 \mathrm{~h} 30$ (desc.) \\
\hline \multirow{5}{*}{$\begin{array}{c}\text { Bandas Espectrais } \\
(\mu \mathrm{m})\end{array}$} & 1 & $0,58-0,68$ \\
\hline & 2 & $0,725-1,10$ \\
\hline & 3 & $3,55-3,93$ \\
\hline & 4 & $10,3-11,3$ \\
\hline & 5 & $11,5-12,5$ \\
\hline
\end{tabular}

\subsection{3 - Material cartográfico}

O mapa de vegetação do Brasil utilizado para delimitar a área de estudo, e as cartas topográficas necessárias para fazer o registro das imagens TM/Landsat estão relacionadas abaixo:

- Mapa de Vegetação do Brasil, escala 1:5.000.000 (IBGE, 1993).

- Cartas topográficas, escala 1:250.000, folhas SD.21-X-D, Boca da Mata, MT (DSG, 1983); SD.22-Y-C, General Carneiro, MT (DSG, 1986); SD.21-Z-D, Don Aquino, MT (1982); SD.22-V-C, Garapu, MT (DSG, 1983); SD.21-Z-B, Paranatinga, MT (DSG, 1983); SC.23-Z-C, Santa Rita de Cássia, BA (IBGE, 1984); SC.23-Y-D, Formosa do Rio Preto, GO-BA (IBGE, 1984); SD.23-V-B, 
Barreiras, GO-BA (IBGE, 1984); SD.23-X-A, Santana, BA (IBGE, 1984). SD.22-X-D, Porangatu, GO (IBGE, 1983); SD.23-Y-A, Iaciara, GO (IBGE, 1983); SD.23-V-C; Campos Belos, GO (IBGE, 1985); SD.22-Z-D, Goianésia (IBGE, 1980).

- Mapas digitais do IBGE: Rios Permanentes; Áreas Inundáveis no Brasil. Material disponível no banco de dados do SPRING (DPI, 2000).

\subsection{4 - Equipamentos e programas computacionais}

Todos os processamentos, registros e classificações de imagens foram feitos em microcomputador. Foi necessária mesa digitalizadora para fazer o registro das imagens TM/Landsat e para digitalizar a área de estudo. Foram usados programas de computador específicos para imagens AVHRR e também o SPRING - Sistema de Processamento de Informações Geo-referenciadas. A especificação destes itens está abaixo:

- Microcomputador com a seguinte configuração: Processador Pentium III, 500 $\mathrm{MHz}, 256 \mathrm{Mb}$ memória RAM, 2 discos rígidos (6 Mb e $20 \mathrm{Mb}$ ), kit multi-mídia, gravador de CD e monitor de $17 "$.

- Mesa digitalizada Digigraf A1.

- $\quad$ Ploter HP DeskJet 2500 CP.

- $\quad$ SPRING, versão 3.3 (DPI, 1999) e 3.4 (DPI, 2000).

- Programas para processamento de imagens AVHRR/NOAA (Setzer, 2000). Esses programas foram utilizados para decomutar a imagem bruta, ou seja, separar os dados em arquivos correspondentes as bandas espectrais, bem como para geo-referenciar, corrigir as imagens geometricamente, e elaborar os mosaicos com 1,5 km de resolução espacial.

\section{2 - MÉTODOS}

Os procedimentos abaixo descrevem as metodologias utilizadas para: a) elaboração de imagens-mosaico — principal produto utilizado nesse trabalho - a partir das imagens brutas do AVHRR/NOAA-14; b) análise preliminar da variação temporal 
dos dados AVHRR e elaboração do algoritmo de detecção de áreas queimadas nas imagens-mosaico; c) mapeamento de queimadas em imagens TM/Landsat-5, e comparação dessas informações com aquelas resultantes da aplicação do algoritmo nas imagens-mosaico do AVHRR; d) comparação dos dados AVHRR/NOAA-14 com os dados de detecção de queimadas originários do AVHRR/NOAA-12.

\subsection{1 - Regravação das imagens AVHRR/NOAA-14}

Primeiramente, obtiveram-se cópias das imagens brutas do AVHRR a partir do acervo de imagens da Divisão de Operação de Satélites Ambientais — DSA /INPE de Cachoeira Paulista, SP. Esses dados foram regravados em CDs. Por imagem bruta, entende-se os dados gravados pela antena receptora durante uma passagem do satélite e que não foram submetidos a nenhum tipo de processamento, como correção geométrica, geo-referenciamento, etc. Cada imagem bruta ocupa até cerca de $100 \mathrm{Mb}$ e, portanto, foram empregados cerca de 110 CDs no processo de regravação dos dados do período de estudo.

\subsection{2 - Processamento inicial das imagens AVHRR}

A finalidade do processamento inicial das 571 imagens AVHRR foi georeferenciá-las e corrigi-las geometricamente. O geo-referenciamento foi feito com apenas um ponto de controle e a correção geométrica resultou em imagens na projeção cartográfica cilíndrica eqüidistante.

\subsection{3 - Elaboração de mosaicos}

As imagens-mosaico quinzenais foram os principais produtos empregados para estimar e localizar áreas queimadas. Elaboraram-se 24 conjuntos quinzenais de imagens-mosaico (aqui chamadas apenas de "mosaico") abrangendo o período maio/98 a abril/99. Cada conjunto, por sua vez, compreendeu quatro modalidades de imagensmosaicos - IVDN e bandas $1(0,58-0,68 \mu \mathrm{m}), 2(0,72-1,1 \mu \mathrm{m})$ e $3(3,55-3,93 \mu \mathrm{m})$ do AVHRR - , além de dados auxiliares como uma imagem de freqüência de cobertura do satélite e uma listagem das imagens utilizadas. 
A resolução espacial desses mosaicos foi definida por píxeis correspondentes a $1,5 \mathrm{~km} \times 1,5 \mathrm{~km}$.

Cada imagem bruta foi processada individualmente para elaboração do mosaico e, em seguida, foi feita inspeção visual cuidadosa no produto resultante, para verificar a qualidade da "sobreposição" — registro — das imagens individuais. Quando se constatou alguma duplicação de feições, indicando que o registro entre as imagens não estava satisfatório, o procedimento de geo-referenciamento e de "mosaicagem" foi repetido até obtenção de resultado satisfatório.

Para a elaboração do mosaico IVDN, foram selecionados os píxeis de maior valor, à medida em que as imagens iam sendo incorporadas. Esse procedimento permitiu eliminar ou minimizar a presença de nuvens, pois elas apresentam IVDNs baixos e, ao mesmo tempo, selecionar os píxeis relacionados com a presença de fitomassa fotossinteticamente ativa, que apresentam IVDN superior ao de solo exposto e de vegetação senescente ou seca. Nos mosaicos da banda 3, selecionaram-se os píxeis de menor número digital, pois eles indicam as maiores temperaturas. Nos mosaicos das bandas 1 e 2, selecionaram-se os píxeis correspondentes ao maior IVDN para, da mesma forma, eliminar a presença de nuvens. A primeira quinzena correspondeu ao período dos dias 01 a 14 de cada mês, e a segunda do dia 15 até o final do mês.

O algoritmo de identificação de áreas queimadas comparou mosaicos IVDN com um "mosaico IVDN de referência" que contém os mais altos valores de IVDN observados na estação chuvosa. Para tanto, elaborou-se também, um mosaico, contendo os máximos valores de IVDN no período de 15/dezembro/98 a 14/fevereiro/99.

Nos mosaicos e nas imagens AVHRR optou-se por utilizar sempre e apenas os números digitais brutos, conforme metodologia já empregada e justificada em França e Setzer (1998, 2000).

\subsection{4 - Registro dos mosaicos AVHRR}

Depois de concluída a elaboração dos mosaicos, os mesmos foram registrados e transferidos para o ambiente SPRING. Para tanto, selecionou-se um mosaico IVDN primeira quinzena de maio/98 - fazendo-se o registro através de pontos de controle. 
Foram utilizados os pontos de controle indicados no programa de detecção de queimadas do INPE (Setzer, 2000). No ambiente SPRING foram utilizados os seguintes parâmetros para todos os dados e imagens desse trabalho:

a) retângulo envolvente da área de estudo determinado pelas longitudes $37^{\circ} 00^{\prime} 00^{\prime \prime} \mathrm{W}$ e $63^{\circ} 00^{\prime} 00^{\prime \prime} \mathrm{W}$ e pelas latitudes $01^{\circ} 00^{\prime} 00^{\prime \prime} \mathrm{S}$ e $27^{\circ} 00^{\prime} 00^{\prime \prime} \mathrm{S}$.

b) projeção cartográfica Cilíndrica/Hayford.

Em seguida, procedeu-se ao registro do tipo "imagem-imagem" dos outros conjuntos de mosaicos AVHRR, utilizando o mosaico da primeira quinzena de maio/98 como referência. Dessa forma, obtiveram-se 24 conjuntos de mosaicos quinzenais AVHRR geo-referenciados.

\subsection{5 - Digitalização da área de estudo}

A delimitação da área de estudo foi feita com base no Mapa de Vegetação do Brasil (IBGE, 1993), segundo os critérios descritos no item 2.1.1. Elaborou-se um "overlay", delimitando toda a área contínua de Cerrado que, em seguida, foi digitalizada. Dessa forma, obteve-se também uma estimativa de área ocupada pelo Cerrado, conforme o mapa do IBGE (1993).

\subsection{6 - Variação temporal do IVDN e dos valores digitais das bandas 1, 2 e 3 do AVHRR}

A análise da variação temporal do IVDN e dos números digitais das bandas 1, 2 e 3 foi a principal base de informação para a elaboração do algoritmo de detecção de áreas queimadas nos mosaicos AVHRR/NOAA-14.

Para analisar a variação temporal dos números digitais (bandas 1, 2 e 3) e IVDN de diferentes tipos de superfície ao longo de um ano, selecionaram-se 34 amostras de 5 x 5 píxeis em posições fixas em cada um dos 24 conjuntos de mosaicos. As superfícies de interesse no Cerrado foram: a) queimadas ativas e marcas de queimadas; b) superfícies sujeitas a reflexão na banda 3 e, por isso, passíveis de confundir queimadas com solos expostos e corpos d'água; c) superfícies sem ocorrência de 
queimadas, utilizadas como controle, em vegetação e corpos d'água. Foram, então, elaborados gráficos e tabelas mostrando os valores quinzenais dos números digitais e IVDN em cada amostra. Da observação desses dados foram determinadas as regras de decisão utilizadas no algoritmo para identificação e classificação de queimadas nos mosaicos. As coordenadas geográficas centrais das amostras estão na Tabela 2.3.

Tabela 2.3 - Localização das áreas amostrais nos mosaicos AVHRR/NOAA-14.

\begin{tabular}{|c|c|c|}
\hline Área & Latitude Sul & Longitude Oeste \\
\hline 1 & $03^{\circ} 44^{\prime} 41.75^{\prime \prime}$ & $42^{\circ} 57^{\prime} 34.53^{\prime \prime}$ \\
\hline 2 & $04^{\circ} 46^{\prime} 23.60^{\prime \prime}$ & $49^{\circ} 09^{\prime} 16.45^{\prime \prime}$ \\
\hline 3 & $06^{\circ} 34^{\prime} 10.41^{\prime \prime}$ & $45^{\circ} 07^{\prime} 10.59^{\prime \prime}$ \\
\hline 4 & $09^{\circ} 23^{\prime} 38.26^{\prime \prime}$ & $45^{\circ} 36^{\prime} 55.81^{\prime \prime}$ \\
\hline 5 & $12^{\circ} 35^{\prime} 01.89^{\prime \prime}$ & $45^{\circ} 59^{\prime} 04.02^{\prime \prime}$ \\
\hline 6 & $14^{\circ} 46^{\prime} 0.065^{\prime \prime}$ & $45^{\circ} 46^{\prime} 21.91^{\prime \prime}$ \\
\hline 7 & $12^{\circ} 05^{\prime} 37.27^{\prime \prime}$ & $47^{\circ} 41^{\prime} 51.63^{\prime \prime}$ \\
\hline 8 & $10^{\circ} 56^{\prime} 19.40^{\prime \prime}$ & $50^{\circ} 12^{\prime} 19.55^{\prime \prime}$ \\
\hline 9 & $11^{\circ} 53^{\prime} 27.95^{\prime \prime}$ & $49^{\circ} 39^{\prime} 05.01^{\prime \prime}$ \\
\hline 10 & $13^{\circ} 17^{\prime} 48.45^{\prime \prime}$ & $51^{\circ} 00^{\prime} 07.07^{\prime \prime}$ \\
\hline 11 & $13^{\circ} 06^{\prime} 05.14^{\prime \prime}$ & $51^{\circ} 27^{\prime} 10.87^{\prime \prime}$ \\
\hline 12 & $12^{\circ} 24^{\prime} 49.20^{\prime \prime}$ & $50^{\circ} 48^{\prime} 32.55^{\prime \prime}$ \\
\hline 13 & $12^{\circ} 21^{\prime} 14.93^{\prime \prime}$ & $50^{\circ} 19^{\prime} 18.21^{\prime \prime}$ \\
\hline 14 & $14^{\circ} 00^{\prime} 17.26^{\prime \prime}$ & $50^{\circ} 06^{\prime} 21.13^{\prime \prime}$ \\
\hline 15 & $12^{\circ} 33^{\prime} 30.53^{\prime \prime}$ & $49^{\circ} 42^{\prime} 29.86^{\prime \prime}$ \\
\hline 16 & $03^{\circ} 32^{\prime} 57.64^{\prime \prime}$ & $43^{\circ} 24^{\prime} 25.67^{\prime \prime}$ \\
\hline 17 & $06^{\circ} 34^{\prime} 54.62^{\prime \prime}$ & $46^{\circ} 28^{\prime} 37.32^{\prime \prime}$ \\
\hline 18 & $13^{\circ} 12^{\prime} 16.45^{\prime \prime}$ & $45^{\circ} 13^{\prime} 17.35^{\prime \prime}$ \\
\hline 19 & $17^{\circ} 42^{\prime} 44.31^{\prime \prime}$ & $45^{\circ} 14^{\prime} 35.90^{\prime \prime}$ \\
\hline 20 & $18^{\circ} 14^{\prime} 45.00^{\prime \prime}$ & $46^{\circ} 17^{\prime} 12.22^{\prime \prime}$ \\
\hline 21 & $16^{\circ} 07^{\prime} 18.85^{\prime \prime}$ & $53^{\circ} 23^{\prime} 20.38^{\prime \prime}$ \\
\hline 22 & $18^{\circ} 09^{\prime} 04.34^{\prime \prime}$ & $52^{\circ} 54^{\prime} 38.47^{\prime \prime}$ \\
\hline 23 & $17^{\circ} 55^{\prime} 53.76^{\prime \prime}$ & $50^{\circ} 01^{\prime 29.61 "}$ \\
\hline 24 & $15^{\circ} 49^{\prime} 29.50^{\prime \prime}$ & $59^{\circ} 15^{\prime} 33.35^{\prime \prime}$ \\
\hline 25 & $15^{\circ} 41^{\prime} 54.15^{\prime \prime}$ & $59^{\circ} 29^{\prime} 08.60^{\prime \prime}$ \\
\hline 26 & $17^{\circ} 11^{\prime} 14.86^{\prime \prime}$ & $56^{\circ} 20^{\prime} 20.59^{\prime \prime}$ \\
\hline 27 & $17^{\circ} 08^{\prime} 11.26^{\prime \prime}$ & $56^{\circ} 36^{\prime} 29.06^{\prime \prime}$ \\
\hline 28 & $17^{\circ} 25^{\prime} 36.15^{\prime \prime}$ & $43^{\circ} 42^{\prime} 1.670^{\prime \prime}$ \\
\hline 29 & $17^{\circ} 21^{\prime} 27.62^{\prime \prime}$ & $43^{\circ} 37^{\prime} 43.04^{\prime \prime}$ \\
\hline 30 & $09^{\circ} 03^{\prime} 16.08^{\prime \prime}$ & $45^{\circ} 18^{\prime} 59.22^{\prime \prime}$ \\
\hline 31 & $12^{\circ} 50^{\prime} 55.36^{\prime \prime}$ & $46^{\circ} 08^{\prime} 9.11^{\prime \prime}$ \\
\hline 32 & $18^{\circ} 16^{\prime} 09.07^{\prime \prime}$ & $56^{\circ} 22^{\prime} 50.32^{\prime \prime}$ \\
\hline 33 & $16^{\circ} 45^{\prime} 21.10^{\prime \prime}$ & $38^{\circ} 43^{\prime} 06.29^{\prime \prime}$ \\
\hline 34 & $18^{\circ} 29^{\prime} 49.00^{\prime \prime}$ & $45^{\circ} 24^{\prime} 38.22^{\prime \prime}$ \\
\hline
\end{tabular}

\subsection{7 - Elaboração do algoritmo de avaliação de áreas queimadas}

A elaboração de um algoritmo para identificação de áreas queimadas, principal objetivo desse trabalho, foi feito inicialmente com base nas observações das variações temporais dos números digitais da banda 3 e do IVDN, e ajustado com observações adicionais nos próprios mosaicos e vários testes. Procurou-se estabelecer limites de 
números digitais nos mosaicos IVDN e banda 3 que pudessem: a) identificar áreas queimadas; b) identificar áreas não-queimadas; c) identificar solos expostos e corpos d'água sujeitos a reflexos da banda 3 do AVHRR e, dessa forma, evitar, ou ao menos minimizar, as falsas identificações de áreas queimadas do AVHRR; d) identificar as regiões classificadas como queimada nos mosaicos anteriores, evitando-se reclassificação como queimada.

\subsection{8 - Escolha das imagens TM/Landsat-5}

Imagens TM/Landsat-5 foram utilizadas como "verdade de campo" na comparação com os resultados obtidos da aplicação do algoritmo para avaliação de áreas queimadas em mosaicos AVHRR.

Foram selecionados 3 pares de imagens TM/Landsat dentro da área de estudo. A escolha dessas imagens baseou-se nos critérios expostos a seguir:

a) apresentar cobertura de nuvens máxima de $20 \%$ quando somadas aquelas das duas imagens de cada par, permitindo visualizar pelo menos $80 \%$ da superfície abrangida pela área comum às duas imagens $\left(\sim 34.000 \mathrm{~km}^{2}\right)$.

b) ser composto (cada par) por imagens consecutivas da mesma órbita/ponto, ou seja, do mesmo local, porém com 16 dias de diferença entre as datas de gravação. Essa condição teve por finalidade facilitar a comparação dos dados TM com os mosaicos quinzenais AVHRR do mesmo período, já que ambos correspondem a um intervalo semelhante.

c) pertencer aos meses de agosto e/ou setembro, garantindo um maior número de queimadas em cada imagem, conforme discutido no item 1.2.

d) excluir o Pantanal do Mato Grosso, pois trata-se de região de características bem distintas do restante do Cerrado pela presença de planícies inundadas sazonalmente.

e) estar em regiões de alta incidência de queimadas, porém sem incluir casos extremos de ocorrência de queimadas como o ocorrido em julho e agosto/1998 na região da Ilha do Bananal, TO (OESP, 1998). 
f) permitir clara identificação das áreas queimadas.

g) abranger o Cerrado da região nordeste do Brasil em um dos pares, pois considerou-se necessário analisar uma região em que ocorrem casos extremos de reflexos na banda 3 do AVHRR, causando confusão com queimadas, principalmente durante os meses de agosto e setembro.

\subsection{9 - Registro das imagens TM/Landsat}

As imagens TM/Landsat foram geo-referenciadas para comparação com a outra imagem de cada par, bem como com os mosaicos AVHRR e produtos gerados pela aplicação do algoritmo de identificação de queimadas.

A primeira imagem de cada par TM/Landsat foi registrada com cartas topográficas 1:250.000, conforme relacionado no item 2.1.3. Em seguida, elas foram transferidas para o ambiente SPRING e utilizadas como imagem de referência para o registro da segunda imagem de cada par.

\subsubsection{0 - Interpretação das imagens TM/Landsat}

Essa etapa teve por objetivo delimitar as áreas queimadas que ocorreram no período compreendido entre as datas das duas imagens TM de cada par. Essas informações foram utilizadas como "verdade" para efeito de comparação com os dados AVHRR.

Primeiramente, foi feita a classificação automática MAXVER (DPI, 1999), utilizando-se as bandas TM 3, 4 e 5 para identificação de queimadas. Para tanto, selecionaram-se em cada imagem, cerca de 40 amostras de treinamento em áreas queimadas. Em seguida, por meio de um programa desenvolvido em "LEGAL" (Linguagem Espaço-Geográfica baseada em Álgebra), no SPRING, obteve-se a "imagem diferença" entre as duas imagens de cada par. Esse procedimento foi feito inicialmente para os pares de imagens de Mato Grosso e Bahia.

Em seguida, como os resultados preliminares obtidos pela classificação automática foram insatisfatórios — item 3.6 - optou-se por fazer interpretação visual e 
digitalização das queimadas, acompanhando-se com o mouse os contornos no monitor do computador. Para tanto, foram geradas imagens "sintéticas", resultantes da composição colorida das bandas 3 (vermelho), 4 (verde) e 5 (azul). Utilizando a função "acoplar" do SPRING, que permite visualizar na tela uma segunda imagem no interior de uma janela de dimensões definidas pelo usuário, foi possível analisar simultaneamente as duas imagens de cada par TM/Landsat e delimitar as queimadas ocorridas no período entre as datas de gravação delas. A interpretação das imagens TM foi feita na escala aproximada de 1:50.000. Cada par de imagem consumiu cerca de 100 horas de interpretação visual e digitalização na tela, resultando em três novas imagens temáticas: uma para cada par de imagens TM utilizadas.

Nos dados resultantes da interpretação das imagens da Bahia, aplicou-se uma "máscara" com os limites da área de estudo, pois uma porção dessa região, com cerca de $2.200 \mathrm{~km}^{2}$, não pertence ao Cerrado.

Obteve-se, em seguida, o número de polígonos de queimadas e também a estimativa de área queimada correspondente a cada par de imagens TM.

Foram então, gerados mapas cadastrais de queimadas obtidos dos dados TM. Dessa forma, cada queimada passou a ser identificada por um número. Esse procedimento permitiu gerar tabelas associando um ou mais atributos, como área, por exemplo, a cada polígono de queimada cadastrado.

Finalmente, as queimadas foram agrupadas em classes de tamanho, conforme os seguintes intervalos:

a) $x<0,5 \mathrm{~km}^{2}$

b) $0,5 \mathrm{~km}^{2} \leq x<2 \mathrm{~km}^{2}$

c) $2 \mathrm{~km}^{2} \leq x<10 \mathrm{~km}^{2}$

d) $x \geq 10 \mathrm{~km}^{2}$

Para cada classe, contou-se o número de áreas de queimadas identificadas (polígonos) e obteve-se a soma das áreas dos polígonos. Conforme apresentado em França e Setzer (1997), o dígito das unidades obtidas nas estimativas de áreas em 
imagens TM são incertos e, em muitos casos, possivelmente o das dezenas também. Spiegel (1972) ressalta que a prática de arredondamento de números é indicada para reduzir erros acumulados, quando tratar-se de um grande número de operações. Nesse trabalho os resultados obtidos da soma de áreas de polígonos interpretados nas imagens TM foram arredondados nos dígitos das dezenas; estimativas finais de áreas queimadas para todo o Cerrado foram arredondadas nos dígitos das centenas.

Por último, os dados de áreas queimadas das três regiões foram colocados em forma gráfica de freqüência acumulada relativa, para obtenção de uma função matemática que melhor descrevesse o comportamento dos dados.

\subsubsection{1 - Elaboração adicional de mosaicos AVHRR/NOAA-14}

A elaboração de novos mosaicos teve por objetivo gerar dados AVHRR que correspondessem aos mesmos intervalos de tempo de cada par de imagens TM/Landsat. No entanto, como o horário de passagem do Landsat-5 ( $\sim 10 \mathrm{~h}$, local) foi anterior ao do NOAA-14 ( $16 \mathrm{~h}$, local) não foram utilizadas as imagens AVHRR correspondentes a data da segunda imagem de cada par TM/Landsat. Dessa forma, para os pares de imagens TM/Landsat, cujas datas de passagem foram 01 e 17/agosto, 14 e 30/agosto e 06/agosto e 21/setembro, elaboraram-se novos mosaicos AVHRR com imagens dos períodos de 01 a 16/agosto, 14 a 29/agosto e 06 a 20/setembro, respectivamente.

Também foram elaborados mosaicos AVHRR dos períodos 1 a 13/agosto e 15 a 20/setembro. Esse procedimento foi necessário, para garantir a continuidade temporal dos dados, pois o algoritmo de avaliação de área queimada utiliza informações de ocorrência de queimadas do período imediatamente anterior ao que está sendo estudado.

Todos os conjuntos adicionais de mosaicos AVHRR foram registrados transferidos para o ambiente SPRING, conforme métodos descritos no item 2.2.5.

\subsubsection{2 - Subdivisão da área de estudo}

Avaliação preliminar dos resultados da aplicação do algoritmo de identificação de queimadas mostrou a persistência dos efeitos dos reflexos da banda 3 no Nordeste brasileiro (Setzer e Malingreau, 1996). Dessa forma, a área de estudo foi dividida em 
duas regiões: a primeira, designada Cerrado 1, de modo geral, não é sujeita a ocorrência de reflexos em solos nas imagens da banda 3; a segunda, chamada de Cerrado 2, por outro lado, é fortemente afetada por esses reflexos, principalmente nos meses de agosto e setembro. A divisão nessas duas regiões foi feita inicialmente pela classificação automática - MAXVER (DPI, 1999) — do mosaico IVDN de referência, considerando apenas três classes genéricas dentro do Cerrado: a) com os maiores valores de IVDN no Cerrado, em torno de 0,28 a 0,40 ; b) com os menores valores; em torno de 0,16 a 0,22 ; c) cultivos agrícolas, com IVDN em torno de 0,45 a 0,53. Foram utilizadas cerca de 12 amostras para cada classe em questão. Em seguida, após a classificação automática, foi traçado manualmente o limite entre as duas classes, originando dois polígonos. A classe "Cultivo Agrícola" foi desconsiderada nessa divisão, ou seja, passou a integrar a região que a circundava. A Figura 2.2 mostra a área de estudo subdivida nas regiões Cerrado 1 e Cerrado 2, bem como a localização das imagens Landsat utilizadas.

\subsubsection{3 - Aplicação do algoritmo de avaliação de áreas queimadas}

O algoritmo de avaliação de áreas queimadas foi aplicado para todos os mosaicos, em ordem temporal, com início na segunda quinzena de maio/98, e término na segunda quinzena de abril/99.

Para efeito de comparação com os dados de queimadas das imagens TM, o algoritmo foi aplicado nos mosaicos adicionais, descritos no item 2.2.11, respeitando igualmente a seqüência temporal de dados. Nesse caso, após o processamento, foi aplicada uma "máscara" para gerar imagens temáticas correspondentes às áreas das imagens TM analisadas.

Obtiveram-se, ao final do processo, 23 imagens temáticas indicando áreas queimadas no Cerrado, em cada quinzena do período de estudo. A primeira quinzena de maio/98 não foi analisada, pois não se dispunha dos dados relativos ao período anterior.

As imagens temáticas obtidas foram então avaliadas visualmente e comparadas aos mosaicos originais e aos dados TM. A partir dessa avaliação inicial, os valores de números digitais utilizados no algoritmo foram alterados. Após cada alteração, repetiu- 
se todo o processamento dos mosaicos. Esses testes consumiram centenas de horas de trabalho.
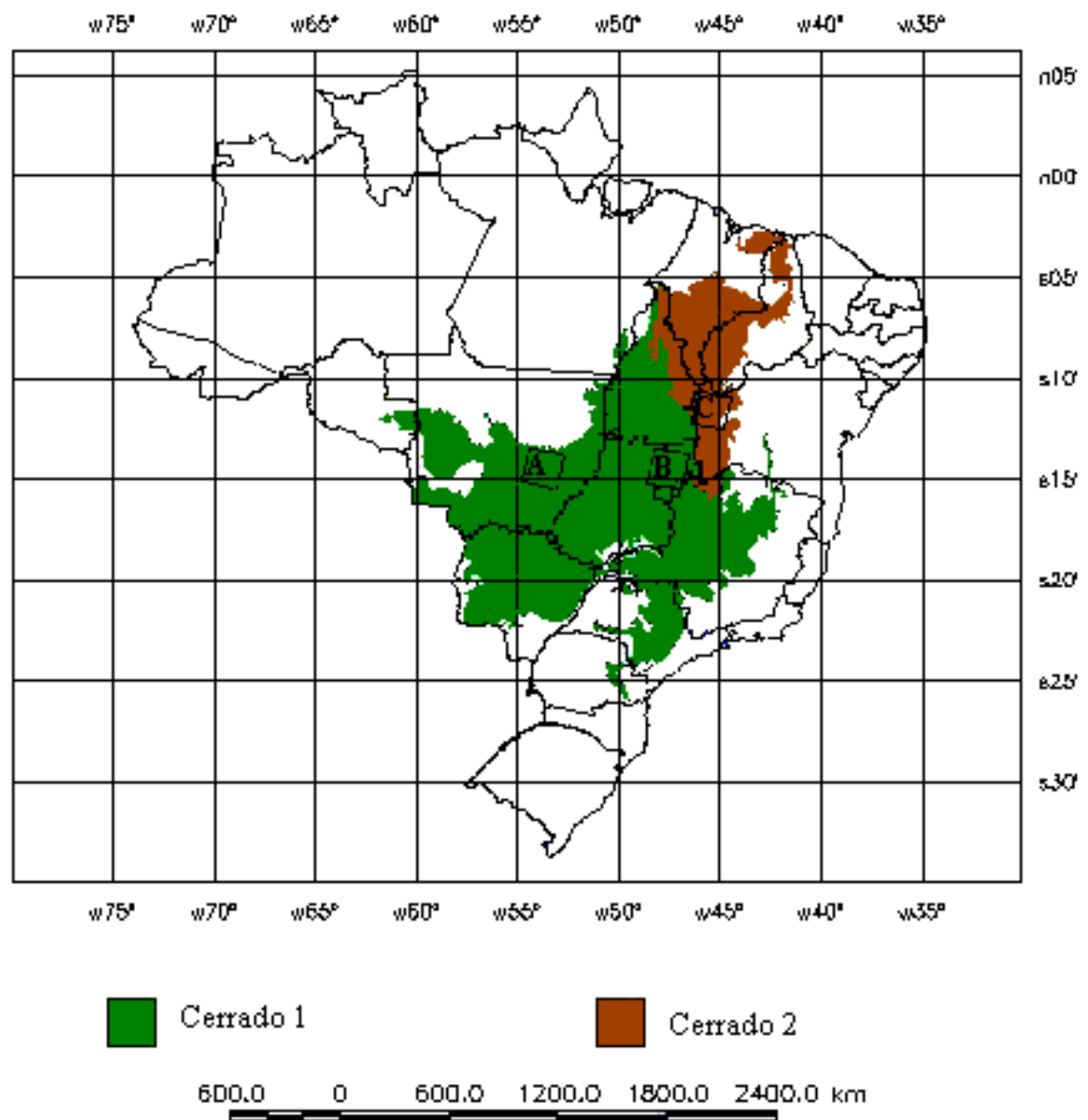

Figura 2.2 - Regiões Cerrado 1 e Cerrado 2 com localização das imagens TM/Landsat: A - Mato Grosso (225/70); B - Goiás (221/70); C - Bahia (220/68).

\subsubsection{4 - Comparação dos dados AVHRR com os dados TM}

Para avaliar o desempenho do algoritmo e elaborar equações para estimar a área queimada em todo o Cerrado a partir de mosaicos AVHRR/NOAA-14, os dados TM/Landsat-5 foram comparados aos dados AVHRR. Para tanto, foram geradas 3 imagens temáticas produzidas pela aplicação do algoritmo nos mosaicos adicionais item 2.2.11. Finalmente, utilizou-se uma "máscara" nos mosaicos para obter imagens 
temáticas das áreas correspondentes às imagens TM. Dessa forma, para cada uma das três áreas estudadas, foram geradas 2 imagens temáticas: a primeira, considerada "verdade", contém a delimitação das queimadas e resultou da interpretação das imagens TM/Landsat; a segunda resultou da aplicação do algoritmo nos mosaicos AVHRR, também apresentando áreas queimadas classificadas. A imagem temática AVHRR foi transformada em mapa cadastral, permitindo a identificação numérica dos polígonos de queimadas individualmente, bem como informação sobre a área de cada um.

\subsubsection{1 - Interpretação visual dos resultados}

Foram gerados no SPRING mapas com limites das queimadas TM sobrepostos às áreas identificadas como queimadas nos mosaicos AVHRR. Ressalta-se que, em ambos conjuntos de dados, os polígonos de queimadas estavam identificados individualmente e a área de cada um deles era conhecida. Tais mapas temáticos foram impressos em escala 1:140.000, totalizando 12 folhas de $1 \mathrm{mx} 1 \mathrm{~m}$. Cada folha correspondeu a cerca de 1/4 da área abrangida por uma imagem TM. Nessas folhas foi feita interpretação visual para estabelecer correspondência entre as queimadas identificadas pelo TM com aquelas identificadas nos mosaicos AVHRR. Tal correspondência nem sempre foi biunívoca, pois muitas queimadas pequenas e próximas identificadas no TM, por exemplo, foram em vários casos interpretada como um único polígono de queimada nos dados AVHRR, devido, sobretudo, a diferença de resolução espacial entre os dois sensores. Adotou-se como medida limite de erro de localização a distância de equivalente 4 píxeis dos mosaicos AVHRR, ou seja, $6 \mathrm{~km}$ (cerca de 4 a $5 \mathrm{~cm}$ nos mapas impressos). Foi elaborada uma lista com as queimadas que apresentaram correspondência nas imagens TM e AVHRR. Listaram-se também, as queimadas classificadas nas imagens TM, porém omitidas pelo algoritmo, bem como aquelas que foram identificadas nos mosaicos AVHRR, mas que não tinham correspondência nas imagens TM. Nas listagens constaram também as estimativas de área de cada polígono de queimada, em $\mathrm{m}^{2}$, obtidas dos dados TM e AVHRR. 


\subsubsection{2 - Estimativas de áreas queimadas por células}

Para realizar a análise de regressão entre os dados de área queimadas obtidos pelas imagens TM e aqueles dos mosaicos AVHRR, os mapas digitais resultantes da interpretação das imagens TM foram subdivididos por uma grade de 6 x 6 células. Obtiveram-se células com média de $1.013 \mathrm{~km}^{2}$. Calculou-se então, a área queimada obtida pelo TM e pela aplicação do algoritmo nos mosaicos AVHRR em cada uma das células. Em seguida esses valores foram ajustados, por proporção, a um tamanho de célula padrão, visto que elas não possuiam áreas idênticas. Diferenças no tamanho da células foram conseqüência de pequenas imprecisões na determinação da área comum em cada par de imagens TM. Descartaram-se as células com mais de 50\% de sua área coberta por nuvens ou fora do limite do bioma Cerrado. Nas células em que ocorreram nuvens ou áreas fora dos limites do Cerrado em proporções inferiores a 50\% da área da célula, foram feitos ajustes nos cálculos de áreas queimadas por simples proporção, supondo uma célula padrão localizada inteiramente no Cerrado e livre de nuvens. A partir desses dados foram feitas as análises estatísticas de regressão.

\subsubsection{5 - Análises estatísticas}

As análises estatísticas empregadas tiveram por objetivo:

a) verificar se as três amostras de áreas queimadas resultantes da interpretação das imagens TM representavam a mesma população;

b) determinar, por análise de regressão, as equações de ajuste dos dados AVHRR aos dados TM.

Os cálculos relativos à análise de regressão foram feitos em planilha eletrônica, através de suas funções estatísticas internas. Alguns procedimentos adicionais foram necessários para verificar a adequação do modelo de regressão obtido à análise de variância e de normalidade dos erros (Netter e Wasserman, 1974). A seguir encontramse descritos os testes utilizados para verificar se as amostras de áreas queimadas pertenciam à mesma população (teste de Kolmogorov-Smirnov para duas amostras), bem como aqueles aplicados para estimar a constância da variância dos erros resultantes da regressão (teste de Bartlett), bem como sua normalidade (teste de Kolmogorov- 
Smirnov para uma amostra). Por último, descreve-se o método utilizado para calcular o intervalo de confiança.

\section{Teste de Kolmogorov-Smirnov para duas amostras}

O teste de Kolmogorov-Smirnov (Sokal e Rohlf, 1997; Siegel, 1977) comparou, duas a duas, a distribuição cumulativa das áreas queimadas nas três amostras - Mato Grosso, Goiás e Bahia — para verificar se representavam a mesma população.

Inicialmente, as amostras de cada uma das três regiões foram divididas em 40 intervalos de $0,5 \mathrm{~km}^{2}$, com início em zero e final em $20 \mathrm{~km}^{2}$. Foram, portanto desconsideradas as queimadas superiores a $20 \mathrm{~km}^{2}$.

A função acumulada $S_{n 1}(X)$ da amostra 1 é dada por:

$$
S_{n 1}(X)=K / n_{1}
$$

onde

$$
\begin{aligned}
& X=\text { limite para cálculo do valor acumulado, } \\
& K=\text { número de escores não superiores a } X, \\
& n 1=\text { número de elementos da amostra } 1 .
\end{aligned}
$$

Similarmente, a função acumulada da amostra 2 é dada por:

$$
S_{n_{2}}(X)=K / n_{2}
$$

Determinou-se então, a diferença máxima entre as duas funções acumuladas "D obs"

$$
D_{o b s}=\max \left|S_{n_{1}}(X)-S_{n 2}(X)\right|
$$

e comparou-se o valor obtido com $D_{t a b}$, calculado pela "Tabela de Valores Críticos na prova de Kolmogorov-Smirnov para duas amostras grandes", sendo que grandes amostras pressupõem, segundo Siegel (1977) mais de 40 elementos em cada uma.

Para o nível de significância 0,05 temos: 


$$
D_{t a b}=1,36 \sqrt{\frac{n_{1}+n_{2}}{n_{1} n_{2}}}
$$

Duas amostras representam a mesma população quando

$$
D_{t a b} \geq D_{o b s}
$$

\section{Análise de regressão}

Inicialmente, os dados "brutos" de área queimada obtidos dos mosaicos AVHRR (" $\left.X^{\prime \prime}\right)$ e aqueles obtidos das imagens TM (" $\left.Y^{\prime \prime}\right)$ foram colocados na forma de gráfico de dispersão, utilizando planilha eletrônica. Obteve-se então, a equação da reta de ajuste dos dados. Em seguida, foi feita uma análise gráfica da variância dos erros padronizados "EP". Calculou-se "EP" segundo as equações abaixo (Netter e Wasserman, 1974):

$$
E P_{i}=\frac{\left(Y_{i}-\hat{Y}_{i}\right)}{\sqrt{E Q M}}
$$

onde

$$
\begin{aligned}
& E Q M=\sum_{i=1}^{n} \frac{\left(Y_{i}-\hat{Y}_{i}\right)^{2}}{n-2} \\
& E P_{i}=\text { erro padronizado de } i \\
& E Q M=\text { erro quadrático médio, } \\
& Y_{i}=\text { valor de } Y \text { observado, } \\
& \hat{Y}_{i}=\text { valor de } Y \text { estimado, } \\
& n=\mathrm{n}^{\mathrm{o}} \text { de observações. }
\end{aligned}
$$

A variância de $E P$ em função de $X$ foi avaliada visualmente, na forma gráfica, conforme Netter e Wasserman (1974). Em seguida foi feita uma transformação nos dados, procedimento indicado por Netter e Wasserman (1974) e Chattergee e Price (1977) para estabilizar a variância dos erros. A transformação escolhida foi a extração da raiz quadrada das varáveis $X$ e $Y$. Assim, temos: 


$$
X^{\prime}=\sqrt{\mathrm{X}} \quad(2.7) \quad Y^{\prime}=\sqrt{Y}
$$

Da mesma forma, foram calculados os erros padronizados $-E P$ - para a regressão feita com os dados transformados. Em seguida, removeram-se os "outliers" que, em ambos os casos, foram considerados como os pontos cujos $E P \geq|2,0|$ (Netter e Wasserman , 1974; Chatergee e Price, 1977).

Foram então, calculadas as estatísticas da análise de regressão e obteve-se a equação da reta de ajuste para o novo conjunto de dados, ou seja, dados transformados pela extração da raiz quadrada e livres de "outliers".

\section{Teste de Bartlett}

A seguir, aplicou-se o teste de Bartlett (Netter e Wasserman, 1974) estatística " $B "$ - para verificar a constância da variância dos erros. Esse teste pressupõe a divisão da amostra em " $j$ "intervalos, e é feito pelas seguintes equações:

$$
B=\frac{2,0302585}{C}\left[\left(n_{T}-r\right) \log _{10}\left(\frac{1}{n_{T}-r} \sum\left(n_{j}-1\right) S_{j}^{2}\right)-\sum_{j=1}^{r}\left(n_{j}-1\right) \log _{10} S_{j}^{2}\right]
$$

onde

$$
\begin{aligned}
& C=1+\frac{1}{3(r-1)}\left[\sum_{j=1}^{r} \frac{1}{n_{j}-1}-\frac{1}{n_{T}-t}\right] \\
& n_{T}=\mathrm{n}^{\mathrm{o}} \text { total de observações, } \\
& \mathrm{r}=\text { graus de liberdade, } \\
& n_{j}=\text { número de observações em cada intervalo } j, \\
& S_{j}^{2}=\text { variância no intervalo } j .
\end{aligned}
$$

Se $\left.B \leq \chi^{2}(1-\alpha),(r-1)\right)$, então pode-se considerar as variâncias iguais;

se $\left.B>\chi^{2}(1-\alpha),(r-1)\right)$, então as variâncias não são iguais.

Onde, $\chi^{2}(1-\alpha, r-1)$ é o percentil $(1-\alpha) 100$ da distribuição $\chi^{2}$ com $r$-1 graus de liberdade. 


\section{Teste de Kolmogorov-Smirnov para uma amostra}

A seguir, foi feito o teste de Kolmogorov-Smirnov para uma amostra (Siegel, 1977) como prova de aderência, que, no caso, comparou a distribuição da freqüência acumulada observada com uma distribuição normal padrão. Determinou-se o ponto de maior divergência, e calculou-se se essa diferença poderia ser atribuída ao acaso.

Inicialmente, as amostras de $E P$ foram divididas em " $j$ " intervalos. Em seguida, calculou-se a distribuição de freqüência acumulada $S n(E P)$, segundo a equação 2.1. Obteve-se então, para cada intervalo $j$ a diferença entre $S_{n}$ observado e $S_{n}$ estimado. A maior diferença encontrada foi então comparada com $D_{t a b}$ para 0,05 de significância.

$$
D_{t a b}=\frac{1,36}{\sqrt{n}}
$$

Quando $D_{t a b}$ é maior que $D_{o b s}$, considera-se que a distribuição de freqüência acumulada dos erros é uma normal padrão.

\section{Intervalos de confiança}

Por último, fez-se em planilha eletrônica o cálculo dos intervalos de confiança, de acordo com as equações abaixo, ressaltando-se que $X^{\prime}=\sqrt{X}$ e $Y^{\prime}=\sqrt{Y}$, conforme exposto anteriormente.

$$
\begin{aligned}
& \hat{Y}_{h}^{\prime}-t(1-\alpha / 2 ; n-2) s\left(\hat{Y}_{h}^{\prime}\right) \leq E\left(Y_{h}^{\prime}\right) \leq \hat{Y}_{h}^{\prime}+t(1-\alpha / 2 ; n-2) s\left(\hat{Y}_{h}^{\prime}\right) \\
& \text { onde } \\
& s^{2}\left(\hat{Y}_{h}^{\prime}\right)=E Q M^{\prime}\left[\frac{1}{n}+\frac{\left(X_{h}^{\prime}-\bar{X}^{\prime}\right)^{2}}{\sum\left(X_{i}^{\prime}-\bar{X}^{\prime}\right)}\right] \\
& \hat{Y}_{h}^{\prime}=\text { valor estimado de } Y \text { para } X_{h}^{\prime}, \\
& X_{h}=\text { valor de } X \text { para o qual se deseja estimar a resposta média de } Y, \\
& t(1-\alpha / 2 ; n-2) \quad \text { é o percentil }(1-\alpha) 100 \text { da distribuição } t \text {-student com } \\
& \quad r-1 \text { graus de liberdade, }
\end{aligned}
$$




$$
\begin{aligned}
& s\left(Y_{h}^{\prime}\right)=\text { desvio padrão de } \hat{Y}_{h}^{\prime}, \\
& E\left(Y_{h}^{\prime}\right)=\text { Esperança de } Y_{h}^{\prime}, \\
& S^{2}\left(\hat{Y}_{n}^{\prime}\right)=\text { variância estimada de } \hat{Y}_{h}^{\prime}, \\
& \bar{X}^{\prime}=\text { valor médio de } X^{\prime}, \\
& X_{i}^{\prime}=\text { valor observado de } X^{\prime}, \\
& E Q M^{\prime}=\text { erro quadrático médio de } \mathrm{Y}^{\prime} .
\end{aligned}
$$

\subsubsection{6 - Estimativas de áreas queimadas para o Cerrado}

Utilizando as equações obtidas pelas regressões descritas no item anterior, foram estimados, quinzenalmente, os totais de área queimada no Cerrado a partir dos mosaicos AVHRR, conforme descrito no item 2.2.13.

Essas equações resultaram de estimativas de área feitas em células de tamanho padronizados em $1.009 \mathrm{~km}^{2}$ e $986 \mathrm{~km}^{2}$ nas amostras Cerrado 1 e Cerrado 2, respectivamente. Admitiu-se então, que toda a área de estudo fosse dividida em células com essas dimensões. Pressupôs-se também, que a distribuição das queimadas no Cerrado é homogênea, ou seja que elas ocorrem numa densidade média constante. Assim, determinou-se a área média queimada em uma célula padrão ideal de Cerrado 1 e outra de Cerrado 2. Esse procedimento garante a utilização da equação de regressão dentro do intervalo da variável independente (estimativas AVHRR). Posteriormente, o resultado, relativo à célula ideal, foi multiplicado pelo número de células de cada região para estimar o total queimado.

Determinou-se o número de "células ideais" contidas na região Cerrado 1 e Cerrado 2, dividindo-se a área estimada total para as regiões Cerrado 1 e Cerrado 2 pelas áreas das células padrão.

$$
N C_{1}=\frac{\text { Área total da Região Cerradol }}{\text { Área da célula padrão de Cerrado } 1}
$$




$$
N C_{2}=\frac{\text { Área total da Região Cerrado } 2}{\text { Área da célula padrão de Cerrado } 2}
$$

Em seguida, dividiu-se as estimativas brutas de áreas queimadas $(A Q B)$ nas regiões Cerrado 1 e Cerrado 2, obtidas pela aplicação do algoritmo de identificação de queimadas nos mosaicos AVHRR, pelo número correspondente de células. Obteve-se assim, uma estimativa da área média queimada nas células padrão das regiões Cerrado 1 e Cerrado 2:

$$
A Q M_{1}=\frac{A Q B_{1}}{N C_{1}} \quad(2.16) \quad \text { e } \quad A Q M_{2}=\frac{A Q B_{2}}{N C_{2}}
$$

Em seguida, extraiu-se a raiz quadrada do resultado obtido, conforme o procedimento feito na análise de regressão:

$$
Y_{1}^{\prime}=\sqrt{A Q M_{1}} \quad(2.18) \quad \text { e } \quad Y_{2}^{\prime}=\sqrt{A Q M_{2}}
$$

Calculou-se então, $X_{1}^{\prime}$ e $X_{2}^{\prime}$ pela aplicação da equação resultante da análise de regressão. Finalmente, os resultados obtidos foram elevados ao quadrado, para obtenção de estimativas de áreas queimadas.

$$
Y_{1}=\left(Y_{1}^{\prime}\right)^{2} \quad(2.20) \quad \text { e } \quad Y_{2}=\left(Y_{2}^{\prime}\right)^{2}
$$

Por último, determinaram-se os intervalos de confiança dos resultados estimados.

A partir destas estimativas e das equações obtidas pela análise de regressão, calculou-se a área queimada no Cerrado em cada quinzena do período de estudo. Não foi possível estimar pelos mosaicos a área queimada no Cerrado durante a primeira quinzena de maio/98, pois não se dispunha do mosaico da quinzena anterior, e essa informação é necessário no algoritmo de identificação de queimadas. Para suprir essa informação e completar um ano avaliações de áreas queimadas, foram utilizados os dados de detecção de queimadas do NOAA-12 por proporções simples.

$$
A_{m_{a}}=\frac{A_{m_{b}} F_{m_{a}}}{F_{m_{b}}}
$$


onde,

$$
\begin{aligned}
A_{m_{a}}= & \text { Área queimada no Cerrado na primeira quinzena de maio/98, } \\
A_{m_{b}}= & \text { Área queimada no Cerrado na segunda quinzena de maio/98, } \\
F_{m_{a}}= & \mathrm{N}^{\mathrm{o}} \text { de focos de queimada detectados pelo NOAA-12 durante a } \\
& \text { primeira quinzena de maio/98, } \\
F_{m_{b}}= & \mathrm{N}^{\mathrm{o}} \text { de focos de queimada detectados pelo NOAA-12 durante a } \\
& \text { segunda quinzena de maio/98. }
\end{aligned}
$$

\subsubsection{7 - Relação entre os dados AVHRR/NOAA-14 e AVHRR/NOAA-12}

Foi verificada a possibilidade de avaliar a extensão de áreas queimadas no Cerrado a partir de dados de detecção de queimadas ativas originários do AVHRR/NOAA-12; para tanto, eles foram comparados com os dados resultantes da aplicação do algoritmo na identificação de área queimada aplicado aos mosaicos AVHRR/NOAA-14 no período agosto/98 a abril/99.

As matrizes contendo os totais de queimadas detectadas pelo NOAA-12 em períodos de 7 dias foram somadas de forma que coincidissem com os mesmos períodos dos mosaicos AVHRR. Em seguida, elas foram transferidas para o ambiente SPRING na forma de grade regular de Modelo Numérico de Terreno (NMT). Calculou-se então, a soma de todos os elementos contidos no polígono do Cerrado. Dessa forma, obteve-se, para cada quinzena, o total de focos de queimada detectados pelo NOAA-12 no Cerrado.

A partir da regressão dos valores de $X\left(\mathrm{n}^{\mathrm{o}}\right.$ de focos de queimadas no Cerrado, obtidos pelo NOAA-12) e $Y$ (área total queimada no Cerrado, estimada pelos mosaico AVHRR/NOAA-14), obteve-se a equação da reta de ajuste dos dados. Com essa equação foram feitas estimativas preliminares de área total queimada quinzenalmente no Cerrado no período maio/99 a outubro/00. 


\section{3 - RESULTADOS E DISCUSSÃO}

\section{1 - Mosaicos AVHRR/NOAA-14 e registro}

A partir do processamento das 571 imagens diárias AVHRR/NOAA-14 de maio/98 a abril/99 — Tabelas A1 e A2 do Anexo - obtiveram-se 24 conjuntos de mosaicos quinzenais, com $1,5 \mathrm{~km}$ x $1,5 \mathrm{~km}$ de resolução espacial. Exemplos de mosaicos das bandas $1(0,58-0,68 \mu \mathrm{m}) 2(0,725-1,10 \mu \mathrm{m})$ e $3(3,55-3.93 \mu \mathrm{m})$ e do IVDN com o limite da área da estudo encontram-se nas Figuras 3.1 a 3.4. Os números digitais e IVDNs baixos foram associados aos tons escuros de cinza, indicando menor atividade fotossintética; números digitais e IVDNs altos apareceram em tons claros de cinza indicando, de modo geral, maior atividade fotossintética. No mosaico da banda 3, as temperaturas mais elevadas da superfície foram representadas por tons escuros de cinza e, inversamente, temperaturas mais frias relacionaram-se aos píxeis mais claros. A Tabela 3.1 indica o número de imagens utilizadas em cada mosaico, bem como o número de pontos de controle usados no registro dos mosaicos e os erros de registro, medido em píxeis. Os mosaicos estão indicados pela abreviação do mês correspondente, seguido da letras "a" quando se tratar da primeira quinzena ou "b" quando se tratar da segunda quinzena. Ressalta-se que foram utilizadas duas imagens diárias contíguas, quando disponíveis, resultando portanto, em mais de 15 imagens por quinzena. $\mathrm{O}$ procedimento de "mosaicagem" exigiu inúmeras repetições do geo-referenciamento das imagens AVHRR e consumiu cerca de 2.000 horas de trabalho. Note-se que os erros de registro constatados foram sempre inferiores à resolução máxima do AVHRR $(1,1 \mathrm{~km})$, indicando produtos de excelente qualidade, possivelmente não superáveis. 


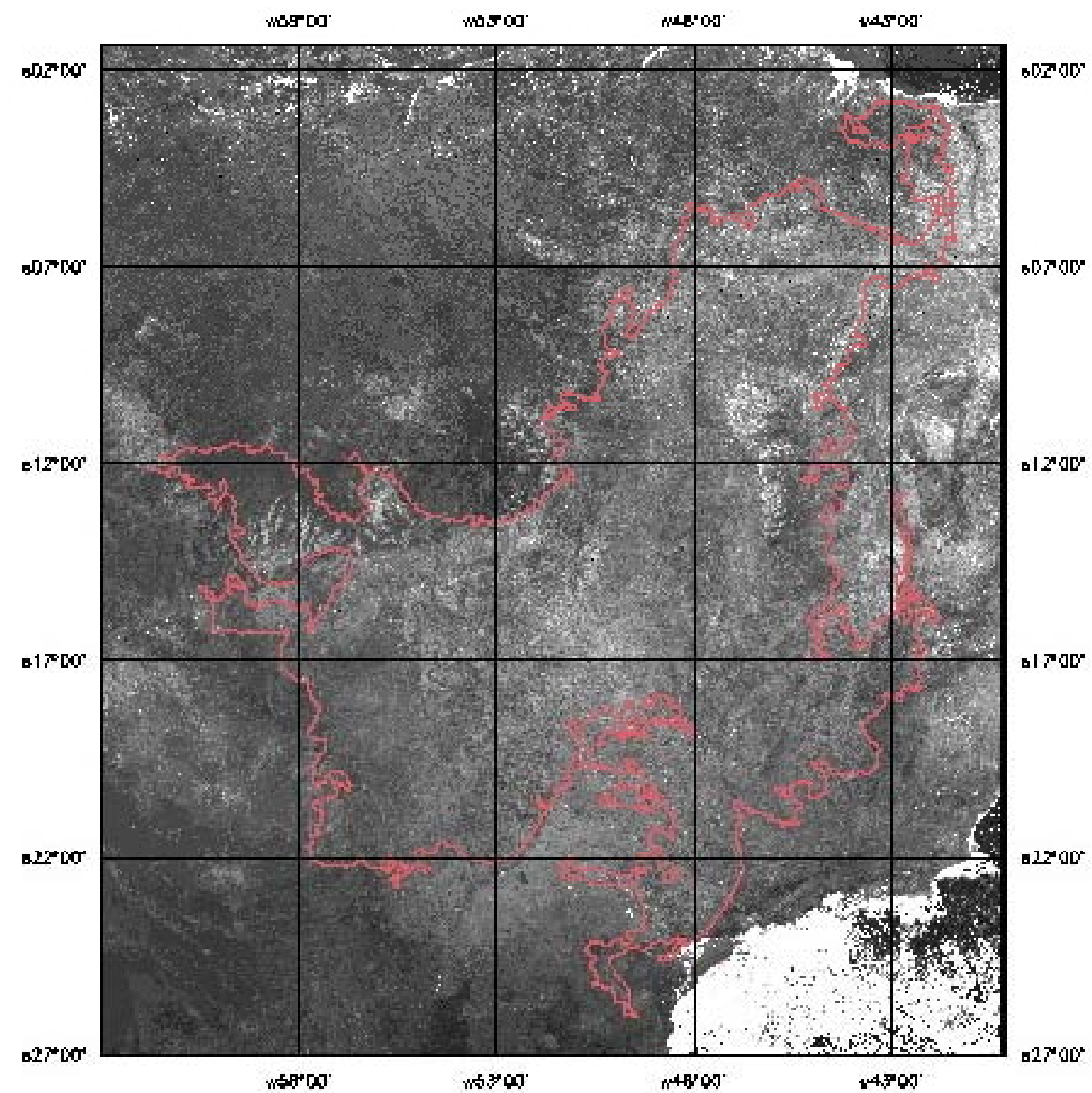

Figura 3.1 - Mosaico AVHRR/NOAA-14 com limite do Cerrado, banda 1; $2^{\underline{a}}$ quinzena de julho/98. 


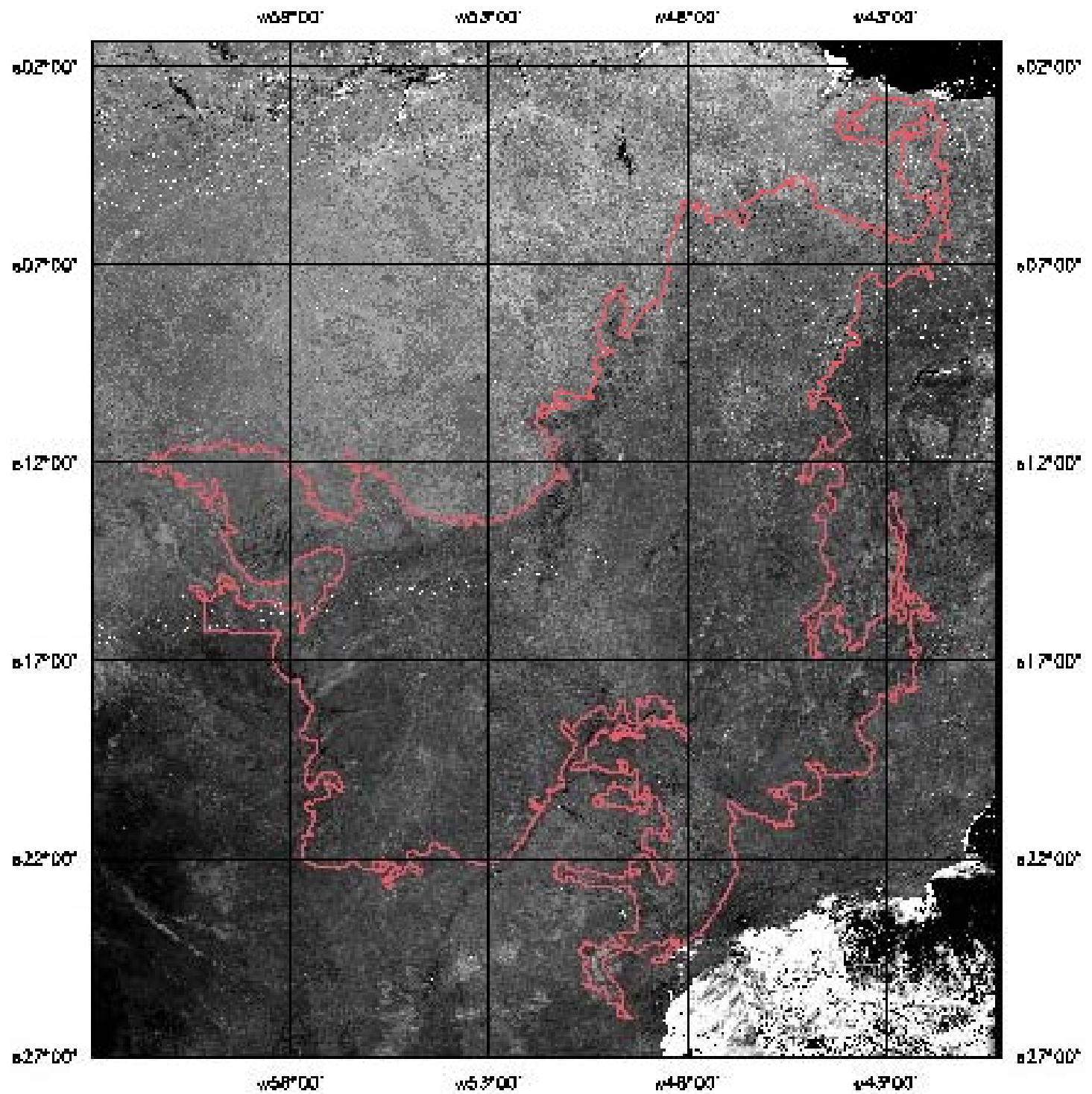

Figura 3.2 - Mosaico AVHRR/NOAA-14 com limite do Cerrado, banda 2; 2a quinzena de julho/98. 


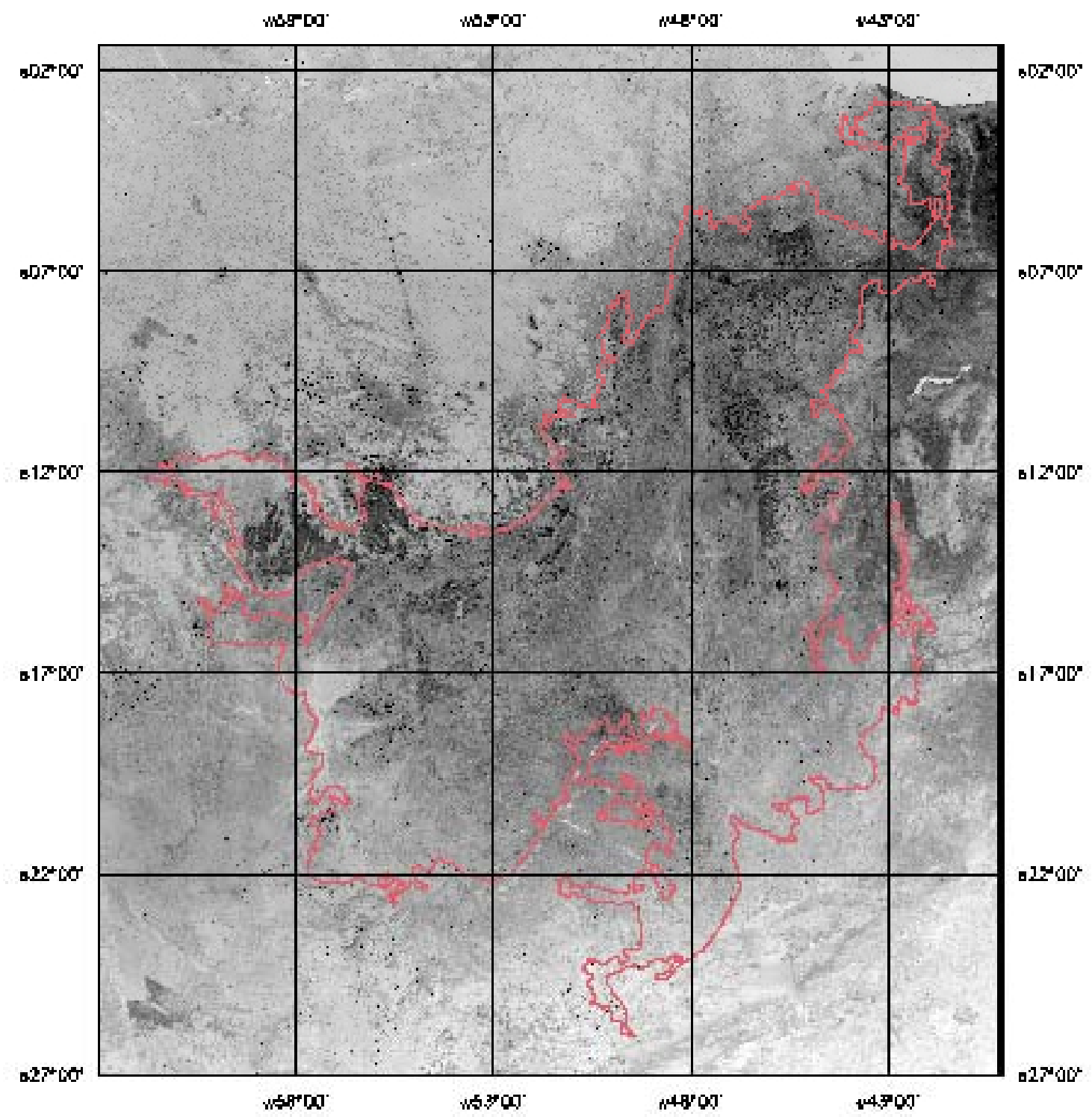

Figura 3.3 - Mosaico AVHRR/NOAA-14 com limite do Cerrado, banda 3; $2^{\mathrm{a}}$ quinzena de julho/98. 


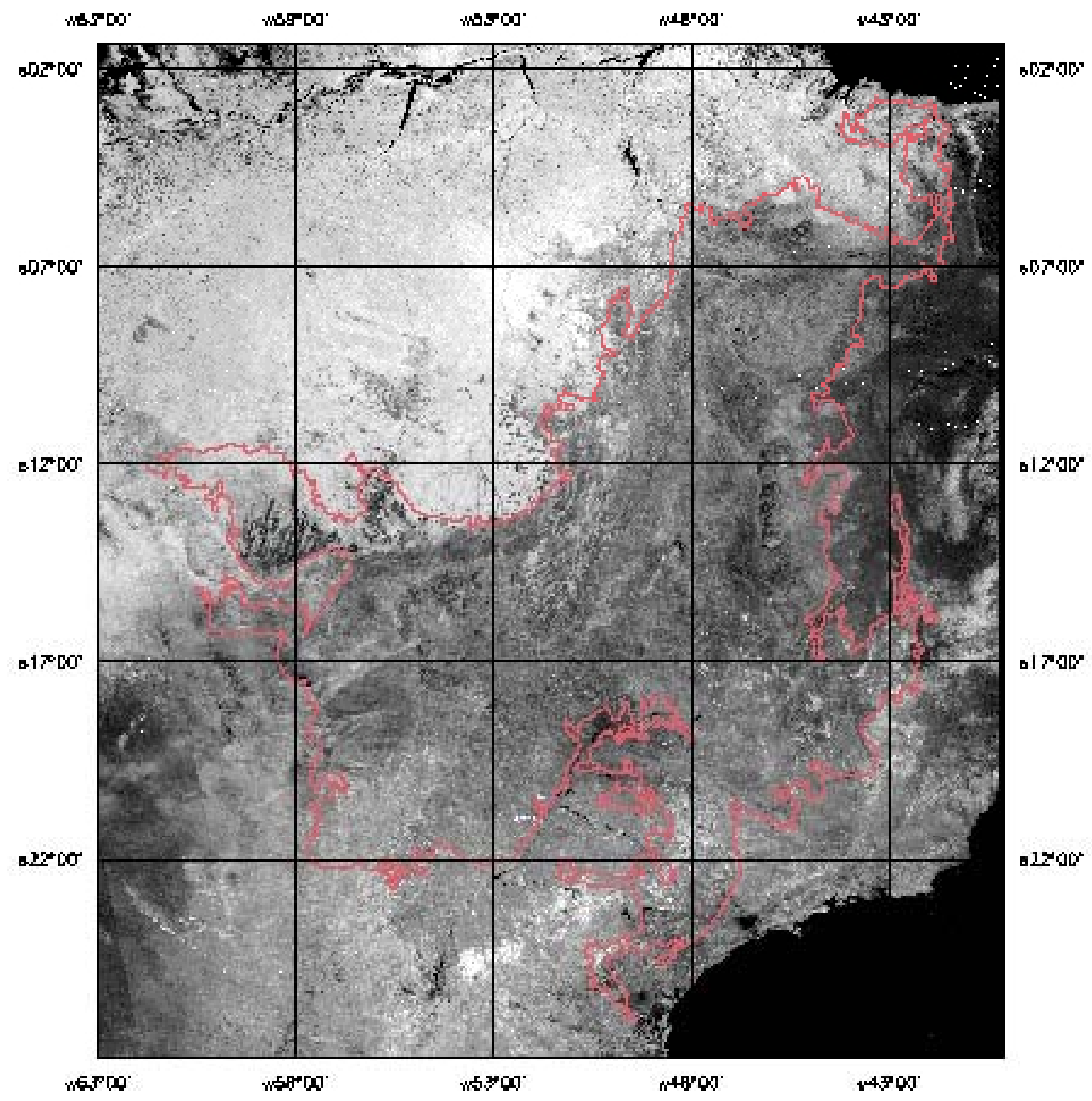

Figura 3.4 - Mosaico AVHRR/NOAA-14 com limite do Cerrado, IVDN; $1^{\text {a }}$ quinzena de agosto/98. 
Tabela 3.1 - Número de imagens utilizadas nos mosaicos AVHRR, de pontos de controle e erro de registro.

\begin{tabular}{l|c|c|c}
\hline \multicolumn{1}{c|}{ Mosaico } & $\begin{array}{c}\mathbf{N}^{\mathbf{0}} \text { de imagens } \\
\text { Utilizadas }\end{array}$ & $\begin{array}{c}\mathbf{N}^{\mathbf{0}} \text { de pontos } \\
\text { de controle }\end{array}$ & $\begin{array}{c}\text { Erro de registro } \\
\text { (píxel) }\end{array}$ \\
\hline Maio-a & 20 & 19 & 0,712 \\
Maio-b & 19 & 14 & 0,629 \\
Junho-a & 18 & 12 & 0,540 \\
Junho-b & 22 & 12 & 0,848 \\
Julho-a & 21 & 12 & 0,851 \\
Julho-b & 26 & 12 & 0,577 \\
Agosto-a & 25 & 14 & 0,813 \\
Agosto-b & 31 & 14 & 0,504 \\
Setembro-a & 26 & 13 & 0,658 \\
Setembro-b & 27 & 13 & 0,798 \\
Outubro-a & 24 & 14 & 0,780 \\
Outubro-b & 25 & 14 & 0,534 \\
Novembro-a & 22 & 17 & 0,838 \\
Novembro-b & 27 & 15 & 0,704 \\
Dezembro-a & 25 & 12 & 0,805 \\
Dezembro-b & 26 & 13 & 0,749 \\
Janeiro-a & 26 & 14 & 0,624 \\
Janeiro-b & 24 & 12 & 0,695 \\
Fevereiro-a & 17 & 14 & 0,698 \\
Fevereiro-b & 22 & 12 & 0,757 \\
Março-a & 21 & 12 & 0,565 \\
Março-b & 29 & 12 & 0,692 \\
Abril-a & 22 & 14 & 0,749 \\
Abril-b & 26 & 14 & 0,742 \\
\hline
\end{tabular}

\section{2 - Variação temporal dos números digitais e do IVDN nos mosaicos AVHRR}

Foram analisadas 34 áreas amostrais de 5 x 5 píxeis para observar a variação temporal do IVDN e dos números digitais das bandas 1, 2 e 3. As Tabelas A3 a A37 com os valores de IVDN e números digitais das amostras, encontram-se no Anexo desta tese. Abaixo, nas Figuras 3.5 a 3.10 são mostrados exemplos de gráficos que ilustram o comportamento do IVDN e das bandas 1, 2 e 3 em diversas superfícies de interesse: queimada, não-queimada, solo exposto com reflexo na banda 3 e corpos de água com reflexo na banda 3. Ressalta-se que esses reflexos têm os mesmos números digitais que queimadas ativas e, por isso, podem levar a erros de classificação. Nesses casos, solos expostos e corpos d'água são equivocadamente classificados como queimadas. A partir dos dados das 34 amostras, definiu-se a base para o algoritmo de identificação de queimadas, conforme análises resumidas a seguir. 
a) Em geral, queimadas foram acompanhadas por queda significativa no IVDN e dos números digitais da banda 3, conforme exemplificado na Figura 3.5. Porém, nem sempre houve queda do IVDN após queimadas - Figura 3.6. Por outro lado, também ocorreram quedas de IVDN até valores iguais aqueles encontrados após uma queimada, mas que não estiveram relacionadas à ocorrência de fogo Figura 3.7. Esses valores baixos, encontrados no Cerrado durante a estação seca, devem estar relacionados às fases fenológicas de senescência e queda das folhas, e também a uma maior exposição do solo. Eva (2000), Eva e Lambin (1998) ressaltaram que o IVDN também não é adequado para identificar marcas de queimadas nas savanas africanas, pois esse índice costuma ser baixo também antes da queimada, quando a vegetação está seca. Barbosa et al. (1999) também não recomendaram o uso de IVDN para mapear cicatrizes de queimadas e sugeriram outros índices com combinações das bandas 2 e 3 do AVHRR. Dessas observações, concluiu-se que a utilização exclusiva do IVDN não é recomendável para a identificação e mapeamento de áreas queimadas no Cerrado.

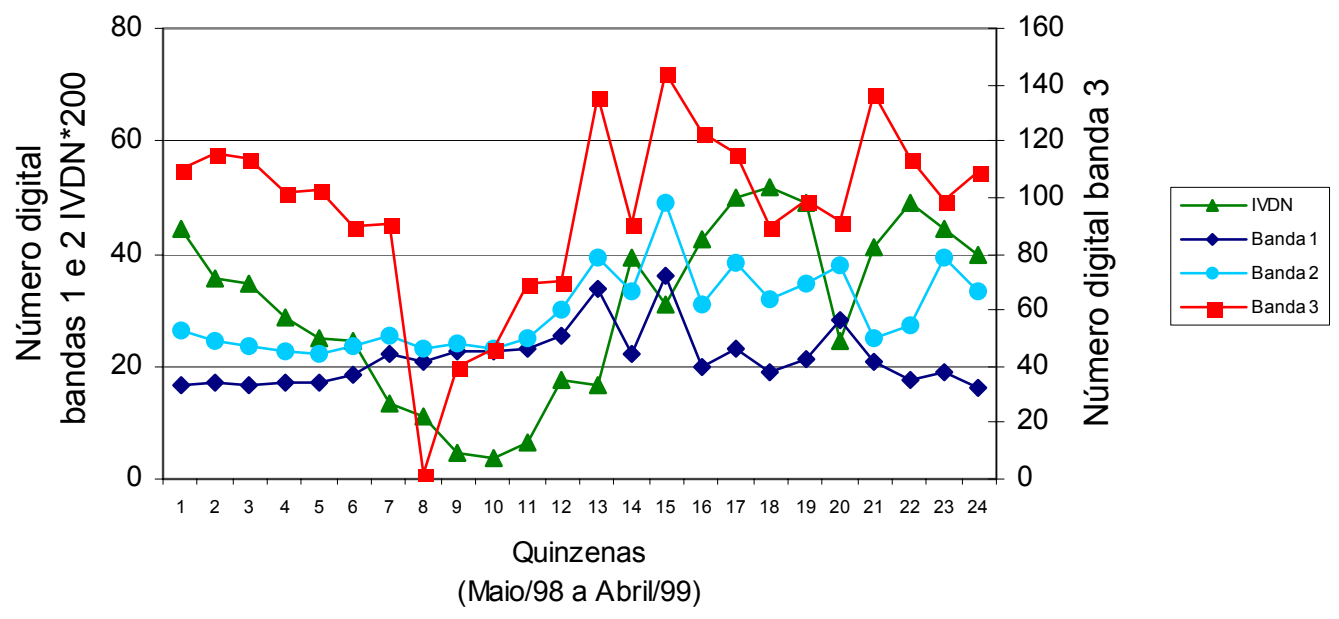

Figura 3.5 - Variação quinzenal dos números digitais nos mosaicos das bandas 1,2 e 3 e do IVDN na área $21, \mathrm{MT}, 16^{\circ} 07^{\prime} 18^{\prime \prime} \mathrm{S}$ e $53^{\circ} 23^{\prime} 20.38^{\prime \prime} \mathrm{W}$; ocorrência de queimada na $8^{\underline{a}}$ quinzena (agosto/98). 


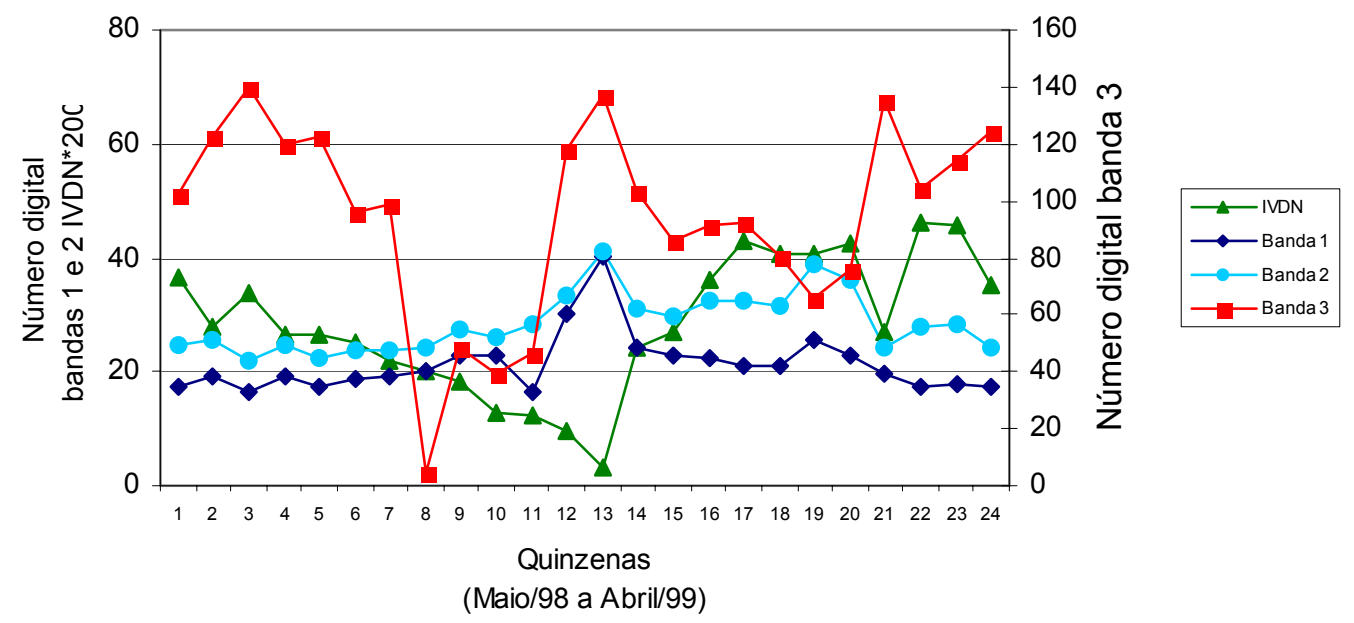

Figura 3.6 - Variação quinzenal dos números digitais nos mosaicos das bandas 1,2 e 3 e do IVDN na área $19, \mathrm{MG}, 17^{\circ} 42^{\prime} 44.31^{\prime \prime S}$ e $45^{\circ} 14^{\prime} 35.90^{\prime \prime} \mathrm{W}$; ocorrência de queimada na $8^{\underline{a}}$ quinzena (agosto/98).

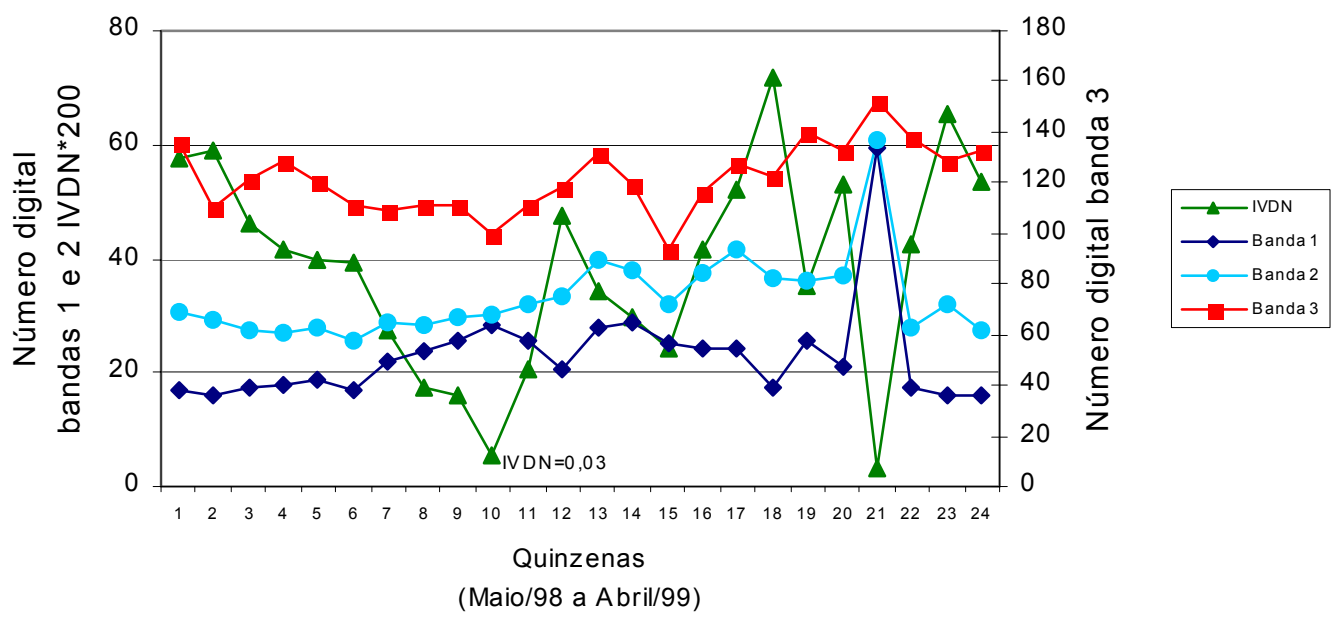

Figura 3.7 - Variação quinzenal dos números digitais nos mosaicos das bandas 1,2 e 3 e

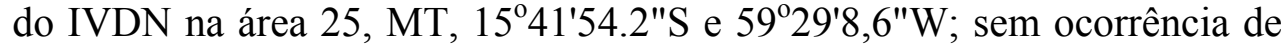
queimada. 
b) O IVDN, por outro lado, é excelente indicador de áreas agrícolas utilizadas para culturas anuais. Nestas áreas, o IVDN é bastante baixo durante a estação seca, quando o solo está exposto, não raro atingindo valores em torno de zero, ou mesmo negativos. No entanto, durante a estação úmida, principalmente de dezembro a fevereiro, observaram-se IVDNs superiores a 0,3 - Figura 3.8 - e valores máximos em torno de 0,5. Esses índices são, inclusive, superiores aos encontrados em áreas recobertas por florestas e por vegetação de cerrado, como, por exemplo, o Parque Nacional das Emas, GO, na estação chuvosa. Esta informação mostrou-se importante na identificação de solos com reflexos na banda 3 e que poderiam ser equivocadamente classificados como queimadas. Tais solos encontram-se expostos durante a estação seca mas, por outro lado, estão recobertos por culturas na estação úmida, apresentando altos valores de IVDN.

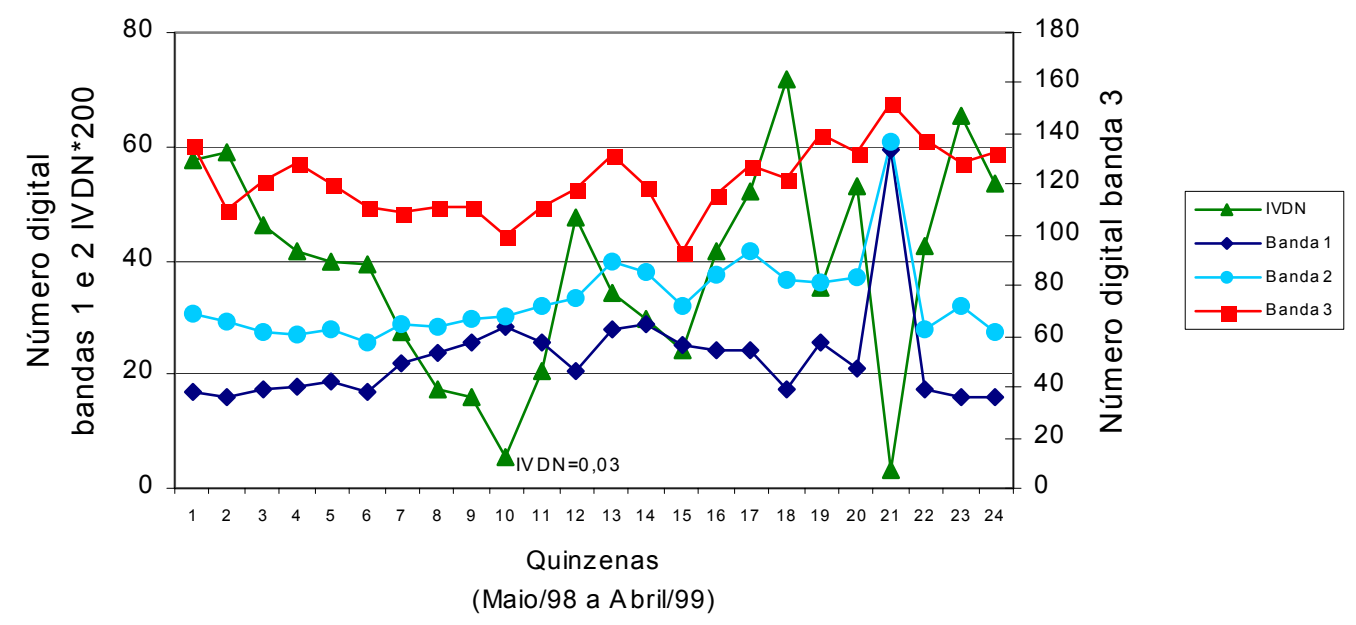

Figura 3.8 - Variação quinzenal dos números digitais nos mosaicos das bandas 1,2 e 3 e do IVDN na área $5, \mathrm{BA}, 12^{\circ} 35^{\prime} 1.9^{\prime \prime} \mathrm{S}$ e $45^{\circ} 59^{\prime} 4.0^{\prime \prime} \mathrm{W}$; área agrícola com ocorrência de reflexo na banda 3. 
c) Queimadas ativas apresentaram-se com números digitais iguais a 0,1 , ou 2 na escala termal invertida de 0 a 255 números digitais das imagens da banda 3 do AVHRR/NOAA-14. No entanto, em alguns casos, esses valores foram verificados nas mesmas áreas nas quinzenas seguintes à ocorrência de uma queimada Figura 3.9. Não é esperado, porém, que novas queimadas surjam no mesmo local nas semanas subseqüentes à ocorrência de queimadas extensas, como aquelas verificadas na Ilha do Bananal em julho e agosto/98 (OESP, 1998). A observação desses dados mostrou que áreas queimadas, provavelmente devido à remoção da cobertura vegetal pela ação do fogo, podem se comportar como alguns tipos de solos expostos, ocasionando reflexão no intervalo espectral da banda 3 do AVHRR. Dessa observação, definiu-se que um algoritmo para identificar áreas queimadas não deve classificar como queimada um píxel em cuja posição já tenha sido identificada uma queimada anteriormente. Assim, diminui-se o risco de classificar reflexos em solos expostos pelo fogo como reincidência de queimada.

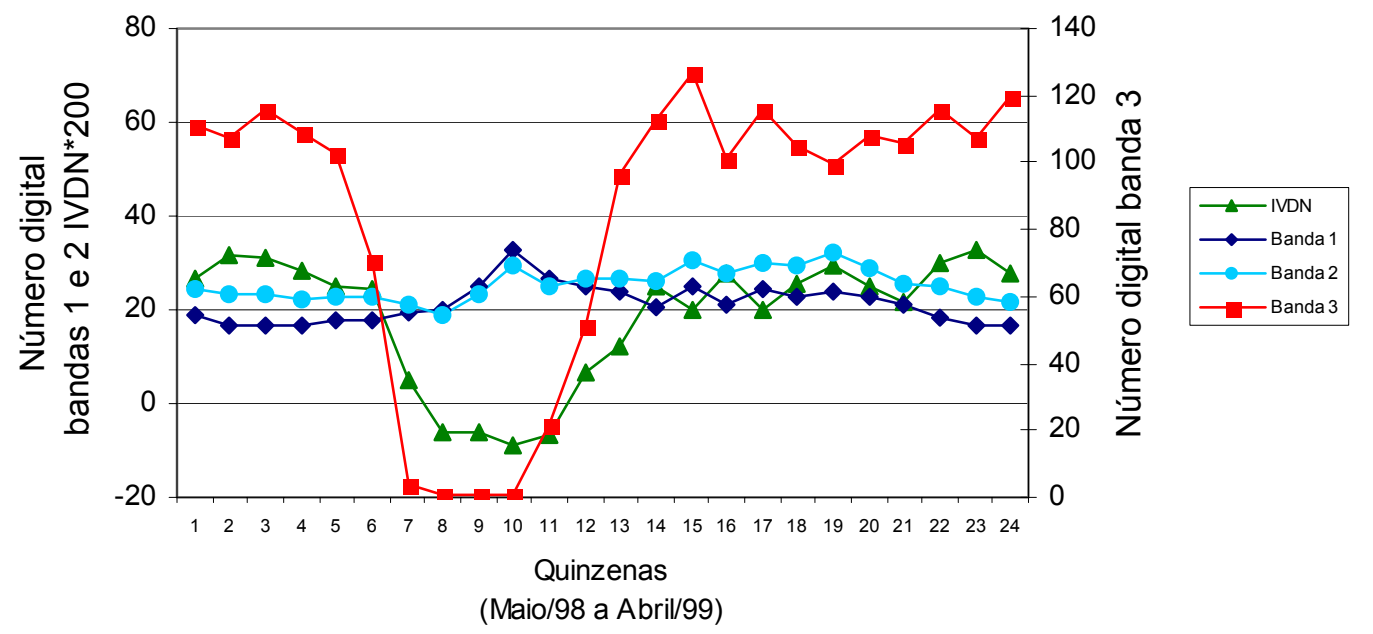

Figura 3.9 - Variação quinzenal dos números digitais nos mosaicos das bandas 1,2 e 3 e do IVDN na área 12 , TO, $12^{\circ} 24^{\prime} 49,2^{\prime \prime S}$ e $50^{\circ} 48^{\prime} 32.6^{\prime \prime} \mathrm{W}$; ocorrência de queimada na $7^{\mathrm{a}}$ quinzena (julho/98). 
d) Queimadas sempre foram sucedidas pela queda abrupta nos números digitais da banda 3 (maiores temperaturas), indicando que esses dados são mais confiáveis que o IVDN para identificação de áreas queimadas. Ressalta-se que essa queda foi verificada não só em píxeis relacionados à presença de focos ativos de fogo, mas também com fogo já extinto. Nesse caso, a remoção da cobertura vegetal pela queimada foi seguida de aquecimento do solo e aumento da refletividade nas imagens AVHRR, banda 3, provocando queda nos NC. Ressalta-se também, que todas quedas bruscas constatadas nos níveis digitais da banda 3 foram relacionadas à queimadas, exceto nos casos de reflexos, como comentado anteriormente e abaixo. A constatação de que a banda 3 do AVHRR é fundamental para identificação de áreas queimadas foi feita também por Eva (2000), Eva e Lambin (1998) e Barbosa et al (1999).

e) Corpos d'água podem ocasionar reflexão em imagens da banda 3 (Setzer e Verstraete, 1994) como freqüentemente ocorre em reservatórios, rios e nos oceanos — Figura 3.10. No entanto, essas superfícies apresentam baixos valores de IVDN em torno de zero - ao longo de todo o ano. Um outro tipo de corpo d'água, causador de reflexos na Banda 3, foi identificado no Pantanal mato-grossense, contendo simultaneamente áreas inundadas e vegetação. Nessa região, o nível de água muda sazonalmente, e o IVDN é baixo na época da cheia e alto no restante do ano, quando o nível de água é menor.

\section{3 - Algoritmo de identificação de área queimada}

Com base nas análises feitas nos gráficos acima, e em centenas de outras consultas adicionais nos mosaicos, elaborou-se um algoritmo para identificar áreas queimadas no Cerrado. O algoritmo foi feito a partir das premissas abaixo.

1) Áreas não-queimadas são aquelas cujos $\mathrm{NC}$ da banda 3 são iguais ou superiores a 50, e cujos IVDNs são superiores a zero. 


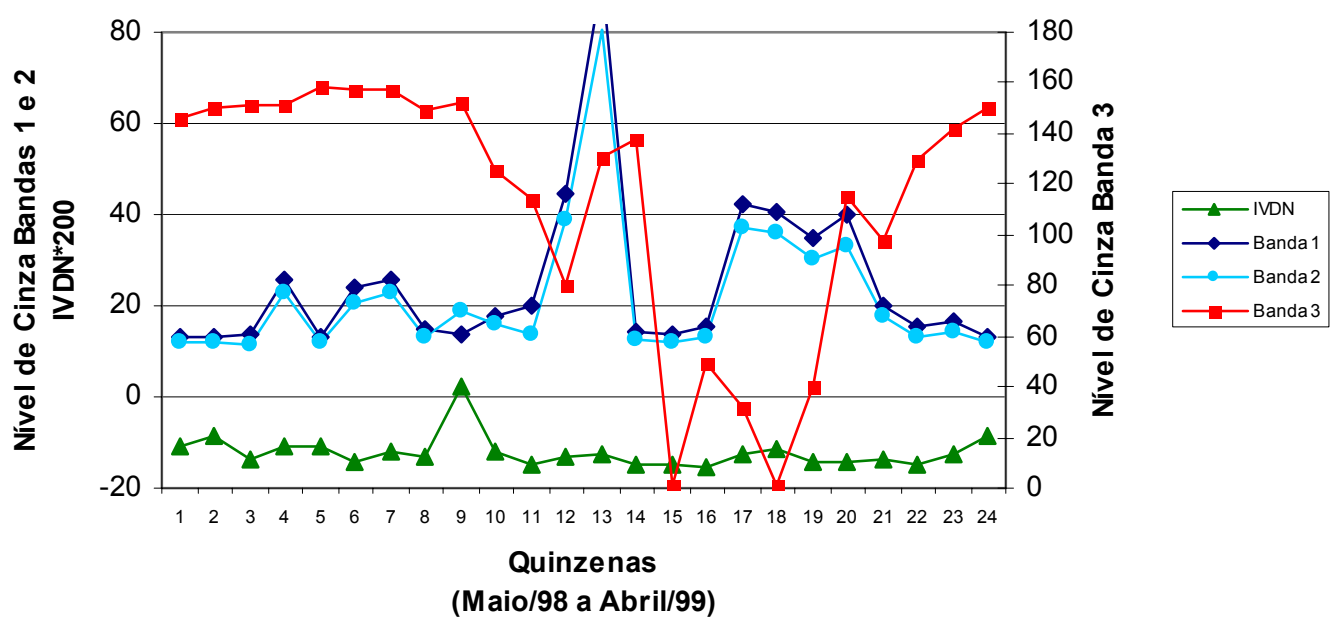

Figura 3.10 - Variação quinzenal dos números digitais nos mosaicos das bandas 1, 2 e 3 e do IVDN na área 33, no Oceano Atlântico, $16^{\circ} 45^{\prime} 21^{\prime \prime S}$ e $38^{\circ} 43^{\prime} 06^{\prime} 29^{\prime \prime} \mathrm{W}$; ocorrência de reflexos na banda 3.

2) Queimadas correspondem aos píxeis nos quais se verificaram queda de $\mathrm{NC}$ da banda 3 igual ou superior a 50 em relação ao píxel de mesma posição no mosaico da quinzena anterior. Além disso, o píxel correspondente a queimada deve ter $\mathrm{NC}$ inferior a 40.

3) Reflexos em água são identificados por píxeis cujos NC na banda 3 são iguais ou inferiores a 30, e cujos IVDNs no mosaico em questão e no mosaico de referência são iguais ou inferiores a $-0,03$. Esse tipo de reflexo pode ocorrer em reservatórios, áreas alagadas, Oceano Atlântico e alguns rios.

4) Reflexos em solos agrícolas expostos são identificados quando o NC na banda 3 é igual ou inferior a 50 e, além disso, o IVDN no mosaico em questão é igual ou inferior a 0,1 , porém é igual ou superior a 0,33 na estação chuvosa, conforme verificado no mosaico IVDN de referência.

5) São classificados como "queimada anterior" aqueles píxeis nos quais já foram identificadas queimadas nos processamentos anteriores. 
Abaixo, está exemplificado o algoritmo na Linguagem Espaço-Geográfica baseada em Álgebra (LEGAL), implementada no SPRING, utilizado para identificar queimadas, ocorridas na primeira quinzena de junho/98, segundo os critérios adotados para a região designada como Cerrado 1, conforme Figura 2.2.

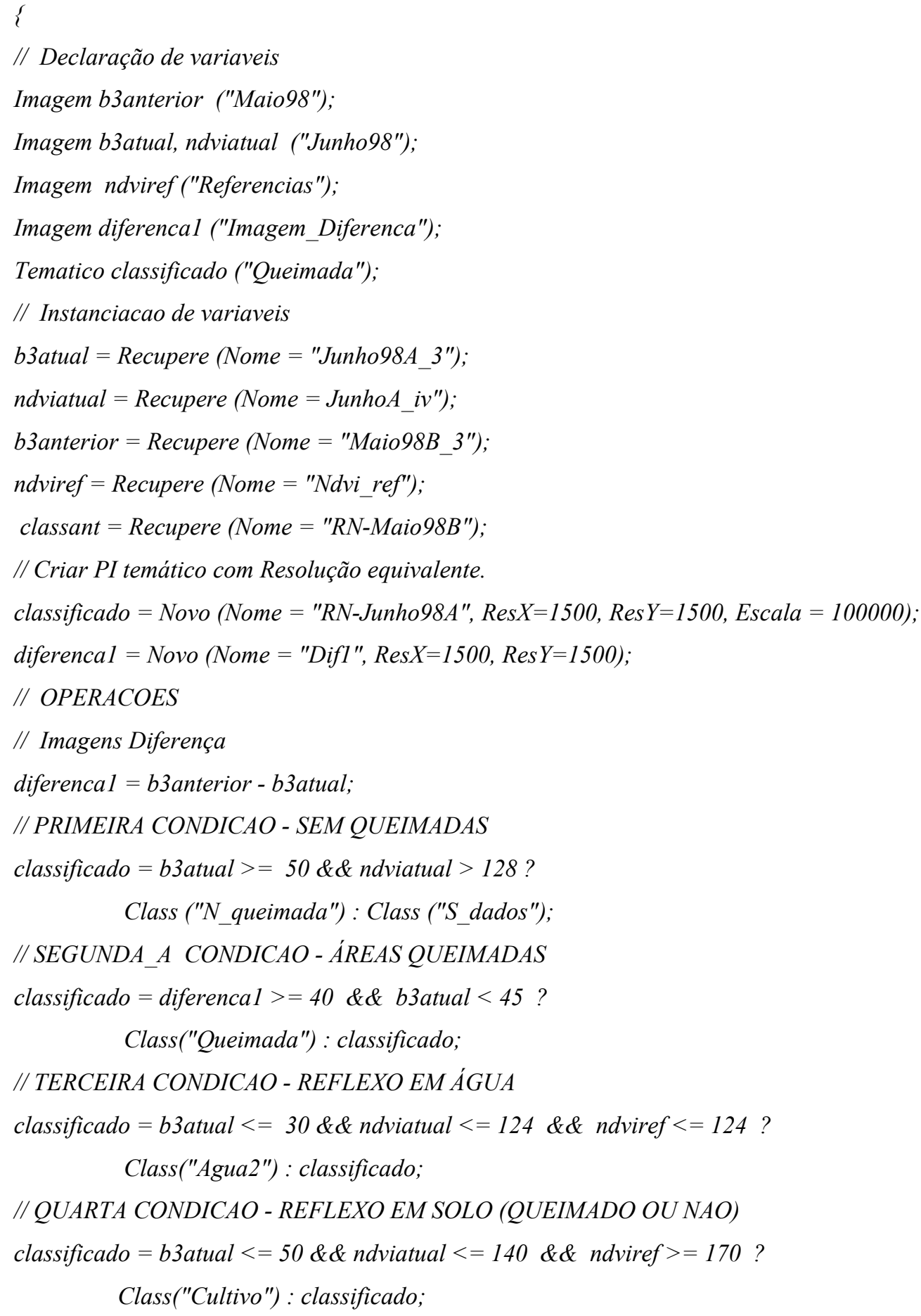




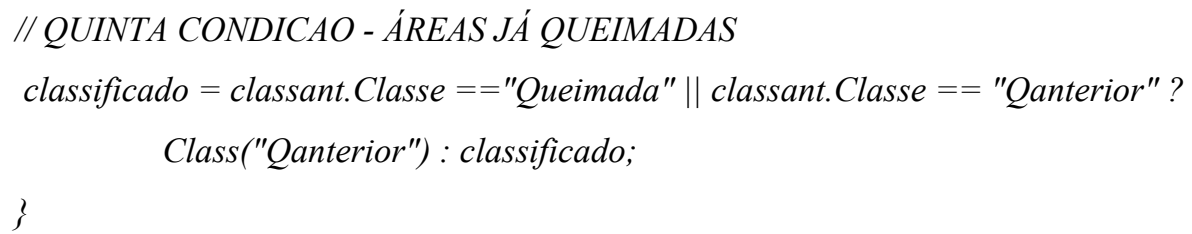

Constatou-se, porém, que falsas queimadas, decorrentes de reflexos em solos não-agrícolas na banda 3, generalizavam-se no Cerrado do Nordeste do Brasil em agosto e setembro, principalmente. Por isso, foi implementada uma variação deste algoritmo para aplicação na região do Cerrado nordestino. Neste caso, houve alteração dos NC utilizados para identificar queimadas na segunda condição do algoritmo: píxel de queimada passou a ser aquele com o NC na banda 3 inferior a 30 e, ao mesmo tempo, com diferença entre esse $\mathrm{NC}$ e aquele do píxel correspondente no mosaico anterior igual ou superior a 60 .

Assim, para a região designada por Cerrado 2, alterou-se a segunda condição do algoritmo (as demais continuaram idênticas), que passou a ser:

$$
\begin{gathered}
/ / S E G U N D A \_ \text {A CONDICAO - ÁREAS QUEIMADAS } \\
\text { classificado }=\text { diferencal }>=60 \& \& \text { b3atual }<30 ? \\
\text { Class("Queimada") : classificado; }
\end{gathered}
$$

Em ambos os casos, as regiões não incluídas em nenhuma das classes anteriores, foram classificadas como "sem dados". Essa classe incluiu nuvens, água (rios, oceanos, lagos e reservatórios) e também píxeis com ocorrência duvidosa de queimada.

\section{4 - Delimitação das áreas queimadas nas imagens TM/Landsat}

A classificação automática das áreas queimadas, feitas pelo classificador MAXVER nas imagens TM de Mato Grosso e Bahia mostrou-se insatisfatória, pois freqüentemente foram incluídos rios, corpos d'água e sombras de nuvens na classe queimada. Por esse motivo, ela não foi feita na imagem de Goiás. Optou-se pela não utilização dos resultados da classificação automática. Fez-se então, interpretação visual e digitalização manual das áreas queimadas, com consumo de cerca de 150 horas adicionais de trabalho. 
Da interpretação dos três pares de imagens Landsat resultou o mapeamento das queimadas ocorridas entre as duas passagens consecutivas do satélite, ou seja, com intervalos de 16 dias, conforme mostrado nas Figuras 3.11, 3.12 e 3.13.
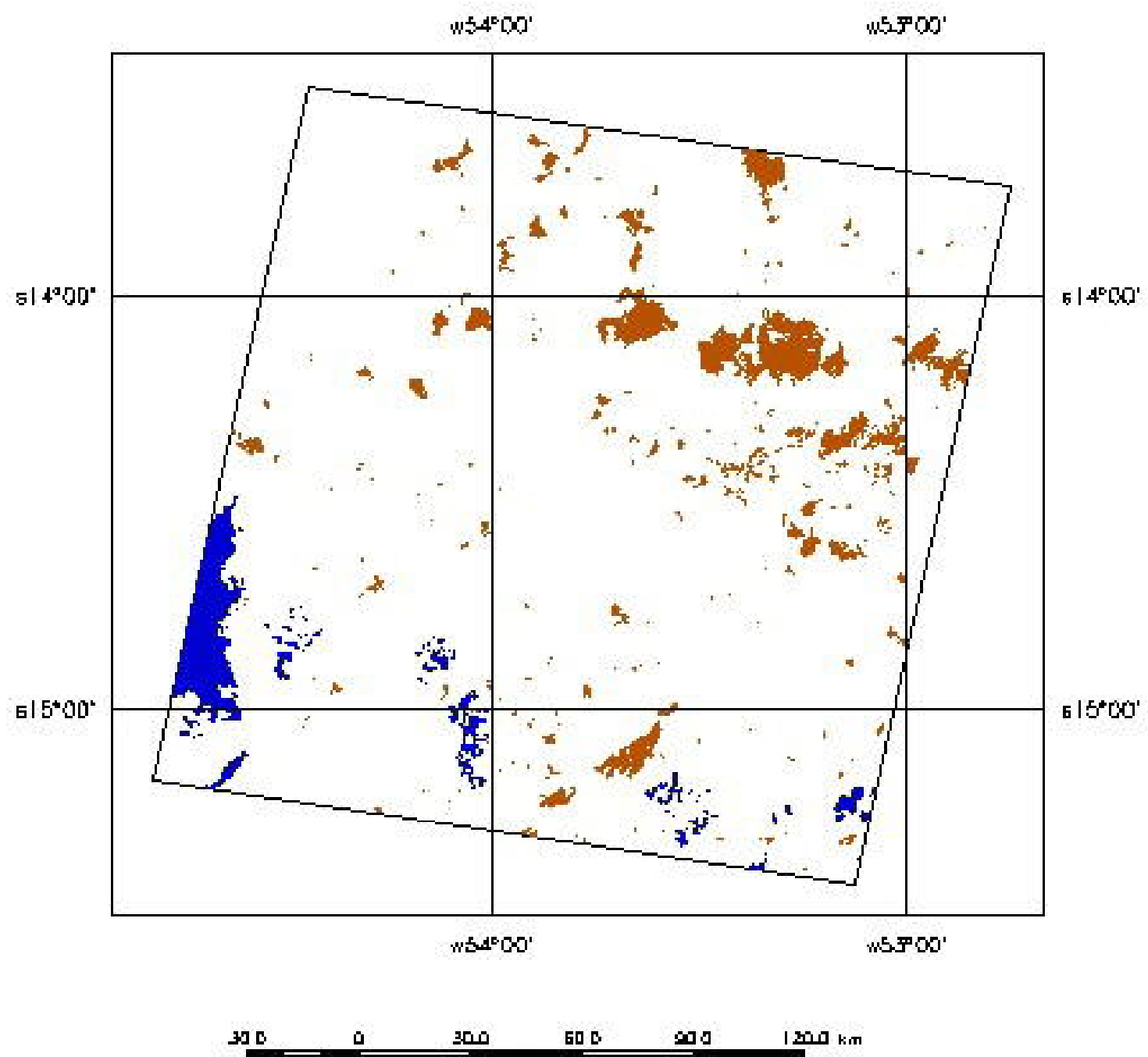

Figura 3.11 - Queimadas ocorridas em Mato Grosso no período 01 a 17/agosto/98, segundo interpretação das imagens TM/Landsat 225/70; nuvens estão em azul. 


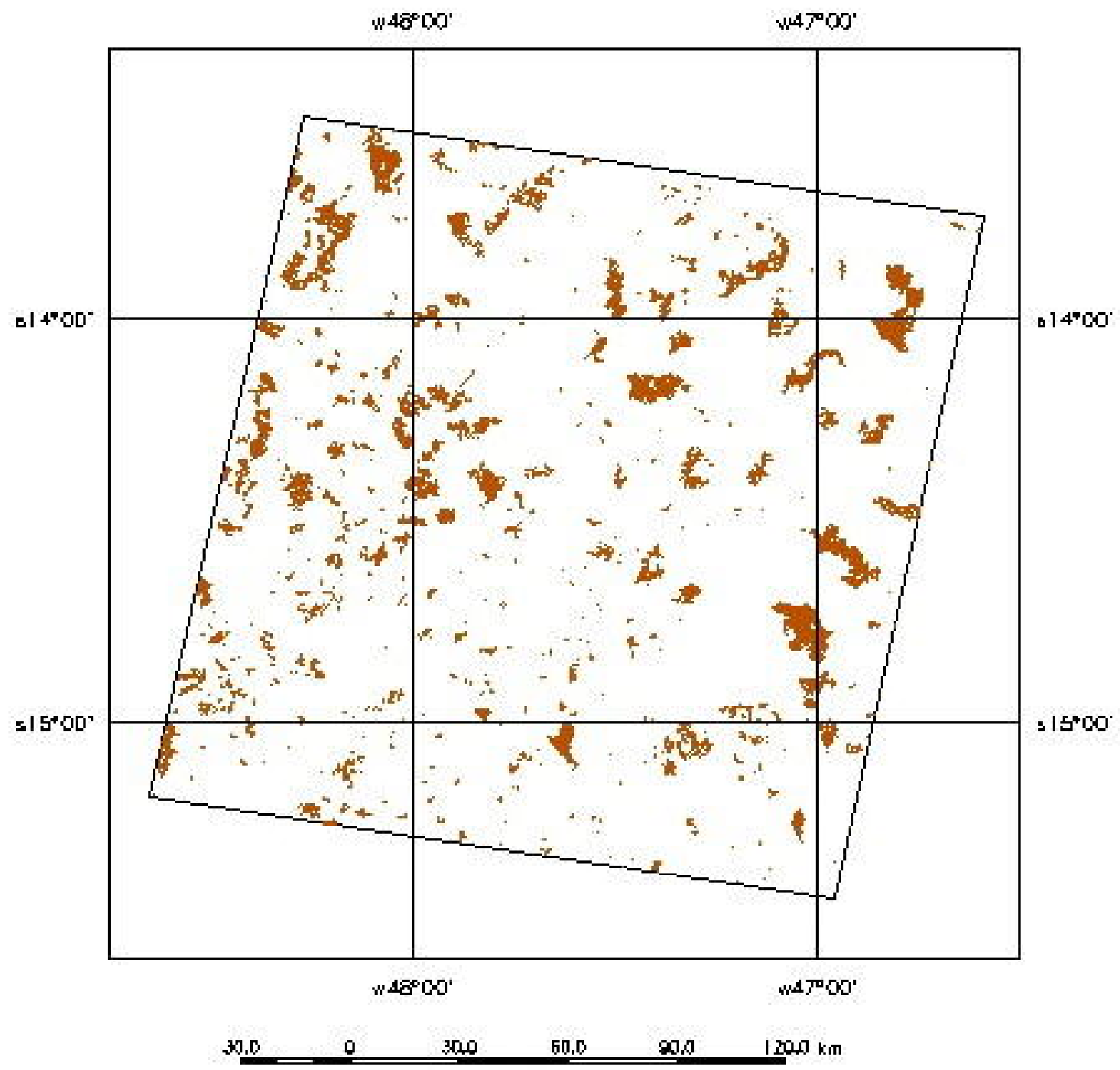

Figura 3.12 - Queimadas ocorridas em Goiás no período de 21/agosto a 06/setembro/98, segundo interpretação das imagens TM/Landsat 221/70. 


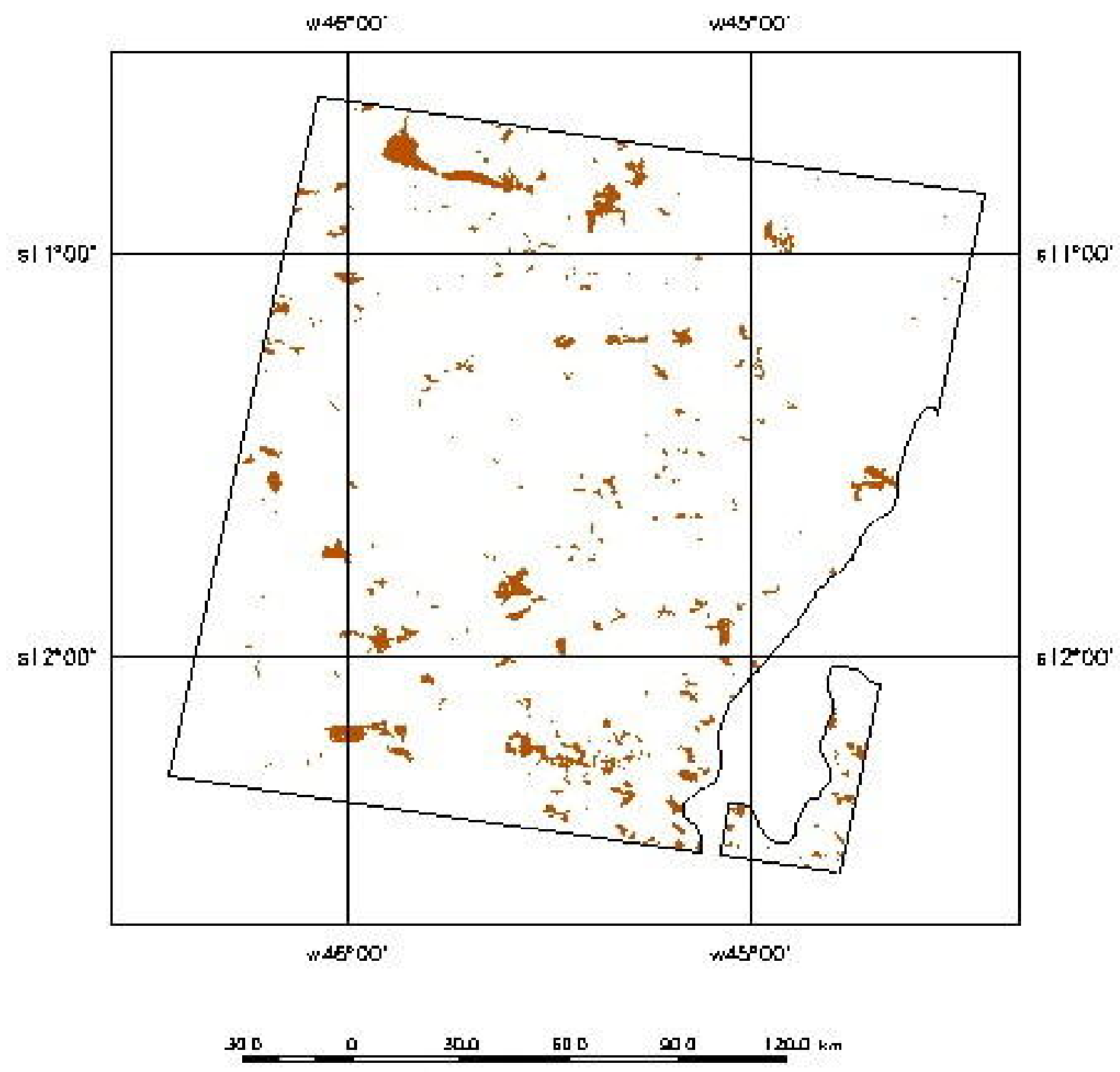

Figura 3.13 - Queimadas ocorridas em Bahia no período de 14 a 30/agosto/98, segundo interpretação das imagens TM/Landsat 220/68. 


\section{5 - Avaliação de área queimada nas imagens TM/Landsat}

A Tabela 3.2 mostra os dados das áreas comuns analisadas em cada par de imagens TM. São apresentadas também as estimativas de áreas que não foram analisadas por causa da cobertura de nuvens ou por não pertencer ao Cerrado. Finalmente, são indicados os percentuais de áreas queimadas em cada par de imagens analisadas.

Nas imagens de Mato Grosso, descontando-se $890 \mathrm{~km}^{2}$ de nuvens, constatou-se que as queimadas ocorridas nos dias 01 a 16/agosto/98, atingiram $1.750 \mathrm{~km}^{2}$, área que corresponde a 4,9\% do total analisado nessa região. Da interpretação das imagens de Goiás estimou-se a área queimada no período de 21/agosto a 06/setembro/98 em 8,4\% da área analisada, ou $3.070 \mathrm{~km}^{2}$. Nas imagens da Bahia, estimou-se que nos dias $14 \mathrm{a}$ 30/agosto/98, foram queimados $1.320 \mathrm{~km}^{2}$, ou $4 \%$ da área de Cerrado analisada.

Considerando-se os três pares de imagens conjuntamente, constatou-se que dos $105.350 \mathrm{~km}^{2}$ analisados, as queimadas atingiram cerca de $6.140 \mathrm{~km}^{2}$, equivalente a 5,8\% da área, num intervalo de 16 dias durante a estação seca de 1998.

Tabela 3.2 - Total de área queimada entre duas passagens consecutivas do TM/Landsat em três regiões do Cerrado, na estação seca de 1998.

\begin{tabular}{|c|c|c|c|c|c|c|c|}
\hline \multirow[b]{2}{*}{ Imagem } & \multirow[b]{2}{*}{ Período } & \multirow[b]{2}{*}{$\begin{array}{l}\text { Área } \\
\text { Total } \\
\left(\mathrm{km}^{2}\right)\end{array}$} & \multirow[b]{2}{*}{$\begin{array}{c}\text { Nuvem } \\
\left(\mathrm{km}^{2}\right)\end{array}$} & \multirow[b]{2}{*}{$\begin{array}{c}\text { Não- } \\
\text { Cerrado } \\
\left(\mathrm{km}^{2}\right)\end{array}$} & \multicolumn{3}{|c|}{ Área útil analisada } \\
\hline & & & & & $\begin{array}{c}\text { Área Útil } \\
\text { de Cerrado } \\
\left(\mathrm{km}^{2}\right)\end{array}$ & $\begin{array}{c}\text { Área } \\
\text { Queimada } \\
\text { no Cerrado } \\
\left(\mathrm{km}^{2}\right)\end{array}$ & $\begin{array}{c}\text { Área } \\
\text { Queimada } \\
\text { no Cerrado } \\
(\%)\end{array}$ \\
\hline $\begin{array}{l}\text { Mato } \\
\text { Grosso }\end{array}$ & $\begin{array}{l}01 \text { a } 17 \mathrm{de} \\
\text { ago/98 }\end{array}$ & 36.520 & 890 & 0 & 35.630 & 1.750 & 4,9 \\
\hline Goiás & $\begin{array}{l}21 \text { de ago a } \\
06 \text { de set/98 }\end{array}$ & 36.430 & 0 & 0 & 36.430 & 3.070 & 8,4 \\
\hline Bahia & $\begin{array}{c}14 \text { a } 30 \text { de } \\
\text { ago/98 }\end{array}$ & 35.490 & 0 & 2.200 & 33.290 & 1.320 & 4,0 \\
\hline TOTAL & & 108.440 & 890 & 2.200 & 105.350 & 6.140 & 5,8 \\
\hline
\end{tabular}




\section{6- Caracterização das queimadas a partir das imagens TM/Landsat}

A relação completa das estimativas de área queimada em cada um dos 1.589 polígonos digitalizados a partir da interpretação das imagens TM encontra-se nas Tabelas A37 a A39, no Anexo. A partir do agrupamento desses dados segundo classes de tamanho de queimada, foram gerados os resultados abaixo. As Tabela 3.3 a 3.5 e as Figuras 3.14 a 3.16 mostram, para cada região estudada, durante um período de 16 dias na estação seca de 1998, a quantidade de queimadas (número de polígonos) em cada classe de tamanho. Nas três áreas estudadas observaram-se situações semelhantes:

a) queimadas pequenas - menores que $0,5 \mathrm{~km}^{2}$ - foram as mais numerosas, respondendo por cerca de $50 \%$ da quantidade total de queimadas ( $\mathrm{n}^{\mathrm{o}}$ de polígonos), porém responsáveis por, no máximo, 3\% do total da área queimada;

b) queimadas grandes - maiores que $10 \mathrm{~km}^{2}$ - representaram de 5 a $10 \%$ da quantidade total de queimadas, porém foram responsáveis por mais de $75 \%$ da área queimada nas imagens de Mato Grosso e Goiás, e cerca de 60\% na da Bahia;

c) queimadas intermediárias - entre 0,5 e $10 \mathrm{~km}^{2}$ - representaram cerca de $40 \%$ do número de queimadas em todas as regiões estudadas; no Mato Grosso e Goiás elas foram responsáveis por cerca de $20 \%$ da área queimada, mas na Bahia esse valor foi $36 \%$.

Ressalta-se que a análise dos dados de áreas queimadas obtidos das imagens TM pode ser feita conjuntamente, pois como será visto na análise estatística — item 3.10.1 — elas representam a mesma população.

A Tabela 3.6 e a Figura 3.17 mostram os dados agrupados das três regiões analisadas. A soma de todas as queimadas totalizou $6.150 \mathrm{~km}^{2}$ distribuídos em 1.589 polígonos. Desse total, 52,6\% (836 polígonos) são queimadas pequenas - inferiores a $0,5 \mathrm{~km}^{2}$, responsáveis por apenas $\sim 150 \mathrm{~km}^{2}$, ou $2,4 \%$ da área queimada. No outro extremo, identificaram-se 130 queimadas grandes — maiores do $10 \mathrm{~km}^{2}$ —, cerca de $8,2 \%$ da quantidade total de queimadas, responsáveis, no entanto, por $\sim 4.530 \mathrm{~km}^{2}$, equivalente a 73,7\% do total da área queimada. As queimadas de dimensões intermediárias - 0,5 a $10 \mathrm{~km}^{2}$ — totalizaram quase $40 \%$ do número total de queimadas 
e representaram cerca de $23,9 \%$ da área total das queimadas, aproximadamente $1.470 \mathrm{~km}^{2}$.

Tabela 3.3 - Número de polígonos e área queimada por classes de tamanho na região de Mato Grosso.

\begin{tabular}{lcccc}
\hline \multicolumn{1}{c}{ Tamanho $\left(\mathrm{km}^{2}\right)$} & $\mathrm{N}^{\mathrm{o}}$ de polígonos & polígonos $(\%)$ & Área $\left(\mathrm{km}^{2}\right)$ & Área $(\%)$ \\
\hline$<0,5$ & 225 & 54,9 & 40 & 2,3 \\
$\geq 0,5 \mathrm{a}<2$ & 100 & 24,4 & 100 & 5,7 \\
$\geq 2 \mathrm{a}<10$ & 54 & 13,2 & 240 & 13,7 \\
$\geq 10$ & 31 & 7,6 & 1.370 & 78,3 \\
\hline Total & 410 & 101 & 1.750 & 100 \\
\hline
\end{tabular}

Tabela 3.4 - Número de polígonos e área queimada por classes de tamanho na região de Goiás.

\begin{tabular}{lcccc}
\hline \multicolumn{1}{c}{ Tamanho $\left(\mathrm{km}^{2}\right)$} & $\mathrm{N}^{\mathrm{o}}$ de polígonos & polígonos $(\%)$ & Área $\left(\mathrm{km}^{2}\right)$ & Área $(\%)$ \\
\hline$<0,5$ & 355 & 49,8 & 70 & 2,3 \\
$\geq 0,5 \mathrm{a}<2$ & 184 & 25,8 & 190 & 6,2 \\
$\geq 2 \mathrm{a}<10$ & 102 & 14,3 & 460 & 14,9 \\
$\geq 10$ & 72 & 10,1 & 2.360 & 76,6 \\
\hline Total & 713 & 100 & 3.080 & 100 \\
\hline
\end{tabular}

Tabela 3.5 - Número de polígonos e área queimada por classes de tamanho na região da Bahia.

\begin{tabular}{lcccc}
\hline \multicolumn{1}{c}{ Tamanho $\left(\mathrm{km}^{2}\right)$} & $\mathrm{N}^{\mathrm{o}}$ de polígonos & polígonos $(\%)$ & Área $\left(\mathrm{km}^{2}\right)$ & Área $(\%)$ \\
\hline$<0,5$ & 256 & 54,9 & 40 & 3,0 \\
$\geq 0,5 \mathrm{a}<2$ & 102 & 21,9 & 100 & 7,6 \\
$\geq 2 \mathrm{a}<10$ & 81 & 17,4 & 380 & 28,8 \\
$\geq 10$ & 27 & 5,8 & 800 & 60,6 \\
\hline Total & 466 & 100 & 1320 & 100 \\
\hline
\end{tabular}


Tabela 3.6 - Número de polígonos de queimadas e área queimada por classe de tamanho nas três áreas de estudo.

\begin{tabular}{lcccc}
\hline \multicolumn{1}{c}{ Tamanho $\left(\mathrm{km}^{2}\right)$} & $\mathrm{N}^{\mathrm{o}}$ de polígonos & polígonos $(\%)$ & Área $\left(\mathrm{km}^{2}\right)$ & Área $(\%)$ \\
\hline$<0,5$ & 836 & 52,6 & 150 & 2,4 \\
$\geq 0,5 \mathrm{a}<2$ & 386 & 24,3 & 390 & 6,3 \\
$\geq 2 \mathrm{a}<10$ & 237 & 14,9 & 1.080 & 17,6 \\
$\geq 10$ & 130 & 8,2 & 4.530 & 73,7 \\
\hline Total & 1.589 & 100 & 6.150 & 100 \\
\hline
\end{tabular}

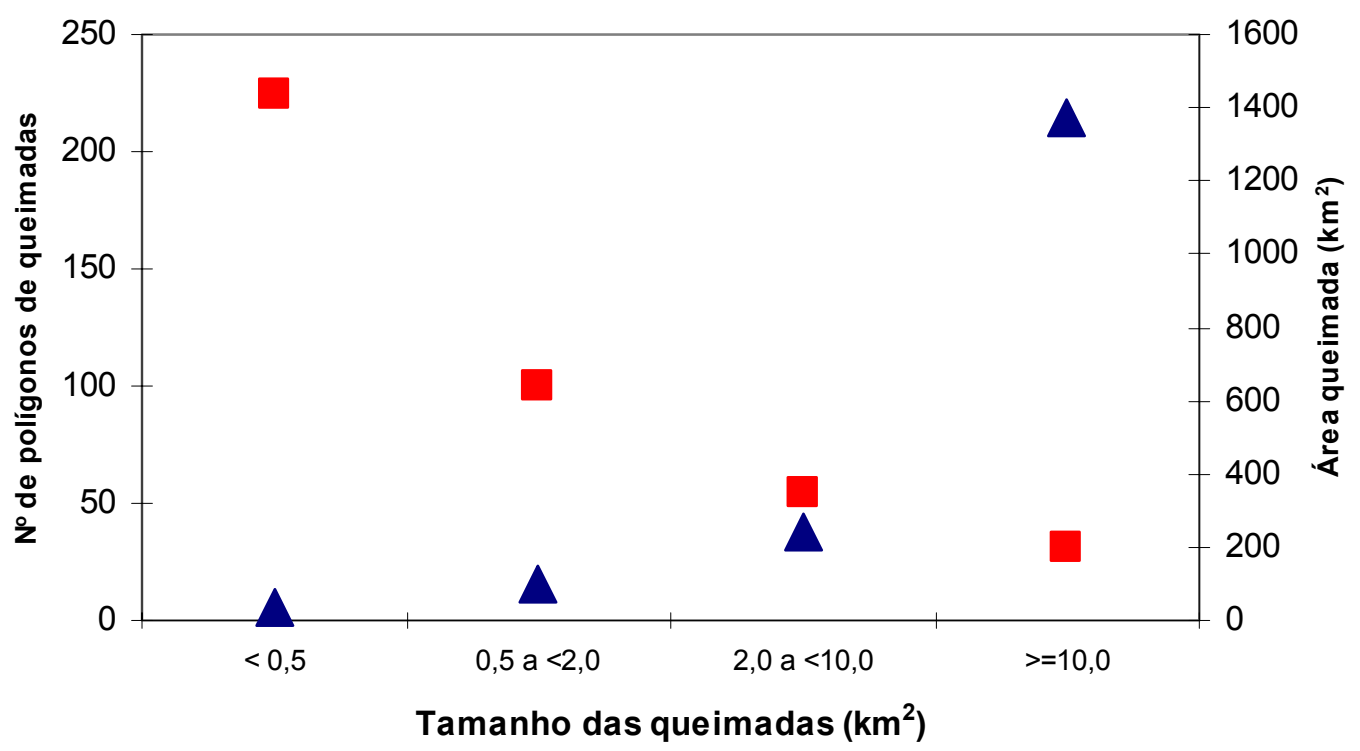

Número de polígonos $\Delta$ Área das queimadas

Figura 3.14 - Número de polígonos e área das queimadas ocorridas no período de $01 \mathrm{a}$ 17/agosto/98 na região de Mato Grosso (TM 225/70). 


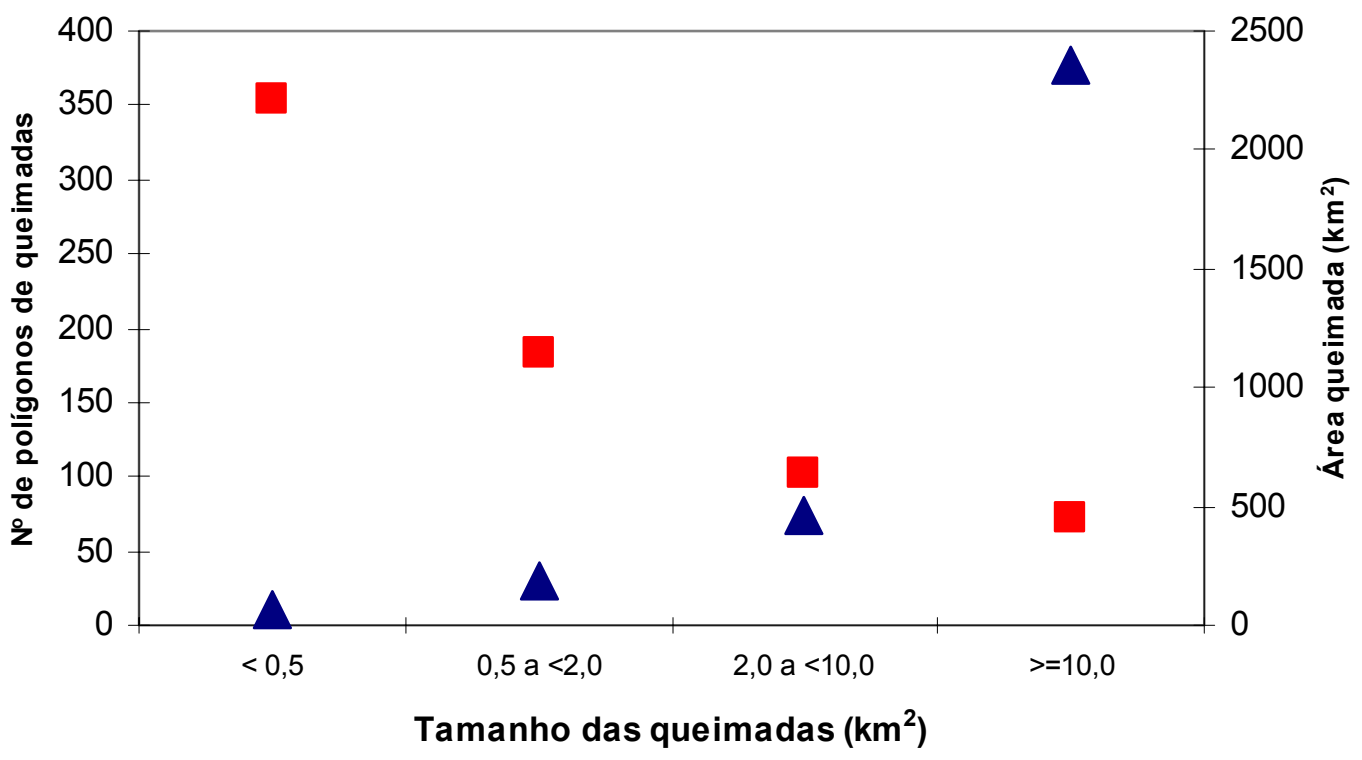

Número de polígonos $\Delta$ Área das queimadas

Figura 3.15 - Número de polígonos e área das queimadas ocorridas no período de 21/agosto a 06/setembro/98 na região de Goiás (TM 221/70).

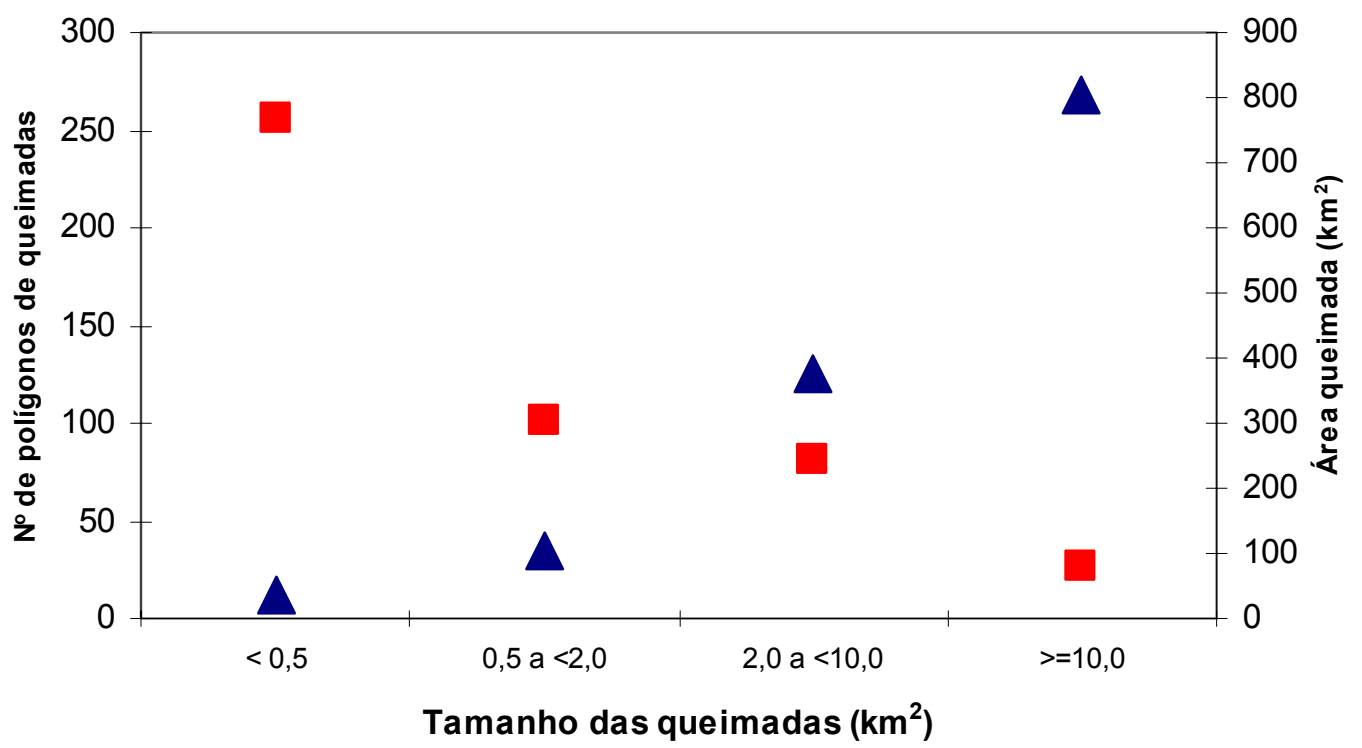

Número de polígonos $\Delta$ Área das queimadas

Figura 3.16 - Número de polígonos e área das queimadas ocorridas no período de $14 \mathrm{a}$ 17/agosto/98 na região de região da Bahia (TM 220/68). 


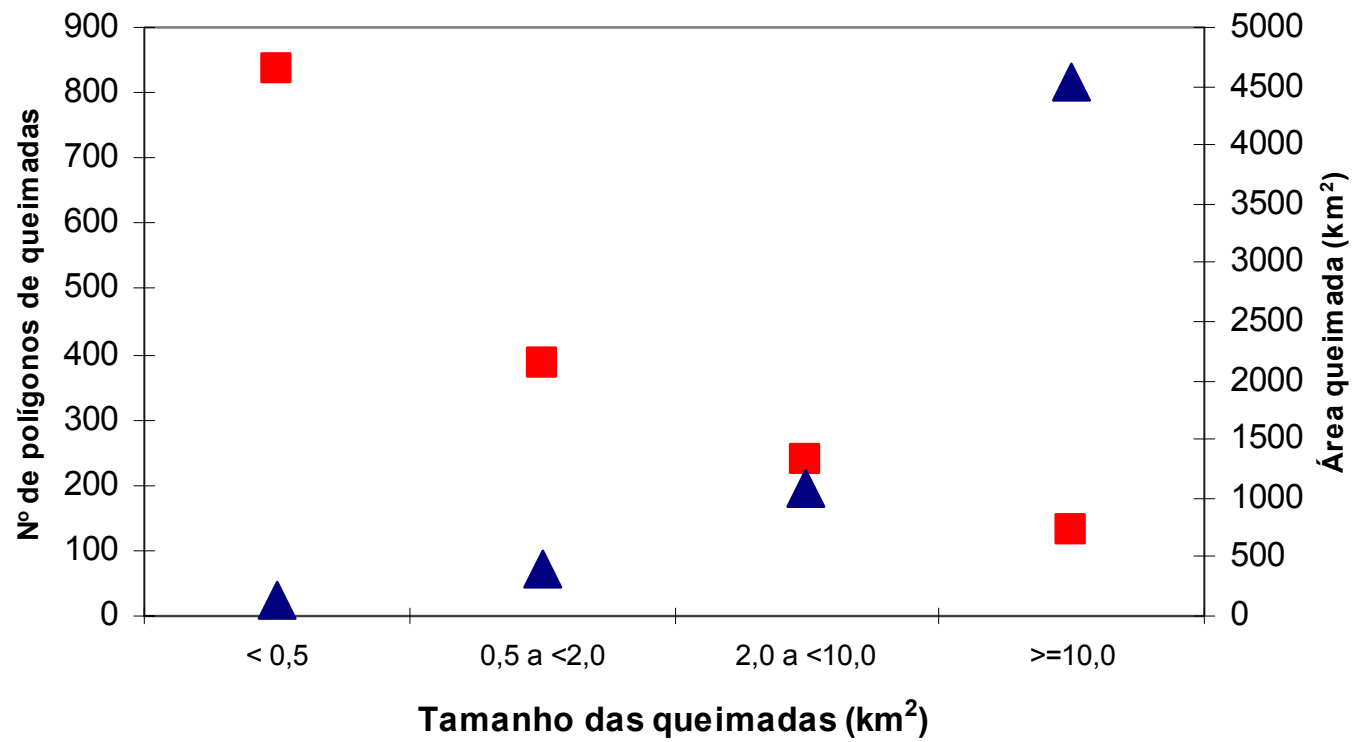

Número de polígonos $\Delta$ Área das queimadas

Figura 3.17 - Número de polígonos e área das queimadas ocorridas nas regiões de Mato Grosso, Goiás e Bahia (TM 225/70; 221/70; 220/68), em períodos de 16 dias durante a estação seca de 1998.

A distribuição desses dados foi semelhante àquela obtida por Pereira e Setzer (1996) a partir de interpretações de imagens TM/Landsat consecutivas abrangendo o Cerrado na região da fronteira de Goiás e Tocantins. Estimou-se que $40 \%$ das queimadas ocorridas no período 25/agosto/89 a 26/setembro/89 eram pequenas $\left(<0,5 \mathrm{~km}^{2}\right)$, mas responderam por apenas $1,6 \%$ da área queimada na região estudada; por outro lado, $12,5 \%$ das queimadas abrangeram áreas superiores a $10 \mathrm{~km}^{2}$ e foram responsáveis por 70\% da área queimada. As estimativas de áreas queimadas em 1999 no Cerrado, calculadas por PNUD (2000) a partir da interpretação de 59 imagens TM/Landsat do Cerrado mostraram que queimadas menores que $0,5 \mathrm{~km}^{2}$ corresponderam a 32\% do total de queimadas no Cerrado ocorridas em julho, mas foram responsáveis por apenas $2 \%$ da área queimada. No outro extremo, avaliou-se que $8 \%$ das queimadas foram superiores a $10 \mathrm{~km}^{2}$ e responderam por $56 \%$ da área queimada total analisada.

Os dados de áreas queimadas das três regiões foram colocados conjuntamente na forma de gráfico de freqüência relativa - Figura 3.18 - e freqüência relativa 
acumulada - Figura 3.19. Determinou-se em planilha eletrônica as curvas de ajustes aos dados. Para tanto, eles foram divididos em classes de $0,5 \mathrm{~km}^{2}$ até o limite de $20 \mathrm{~km}^{2}$. A curva de ajuste obtida para os dados de freqüência acumulada foi uma função gama dada por:

$$
\begin{aligned}
& f(x)=\frac{1}{\beta^{\alpha} \Gamma(\alpha)} x^{\alpha-1} \exp \left(-\frac{x}{\beta}\right) \quad \text { onde } \\
& \alpha=0,25, \beta=5 \quad \text { e } \Gamma(\alpha)=\text { função gama do parâmetro } \alpha .
\end{aligned}
$$

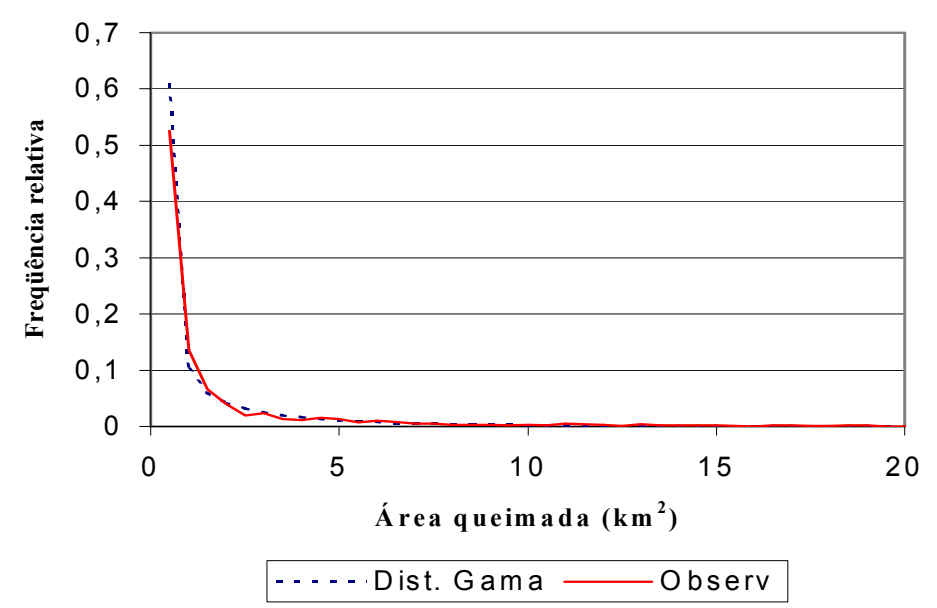

Figura 3.18 - Freqüência relativa das áreas queimadas nas três áreas de estudo combinadas.

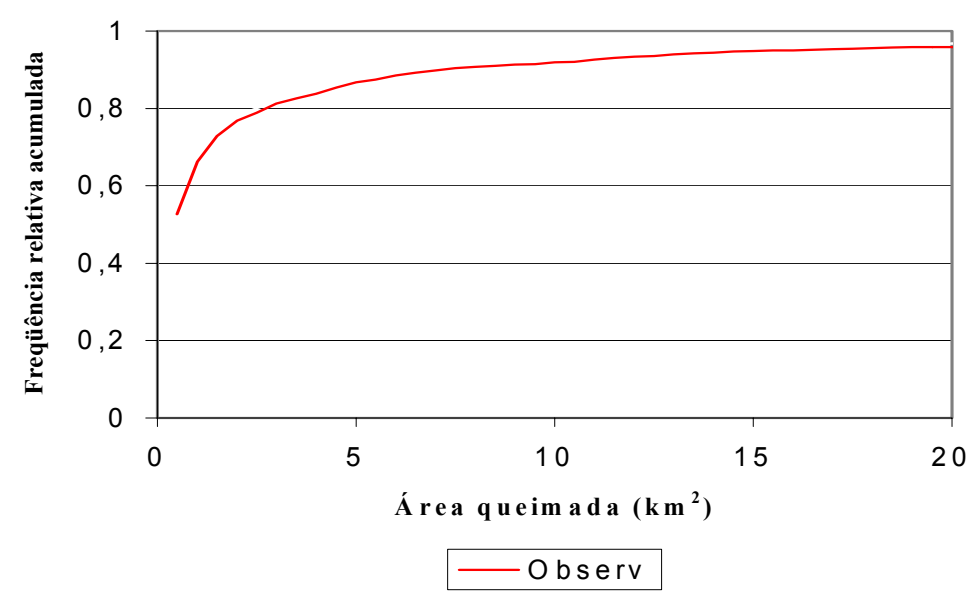

Figura 3.19 - Freqüência relativa acumulada das áreas queimadas nas três áreas de estudo combinadas. 
Cabe observar que estes dois gráficos ilustram a análise anterior, mostrando que a maioria das queimadas no Cerrado é de pequeno tamanho, e que as grandes são poucas, porém responsáveis pela maior parte da superfície afetada.

\section{7 - Uso do algoritmo para identificar queimadas nas regiões de Mato Grosso, Goiás e Bahia}

As Figuras 3.20, 3.21 e 3.22 mostram o resultado da aplicação do algoritmo de identificação de áreas queimadas nos mosaico AVHRR nas mesmas áreas estudadas com as imagens TM/Landsat. A Tabela 3.7 resume os valores "brutos" de áreas obtidos para cada classe identificada.

Comparando-se as estimativas de áreas queimadas obtidas pelo algoritmo com aquelas resultantes das imagens TM - Tabela 3.8 e Figura 3.23 - observou-se que as primeiras sempre foram superiores às segundas. No entanto, essa super-estimativa se deu de forma distinta, principalmente na Bahia, onde a avaliação do AVHRR foi $112 \%$ $\left(480 \mathrm{~km}^{2}\right)$ superior à do TM. Nas outras regiões, no entanto, a diferença foi muito menor: 3,8\% ( $\left.70 \mathrm{~km}^{2}\right)$ em Mato Grosso e $13 \%$ em $\left(440 \mathrm{~km}^{2}\right)$ em Goiás. De modo geral, nos três casos, notou-se que as queimadas grandes foram identificadas pelo algoritmo. Também, foram identificadas as áreas de agricultura anual que teriam sido classificadas como queimada devido a reflexos na banda 3 do AVHRR, caso o algoritmo não compensasse o problema. A classe "sem dados" correspondeu às áreas com ocorrência duvidosa de queimadas, e àquelas em que o baixo IVDN indicou persistência da cobertura de nuvens. A maior discrepância de valores de área queimada, ocorrida na região da Bahia, foi causada por reflexos da banda 3 em solos. Estes reflexos não foram totalmente identificados pelo algoritmo, apesar das alterações de limiares feitas justamente para minimizar esse problema. Em função de inúmeras tentativas com variações no algoritmo, concluiu-se que possivelmente não há como solucionar o problema dos reflexos nestes casos. 


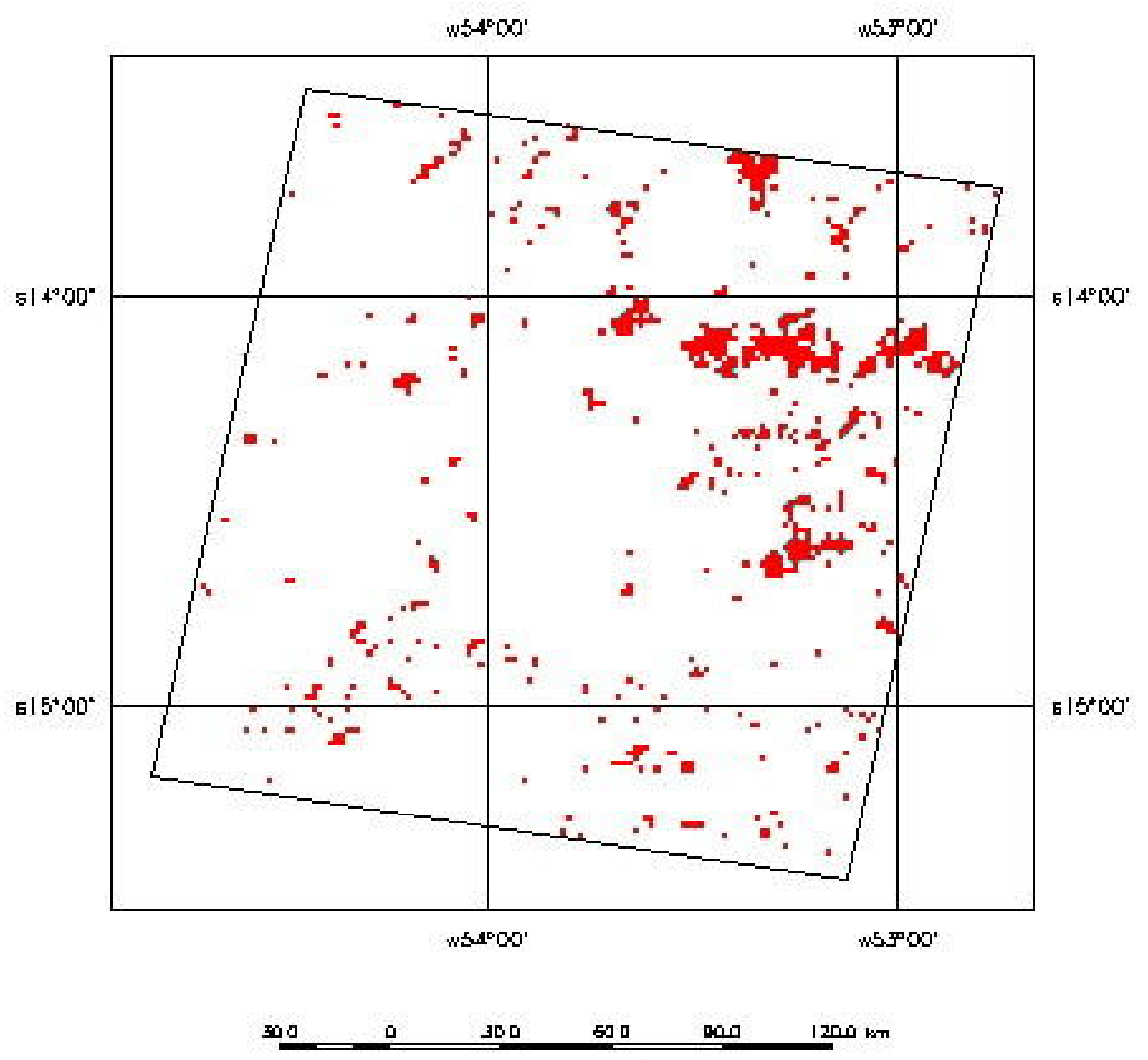

Figura 3.20 - Aplicação do algoritmo de identificação de queimadas nos mosaicos AVHRR, região de Mato Grosso, 01 a 16/agosto/98. 


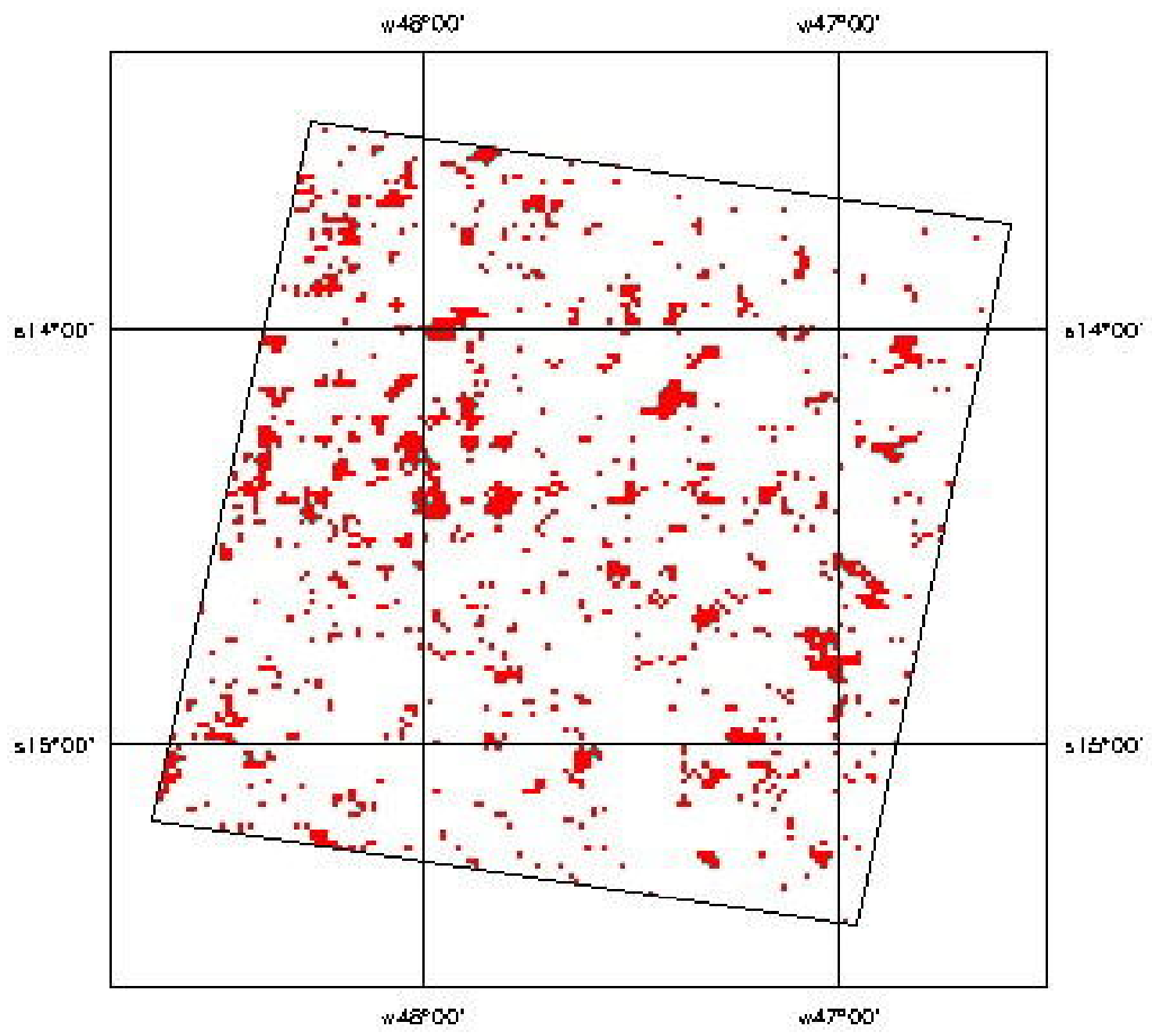

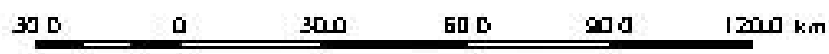

Figura 3.21 - Aplicação do algoritmo de identificação de queimadas nos mosaicos AVHRR, região de Goiás, 21/agosto a 05/setembro/98. 


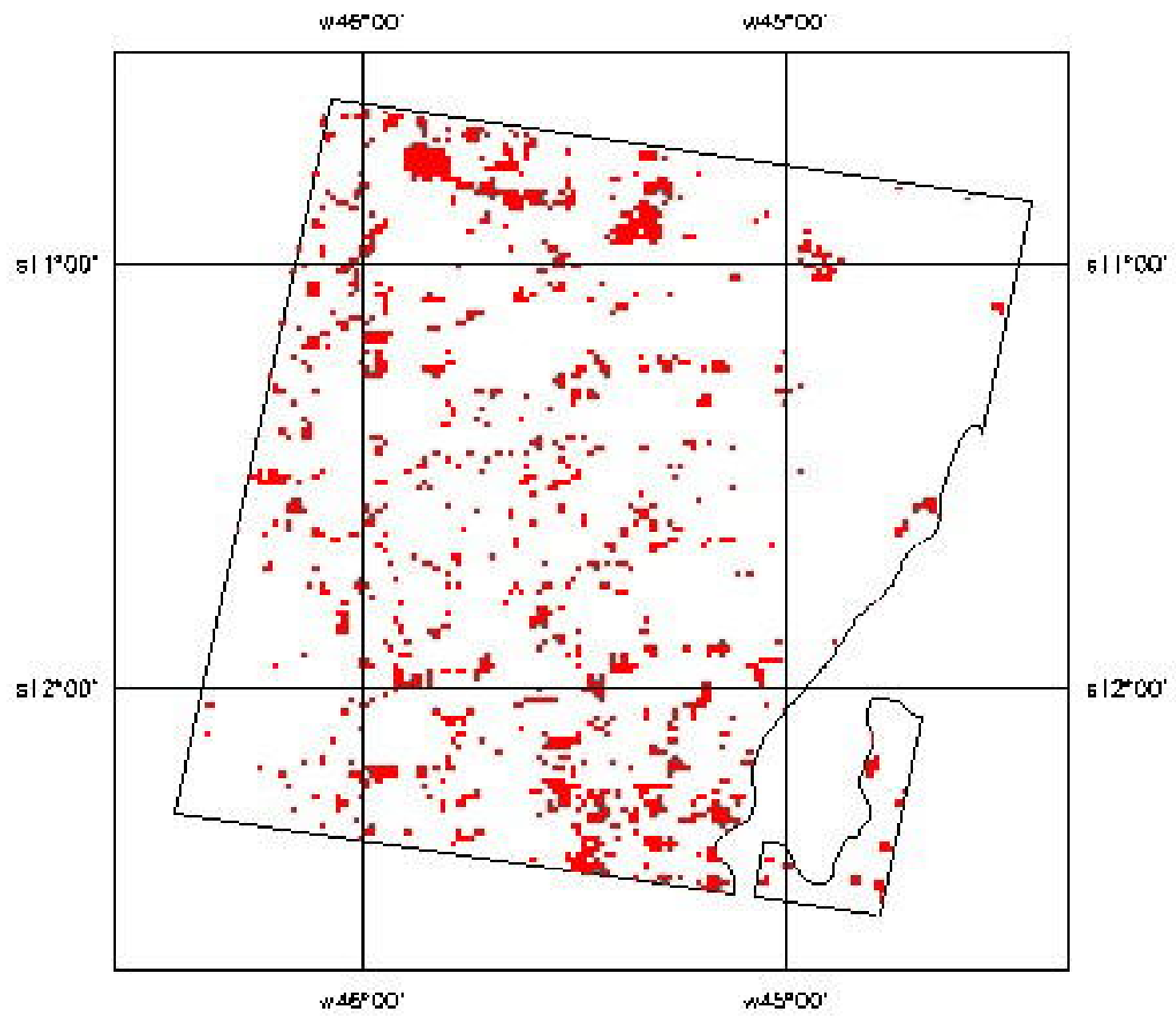

$30 \mathrm{D} \quad \mathrm{O} \quad 300 \quad 60 \mathrm{D} \quad \mathrm{00} \quad 1200 \mathrm{~km}$

Figura 3.22 - Aplicação do algoritmo de identificação de queimadas nos mosaicos AVHRR, região da Bahia, 14 a 30/agosto/98. 
Tabela 3.7 - Estimativas brutas de áreas obtidas nos mosaicos através do algoritmo de identificação de queimadas nas regiões de Mato Grosso, Goiás e Bahia.

\begin{tabular}{lccc}
\hline \multicolumn{1}{c}{ Classes } & $\begin{array}{c}\text { Mato Grosso } \\
\left(\mathrm{Km}^{2}\right)\end{array}$ & $\begin{array}{c}\text { Goiás } \\
\left(\mathrm{Km}^{2}\right)\end{array}$ & $\begin{array}{c}\text { Bahia* } \\
\left(\mathrm{Km}^{2}\right)\end{array}$ \\
\hline Queimada & 1.817 & 3.485 & 2.806 \\
Não-queimada & 27.732 & 18.607 & 15.861 \\
Cultivo & 1.495 & 2.710 & 2.683 \\
Água & 0 & 0 & 0 \\
Sem dados & 3.055 & 8.880 & 10.700 \\
Queimada anterior & 2.426 & 2.746 & 1.231 \\
\hline Total & 36.525 & 36.428 & 33.281 \\
\hline
\end{tabular}

* Inclui apenas área de Cerrado.

Tabela 3.8 - Totais brutos de áreas queimadas obtidos das imagens TM e dos mosaicos AVHRR.

\begin{tabular}{lccc}
\hline & $\begin{array}{c}\text { Mato } \\
\text { Grosso } \\
\left(\mathrm{km}^{2}\right)\end{array}$ & $\begin{array}{c}\text { Goiás } \\
\left(\mathrm{km}^{2}\right)\end{array}$ & $\begin{array}{c}\left(\mathrm{km}^{2}\right) \\
\text { TM }\end{array}$ \\
\hline AVHRR & 1.750 & 3.071 & 1.321 \\
\hline
\end{tabular}




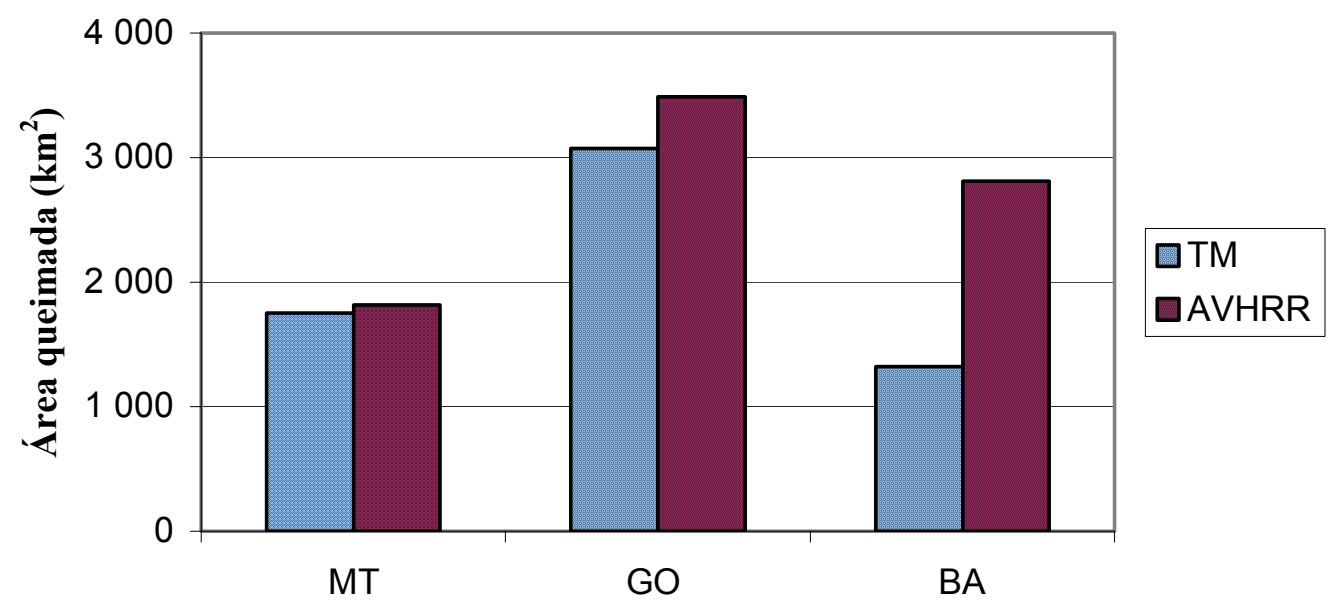

Figura 3.23 - Estimativas de áreas queimadas obtidas das imagens TM/Landsat e da aplicação do algoritmo de identificação de queimadas nos mosaicos AVHRR/NOAA-14. Notar discrepância na Bahia, devido a reflexos na banda 3 do AVHRR.

\section{8 - Resultados da interpretação visual dos dados}

A interpretação visual dos dados TM com os contornos das queimadas impressos conjuntamente com os dados AVHRR gerados pelo algoritmo de identificação de áreas queimadas permitiu verificar, uma a uma, as queimadas com correspondência nos dois conjuntos de dados. Conseqüentemente, foram também identificadas as queimadas omitidas pelo algoritmo, bem como as "falsas" queimadas, ou seja, píxeis classificados como queimadas pelo algoritmo, porém sem correspondência com queimadas nos dados TM. A Figura 3.24 exemplifica a impressão conjunta dos dados TM e AVHRR.

Quando os dados das três regiões foram analisados conjuntamente, verificou-se que $65 \%$ dos 1.589 polígonos de queimadas identificados nas imagens TM tiveram correspondência com polígonos de queimadas nos dados AVHRR, e 33\% não tiveram - Tabela 3.9. No entanto, dos 525 polígonos TM sem correspondência nos dados AVHRR, constatou-se que $66 \%$ eram queimadas pequenas, inferiores $0,5 \mathrm{~km}^{2}$, e apenas 2 polígonos eram queimadas grandes, maiores que $10 \mathrm{~km}^{2}$; as demais eram de tamanho intermediário. Esses dados evidenciaram que a maior parte das omissões de queimadas 
no processamento dos mosaicos AVHRR, provavelmente deveu-se a dimensões diminutas das mesmas, em contraste com a resolução espacial de $2,25 \mathrm{~km}^{2}$ dos mosaicos AVHRR.

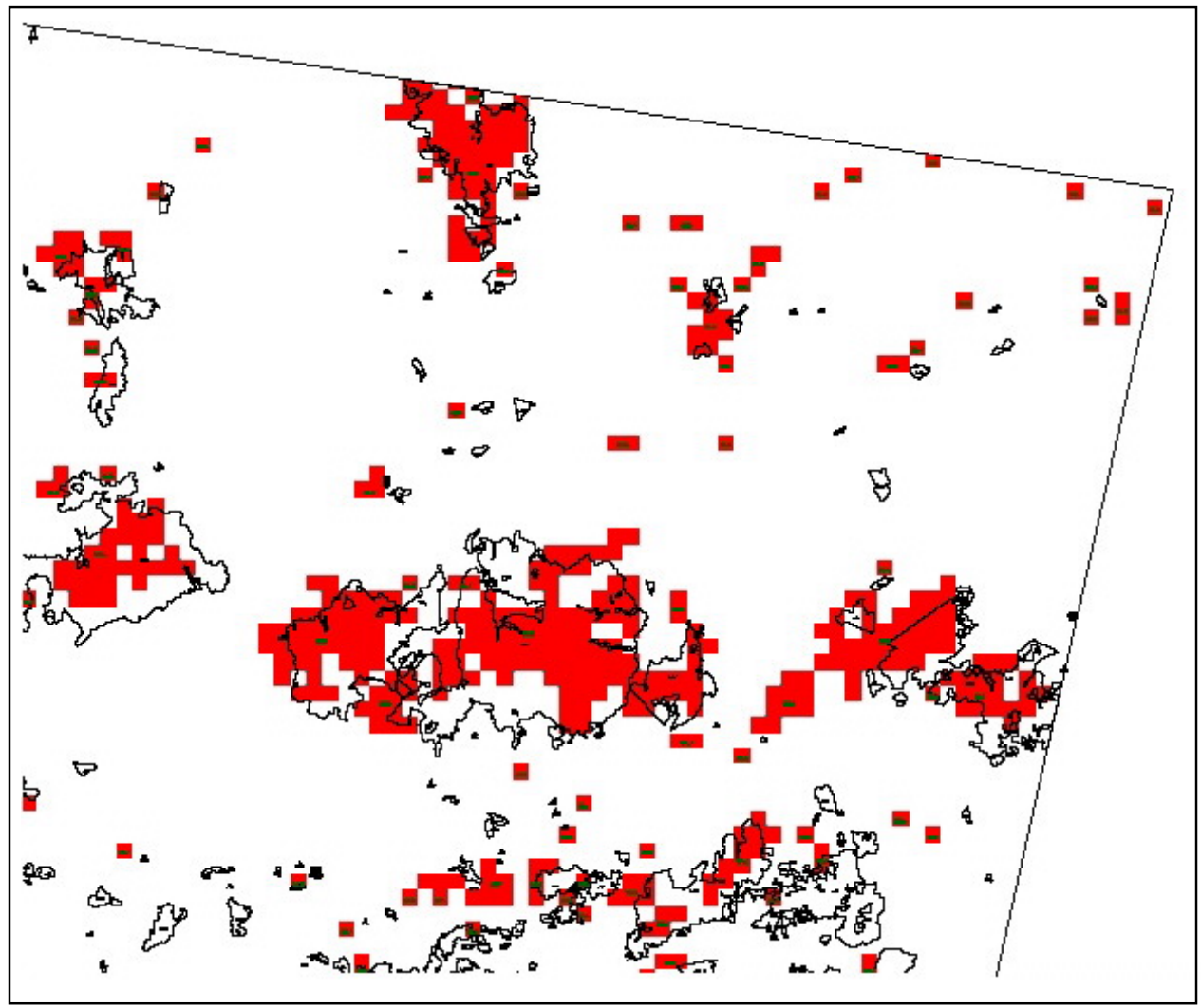

Figura 3.24 - Exemplo da visualização da classificação das queimadas nos mosaicos AVHRR (em vermelho), juntamente com os contornos das queimadas obtidos das imagens TM; região correspondente ao quadrante superior direito da imagem TM de Mato Grosso.

Por outro lado, a área dos polígonos de queimada com correspondência nas imagens TM e AVHRR representaram 94\% da área queimada no TM; apenas 5\% da área queimada no TM não teve correspondência nos mosaicos AVHRR processados Tabela 3.10.

Constatou-se também que havia polígonos de queimadas identificados nos mosaicos AVHRR sem correspondência nas imagens TM, chamados aqui de falsas queimadas. Eles totalizaram $20 \%$ dos polígonos AVHRR e representaram $14 \%$ da área total obtida dos dados AVHRR nas três áreas, conjuntamente. Porém, quando 
considerada a Bahia individualmente, essa proporção de área foi maior: $21,5 \%$ — Tabelas A40 e A41 (Anexo).

Tabela 3.9 - Quantidade de polígonos de queimadas identificados nas imagens TM e sua correspondência nos mosaicos AVHRR.

\begin{tabular}{l|rr|rr|rr|rr} 
& \multicolumn{2}{|c|}{ MT } & \multicolumn{2}{|c|}{ GO } & \multicolumn{2}{|c|}{ BA } & \multicolumn{2}{c}{ Total } \\
\cline { 2 - 9 } & $\mathrm{N}^{\mathrm{o}}$ pol & \multicolumn{1}{c|}{$\%$} & $\mathrm{~N}^{\mathrm{o}}$ pol & \multicolumn{1}{c|}{$\%$} & $\mathrm{~N}^{\mathrm{o}}$ pol & $\%$ & $\mathrm{~N}^{\mathrm{o}}$ pol & \multicolumn{1}{c}{$\%$} \\
\hline TM & 410 & 100 & 713 & 100 & 466 & 100 & 1589 & 100 \\
TM e AVHRR & 221 & 53,9 & 462 & 64,8 & 342 & 73,4 & 1025 & 64,5 \\
TM sem AVHRR & 184 & 44,9 & 237 & 33,2 & 104 & 22,3 & 525 & 33,0 \\
TM borda/nuvem & 5 & 1,2 & 14 & 2,0 & 20 & 4,3 & 39 & 2,5 \\
\hline
\end{tabular}

Tabela 3.10 - Área queimada obtida dos polígonos das imagens TM e sua correspondência com os mosaicos AVHRR.

\begin{tabular}{l|rr|rr|rr|rr} 
& \multicolumn{2}{|c|}{ MT } & \multicolumn{2}{|c|}{ GO } & \multicolumn{2}{c|}{ BA } & \multicolumn{2}{c}{ Total } \\
\cline { 2 - 9 } & \multicolumn{1}{|c|}{ Área } & \multicolumn{1}{c|}{$\%$} & \multicolumn{1}{|c|}{ Área } & \multicolumn{1}{c}{$\%$} & \multicolumn{1}{|c}{ Área } & \multicolumn{1}{c}{$\%$} & Área & \multicolumn{1}{c}{$\%$} \\
\hline TM & 1748 & 100 & 3069 & 100 & 1319 & 100 & 6136 & 100 \\
TM e AVHRR & 1584 & 90,6 & 2948 & 96,1 & 1257 & 95,3 & 5789 & 94,3 \\
TM sem AVHRR & 160 & 9,2 & 118 & 3,8 & 45 & 3,4 & 323 & 5,3 \\
TM borda/nuvem & 4 & 0,2 & 3 & 0,1 & 17 & 1,3 & 24 & 0,4 \\
\hline
\end{tabular}

\section{9 - Aplicação do algoritmo de identificação de queimadas para todo Cerrado}

Todos os mosaicos AVHRR, a partir da segunda quinzena de maio/98, foram processados pelo algoritmo de identificação de queimadas. Obtiveram-se assim, 23 imagens temáticas do Cerrado com cinco classes: não-queimada, queimada, queimada anterior, cultivo e água, conforme exemplificado na Figura 3.25.

Observou-se que os reflexos em solo na banda 3 (Setzer e Malingreau, 1996) foram minimizados quando ocorrriam em área agrícolas. Porém, no Cerrado nordestino, esse problema persistiu, principalmente em agosto e setembro, nas áreas em que não se identificaram culturas anuais no mosaico IVDN de referência. 
Reflexos em solo, erroneamente identificados como queimadas, foram esporadicamente observados também em Goiás, e na região norte de São Paulo, limite com Minas Gerais. Na segunda quinzena de novembro/98, em particular, esse problema foi mais acentuado.

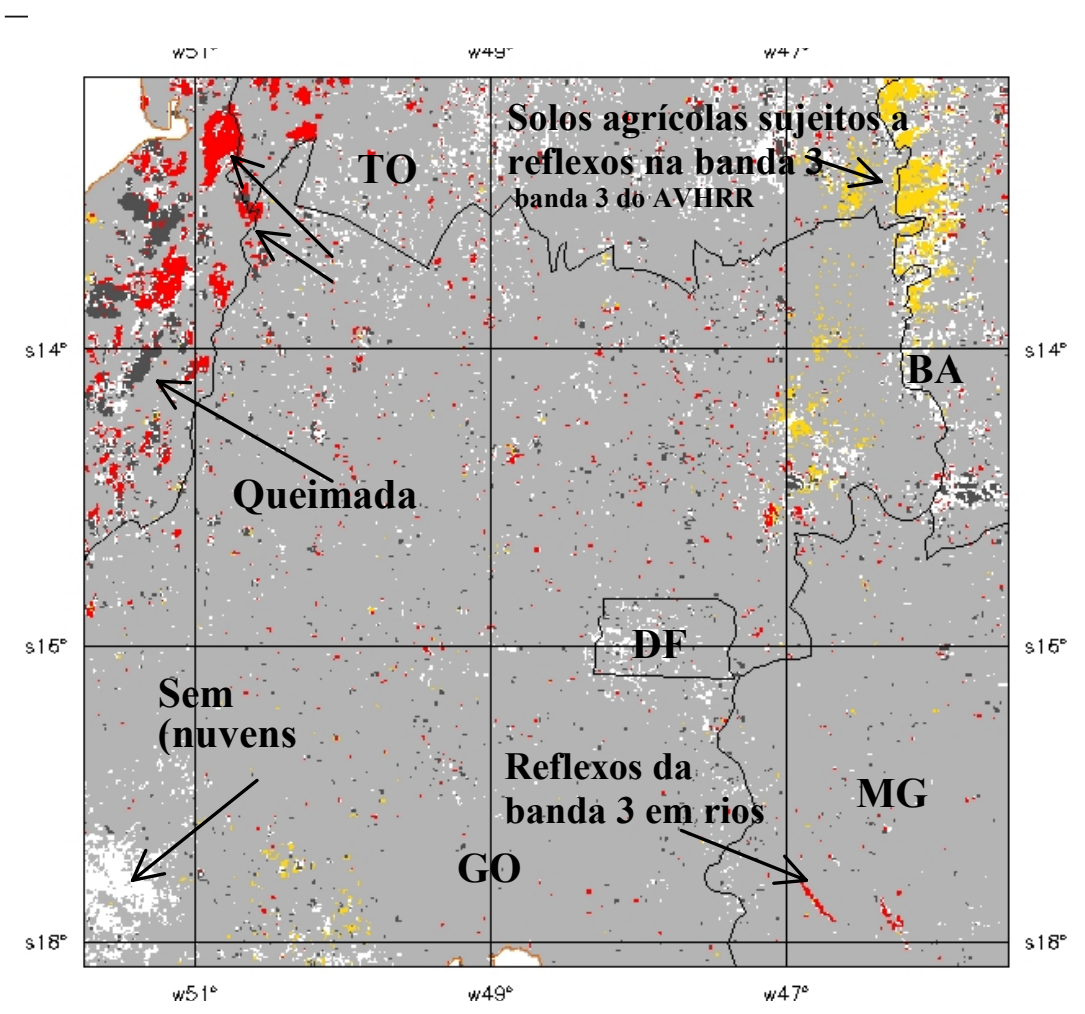

Figura 3.25 - Exemplo de aplicação do algoritmo nos mosaicos de agosto/98 mostrando queimadas, queimadas anteriores, reflexos em rios, nuvens e solos agrícolas.

Áreas alagadas, represas e rios causadores de reflexos na banda 3 também não foram identificados satisfatoriamente pelo algoritmo. Essa limitação foi atribuída a três causas: a) diferenças entre registro do mosaico IVDN que está sendo analisado e do mosaico IVDN de referência; se o píxel correspondente à água nos dois mosaicos não ocupam a mesma posição, possivelmente não foi atendida a terceira condição do algoritmo, ou seja, pixel com baixo IVDN em ambos mosaicos; b) presença de vegetação em algumas superfícies alagadas, como o Pantanal mato-grossense, que 
ocasionou IVDNs superiores aqueles atribuídos a água e, portanto, impossibilitando classificá-las como tal. c) sazonalidade do alagamento identificando a água em apenas um dos mosaicos IVDN, não satisfazendo a terceira condição do algoritmo que prevê valores baixos de IVDN no mosaico em questão e no de referência.

Para minimizar a falsa identificação de queimadas ocasionadas por reflexos na banda 3 em superfícies alagadas sazonalmente, rios e reservatórios, foram utilizados os mapas digitais de "rios permanentes" e "áreas inundáveis" do IBGE (DPI, 2000). Assim, sempre que se identificaram falsas queimadas em corpos d'água, e elas coincidiram com rios ou áreas inundáveis dos mapas, os píxeis em questão foram reclassificados para água. Esse procedimento foi realizado por interpretação visual no SPRING nas imagens temáticas da $2^{\underline{a}}$ quinzena de outubro, $1^{\underline{a}}$ e $2^{\underline{a}}$ quinzena de novembro e $2^{\underline{a}}$ quinzena de janeiro.

As Figuras A1 a A12 no Anexo mostram o resultado da utilização do algoritmo, porém exibem apenas a classe queimada, objeto de interesse deste trabalho.

\subsection{0 - Análise estatística dos dados}

A análise estatística dos dados permitiu verificar que as amostras de áreas queimadas obtidas da interpretação das imagens TM representavam a mesma população. As análises de regressão e os testes estatísticos a elas associados resultaram em modelos adequados de estimativa de área queimada no Cerrado a partir de mosaicos quinzenais das imagens AVHRR/NOAA-14, conforme será visto adiante.

\subsection{1 - Teste de Kolmogorov-Smirnov para duas amostras}

A Tabela 3.11 mostra o resultado da aplicação do teste de Kolmogorov-Smirnov para duas amostras com a finalidade de verificar se pertencem à mesma população.

Como nos três casos analisados obtiveram-se valores de $D_{t a b}$ superiores ao $D_{o b s}$, concluiu-se que as 3 amostras de áreas queimadas em Cerrado nas regiões de Mato Grosso, Goiás e Bahia representavam a mesma população no nível de significância 5\%. 
Tabela 3.11 - Resultados do teste de Kolgomorov-Smirnov para pares de amostras.

\begin{tabular}{cccc}
\hline & MT e GO & MT e BA & GO e BA \\
\hline$D_{t a b(5 \%)}$ & 0,084293 & 0,092089 & 0,081014 \\
$D_{o b s}$ & 0,06075 & 0,02893 & 0,05146 \\
Resultado & $D_{t a b}>D_{o b s}$ & $D_{t a b}>D_{o b s}$ & $D_{t a b}>D_{o b s}$
\end{tabular}

\subsection{2 - Análise de regressão}

Foram feitas análises de regressão entre os dados de área queimada obtidos das imagens TM/Landsat e aqueles calculados pela aplicação do algoritmo de identificação de queimadas nos mosaicos AVHRR/NOAA-14 - Tabela 3.12.

Respeitando-se os critérios estabelecidos para exclusão de células — área de nuvens e/ou não pertencentes ao Cerrado $>50 \%$ da área da células - foram excluídas 2 células das 36 da região da Bahia. Não houve descarte de células para Mato Grosso e Goiás, com 36 células cada.

Os dados das regiões de Mato Grosso e Goiás foram analisados conjuntamente, lembrando que representam a mesma população de áreas queimadas resultantes da interpretação das imagens TM e, além disso, os mosaicos AVHRR dessas áreas foram processados com o mesmo algoritmo - ver item 3.3. Já os dados AVHRR da Bahia, foram processados com uma variação do algoritmo, pois essa região está localizada na subdivisão Cerrado 2 da área de estudo. Assim, foram inicialmente analisadas 72 células correspondentes à subdivisão Cerrado 1 (MT e GO) e 34 células à região Cerrado 2 (BA). Fez-se então, a regressão linear dos dados de área queimada extraídos dos mosaicos AVHRR juntamente com os dados de áreas queimadas calculados pelas imagens TM para células de tamanho padronizados de $1.009 \mathrm{~km}^{2}$ na amostra 1 (MT/GO) e $986 \mathrm{~km}^{2}$ para a amostra $2(\mathrm{BA})$. 
Tabela 3.12 - Dados brutos de área queimada por célula, obtidos dos mosaicos AVHRR (coluna $\mathrm{X}$, em $\mathrm{km}^{2}$ ) e das imagens TM (coluna $\mathrm{Y}, \mathrm{km}^{2}$ ), colocados em ordem crescente segundo área de $\mathrm{Y}$.

\begin{tabular}{crr|rr|rr} 
Célula & \multicolumn{1}{|c|}{$\mathrm{X}$} & \multicolumn{1}{c|}{$\mathrm{Y}$} & \multicolumn{1}{|c|}{$\mathrm{X}$} & \multicolumn{1}{c}{$\mathrm{Y}$} & \multicolumn{1}{|c}{$\mathrm{X}$} & \multicolumn{1}{c}{$\mathrm{Y}$} \\
\hline 1 & 10,00 & 0,00 & 78,27 & 6,92 & 0,00 & 0,43 \\
2 & 2,25 & 0,00 & 30,83 & 21,55 & 17,86 & 0,80 \\
3 & 11,25 & 0,00 & 63,23 & 24,65 & 8,41 & 2,47 \\
4 & 8,97 & 3,13 & 46,50 & 27,78 & 97,84 & 3,47 \\
5 & 0,83 & 5,45 & 44,74 & 27,81 & 6,88 & 5,24 \\
6 & 26,50 & 5,52 & 73,02 & 32,16 & 49,21 & 5,84 \\
7 & 8,95 & 5,91 & 84,46 & 39,72 & 25,74 & 11,61 \\
8 & 13,76 & 5,93 & 88,00 & 43,66 & 4,72 & 13,53 \\
9 & 11,11 & 6,63 & 81,69 & 44,18 & 65,53 & 16,91 \\
10 & 49,71 & 8,06 & 55,34 & 49,87 & 73,60 & 17,49 \\
11 & 30,53 & 8,81 & 68,89 & 50,61 & 75,61 & 17,64 \\
12 & 7,96 & 9,81 & 126,89 & 50,90 & 15,70 & 19,61 \\
13 & 25,52 & 10,42 & 100,38 & 51,84 & 75,97 & 22,38 \\
14 & 7,63 & 11,23 & 59,20 & 56,85 & 43,03 & 23,07 \\
15 & 55,16 & 13,11 & 41,18 & 61,91 & 73,26 & 23,45 \\
16 & 31,22 & 15,11 & 91,79 & 62,09 & 81,39 & 23,88 \\
17 & 28,91 & 19,05 & 75,58 & 66,46 & 136,17 & 27,00 \\
18 & 17,21 & 19,90 & 120,12 & 79,96 & 22,21 & 29,12 \\
19 & 42,83 & 20,47 & 38,13 & 80,19 & 52,26 & 31,81 \\
20 & 13,05 & 25,30 & 16,91 & 85,66 & 55,20 & 37,01 \\
21 & 46,59 & 25,51 & 110,75 & 88,18 & 98,53 & 40,46 \\
22 & 21,74 & 28,28 & 68,63 & 88,52 & 98,10 & 43,42 \\
23 & 88,49 & 31,56 & 105,70 & 89,54 & 153,30 & 43,51 \\
24 & 22,14 & 35,39 & 53,82 & 90,44 & 49,79 & 43,76 \\
25 & 51,98 & 39,00 & 143,09 & 91,89 & 113,19 & 46,71 \\
26 & 80,57 & 40,95 & 84,43 & 95,27 & 36,12 & 46,83 \\
27 & 97,78 & 56,29 & 92,91 & 99,93 & 68,06 & 47,37 \\
28 & 20,25 & 71,46 & 62,42 & 102,29 & 115,01 & 59,15 \\
29 & 84,62 & 78,39 & 160,49 & 121,95 & 90,28 & 78,73 \\
30 & 74,17 & 86,12 & 109,30 & 123,24 & 231,12 & 87,30 \\
31 & 113,70 & 114,84 & 161,06 & 123,99 & 166,79 & 90,26 \\
32 & 157,17 & 117,17 & 149,94 & 127,76 & 218,60 & 92,95 \\
33 & 30,35 & 120,98 & 143,41 & 168,67 & 191,73 & 98,84 \\
34 & 78,49 & 145,70 & 251,24 & 183,66 & 261,92 & 125,93 \\
35 & 170,73 & 223,89 & 174,49 & 209,82 & - & - \\
36 & 265,54 & 333,72 & 211,88 & 212,20 & - & - \\
\hline & & & & & &
\end{tabular}

Em seguida, determinou-se a dispersão dos EP para Cerrado 1 e 2 Figuras 3.26 e 3.27. A análise gráfica indicou que a variância do erro não era constante, apontando a necessidade de transformação dos dados para estabilizá-la (Netter e Wasserman, 1974). A transformação escolhida foi a extração da raíz quadrada dos 
valores da área estimada nos mosaicos $\operatorname{AVHRR}(\mathrm{X})$ e das áreas obtidas pelas imagens TM (Y) (Chatterjee,1977) - Tabelas 3.13 e 3.14.

$$
X^{\prime}=\sqrt{X} \quad \text { e } \quad Y^{\prime}=\sqrt{Y}
$$

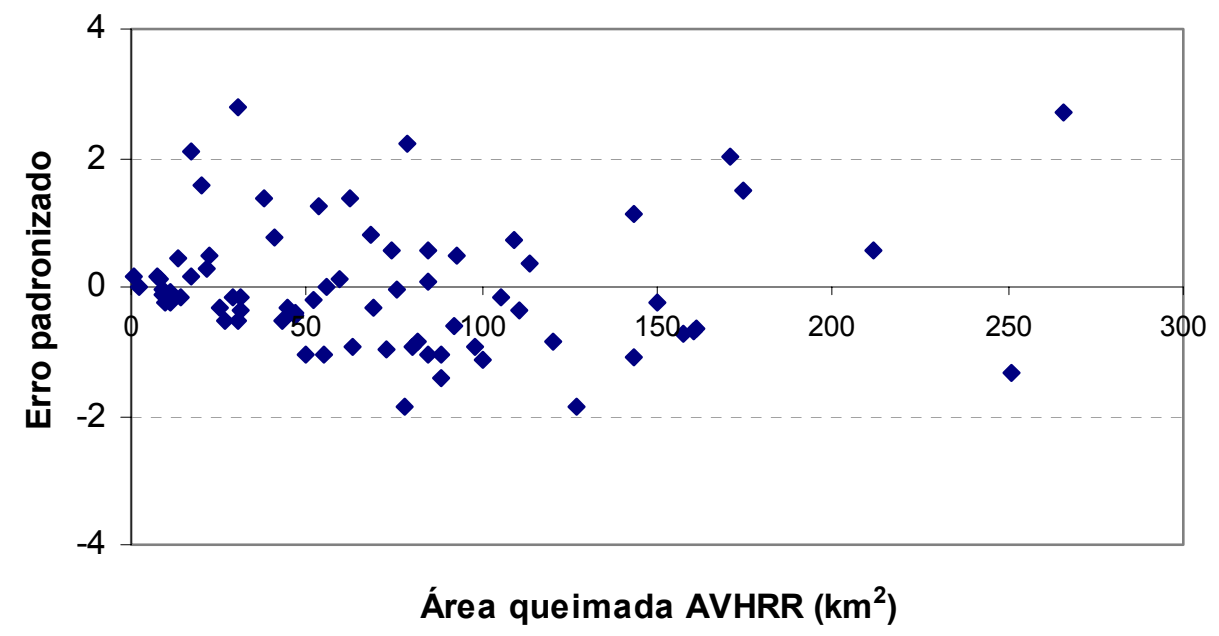

Figura 3.26 - Dispersão dos erros padronizados para os dados originais das regiões de Mato Grosso e Goiás (Cerrado 1).

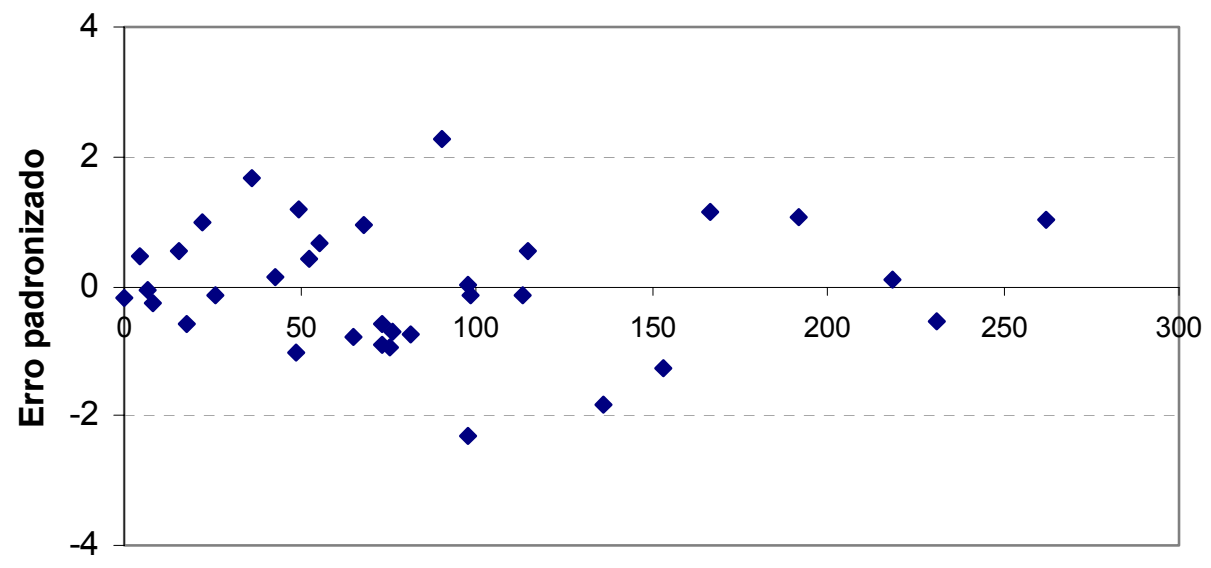

Área queimada AVHRR $\left(\mathrm{km}^{2}\right)$

Figura 3.27 - Dispersão dos erros padronizados para os dados originais da região da Bahia (Cerrado2). 
Tabela 3.13 - Valores transformados de X e Y, erro e erro médio padronizado para a região de Mato Grosso e Goiás (Cerrado 1); os outliers foram suprimidos.

\begin{tabular}{|c|c|c|c|c|}
\hline Célula & $X^{\prime}$ & $Y^{\prime}$ & $E^{\prime}$ & $E P^{\prime}$ \\
\hline 1 & 3,16 & $\overline{0,00}$ & $-2,31$ & $-1,29$ \\
\hline 2 & 1,50 & 0,00 & $-0,66$ & $-0,37$ \\
\hline 3 & 3,35 & 0,00 & $-2,50$ & $-1,39$ \\
\hline 4 & 3,00 & 1,77 & $-0,38$ & $-0,21$ \\
\hline 5 & 0,91 & 2,33 & 2,27 & 1,26 \\
\hline 6 & 5,15 & 2,35 & $-1,94$ & $-1,08$ \\
\hline 7 & 2,99 & 2,43 & 0,29 & 0,16 \\
\hline 8 & 3,71 & 2,44 & $-0,42$ & $-0,23$ \\
\hline 9 & 3,33 & 2,57 & 0,09 & 0,05 \\
\hline 10 & 7,05 & 2,84 & $-3,34$ & $-1,86$ \\
\hline 11 & 5,53 & 2,97 & $-1,70$ & $-0,94$ \\
\hline 12 & 2,82 & 3,13 & 1,16 & 0,64 \\
\hline 13 & 5,05 & 3,23 & $-0,96$ & $-0,54$ \\
\hline 14 & 2,76 & 3,35 & 1,44 & 0,80 \\
\hline 15 & 7,43 & 3,62 & $-2,94$ & $-1,63$ \\
\hline 16 & 5,59 & 3,89 & $-0,84$ & $-0,47$ \\
\hline 17 & 5,38 & 4,36 & $-0,15$ & $-0,08$ \\
\hline 18 & 4,15 & 4,46 & 1,17 & 0,65 \\
\hline 19 & 6,54 & 4,52 & $-1,15$ & $-0,64$ \\
\hline 20 & 5,55 & 4,64 & $-0,05$ & $-0,03$ \\
\hline 21 & 7,95 & 4,97 & $-2,11$ & $-1,18$ \\
\hline 22 & 3,61 & 5,03 & 2,27 & 1,26 \\
\hline 23 & 6,83 & 5,05 & $-0,91$ & $-0,50$ \\
\hline 24 & 6,82 & 5,27 & $-0,68$ & $-0,38$ \\
\hline 25 & 6,69 & 5,27 & $-0,55$ & $-0,30$ \\
\hline 26 & 4,66 & 5,32 & 1,51 & 0,84 \\
\hline 27 & 9,41 & 5,62 & $-2,91$ & $-1,62$ \\
\hline 28 & 8,55 & 5,67 & $-2,00$ & $-1,11$ \\
\hline 29 & 4,71 & 5,95 & 2,10 & 1,17 \\
\hline 30 & 7,21 & 6,25 & $-0,09$ & $-0,05$ \\
\hline 31 & 9,19 & 6,30 & $-2,01$ & $-1,12$ \\
\hline 32 & 8,98 & 6,40 & $-1,70$ & $-0,95$ \\
\hline 33 & 9,38 & 6,61 & $-1,89$ & $-1,05$ \\
\hline 34 & 9,04 & 6,65 & $-1,51$ & $-0,84$ \\
\hline 35 & 7,44 & 7,06 & 0,49 & 0,27 \\
\hline 36 & 8,30 & 7,11 & $-0,31$ & $-0,17$ \\
\hline 37 & 11,26 & 7,13 & $-3,24$ & $-1,80$ \\
\hline 38 & 10,02 & 7,20 & $-1,94$ & $-1,08$ \\
\hline 39 & 9,89 & 7,50 & $-1,50$ & $-0,84$ \\
\hline 40 & 7,69 & 7,54 & 0,72 & 0,40 \\
\hline 41 & 6,42 & 7,87 & 2,32 & 1,29 \\
\hline 42 & 9,58 & 7,88 & $-0,82$ & $-0,46$ \\
\hline 43 & 8,69 & 8,15 & 0,34 & 0,19 \\
\hline 44 & 9,20 & 8,85 & 0,53 & 0,30 \\
\hline 45 & 10,96 & 8,94 & $-1,13$ & $-0,63$ \\
\hline 46 & 6,18 & 8,96 & 3,64 & 2,03 \\
\hline 47 & 8,61 & 9,28 & 1,54 & 0,86 \\
\hline 48 & 10,52 & 9,39 & $-0,25$ & $-0,14$ \\
\hline 49 & 8,28 & 9,41 & 2,00 & 1,11 \\
\hline 50 & 10,28 & 9,46 & 0,07 & 0,04 \\
\hline
\end{tabular}

\begin{tabular}{l|r|r|r|r} 
(cont.) \\
\hline Célula & \multicolumn{1}{|c|}{$X^{\prime}$} & \multicolumn{1}{c|}{$Y^{\prime}$} & \multicolumn{1}{c}{$E^{\prime}$} & \multicolumn{1}{c}{$E P^{\prime}$} \\
\hline 51 & 7,34 & 9,51 & 3,04 & 1,69 \\
52 & 11,96 & 9,59 & $-1,48$ & $-0,82$ \\
53 & 9,19 & 9,76 & 1,45 & 0,81 \\
54 & 9,64 & 10,00 & 1,24 & 0,69 \\
55 & 7,90 & 10,11 & 3,09 & 1,72 \\
56 & 10,66 & 10,72 & 0,94 & 0,52 \\
57 & 12,54 & 10,82 & $-0,82$ & $-0,45$ \\
58 & 12,67 & 11,04 & $-0,73$ & $-0,41$ \\
59 & 10,45 & 11,10 & 1,53 & 0,85 \\
60 & 12,69 & 11,14 & $-0,66$ & $-0,37$ \\
61 & 12,25 & 11,30 & $-0,05$ & $-0,03$ \\
62 & 8,86 & 12,07 & 4,09 & 2,27 \\
63 & 11,98 & 12,99 & 1,91 & 1,06 \\
64 & 15,85 & 13,55 & $-1,39$ & $-0,77$ \\
65 & 13,21 & 14,49 & 2,17 & 1,21 \\
66 & 14,56 & 14,57 & 0,92 & 0,51 \\
67 & 13,07 & 14,96 & 2,80 & 1,56 \\
68 & 16,30 & 18,27 & 2,89 & 1,61 \\
\hline
\end{tabular}

$\begin{array}{ll}Y^{\prime}=\mathrm{a} X^{\prime}+\mathrm{b} \\ \mathrm{a}= & 0,9951 \\ \mathrm{~b}= & -0,8343\end{array}$

MSE $=3,2307$

$X^{\prime}=$ ra1z quadrada de $X(\mathrm{~km})$

$Y^{\prime}=$ raiz quadrada de $Y(\mathrm{~km})$

$X=$ área queimada bruta AVHRR $\left(\mathrm{km}^{\llcorner}\right)$

$\mathrm{Y}=$ área queımada $\mathrm{I} M\left(\mathrm{~km}^{\llcorner}\right)$ 
Tabela 3.14 - Valores transformados de X e Y, erro e erro médio padronizado para a região da Bahia (Cerrado 2); o outlier foi suprimido.

\begin{tabular}{r|r|r|r|r} 
Céluld & \multicolumn{1}{|c|}{$X^{\prime}$} & \multicolumn{1}{|c|}{$Y^{\prime}$} & \multicolumn{1}{|c|}{$E^{\prime}$} & \multicolumn{1}{|c}{$E P^{\prime}$} \\
\hline 1 & 0,00 & 0,66 & $-0,24$ & $-0,17$ \\
2 & 4,23 & 0,90 & $-2,41$ & $-1,70$ \\
3 & 2,90 & 1,57 & $-0,98$ & $-0,69$ \\
4 & 2,62 & 2,29 & $-0,11$ & $-0,07$ \\
5 & 7,01 & 2,42 & $-2,48$ & $-1,76$ \\
6 & 5,07 & 3,41 & $-0,39$ & $-0,27$ \\
7 & 2,17 & 3,68 & 1,54 & 1,09 \\
8 & 8,09 & 4,11 & $-1,41$ & $-0,99$ \\
9 & 8,58 & 4,18 & $-1,61$ & $-1,14$ \\
10 & 8,70 & 4,20 & $-1,66$ & $-1,17$ \\
11 & 3,96 & 4,43 & 1,27 & 0,90 \\
12 & 8,72 & 4,73 & $-1,14$ & $-0,81$ \\
13 & 6,56 & 4,80 & 0,16 & 0,11 \\
14 & 8,56 & 4,84 & $-0,94$ & $-0,67$ \\
15 & 9,02 & 4,89 & $-1,16$ & $-0,82$ \\
16 & 11,67 & 5,20 & $-2,36$ & $-1,67$ \\
17 & 4,71 & 5,40 & 1,81 & 1,28 \\
18 & 7,23 & 5,64 & 0,62 & 0,44 \\
19 & 7,43 & 6,08 & 0,95 & 0,67 \\
20 & 9,93 & 6,36 & $-0,20$ & $-0,14$ \\
21 & 9,90 & 6,59 & 0,04 & 0,03 \\
22 & 12,38 & 6,60 & $-1,37$ & $-0,97$ \\
23 & 7,06 & 6,62 & 1,69 & 1,19 \\
24 & 10,64 & 6,83 & $-0,14$ & $-0,10$ \\
25 & 6,01 & 6,84 & 2,52 & 1,78 \\
26 & 8,25 & 6,88 & 1,28 & 0,90 \\
27 & 10,72 & 7,69 & 0,67 & 0,47 \\
28 & 9,50 & 8,87 & 2,55 & 1,80 \\
29 & 15,20 & 9,34 & $-0,23$ & $-0,17$ \\
30 & 12,91 & 9,50 & 1,23 & 0,87 \\
31 & 14,79 & 9,64 & 0,30 & 0,21 \\
32 & 13,85 & 9,94 & 1,14 & 0,80 \\
33 & 16,18 & 11,22 & 1,08 & 0,77 \\
\hline & & & &
\end{tabular}

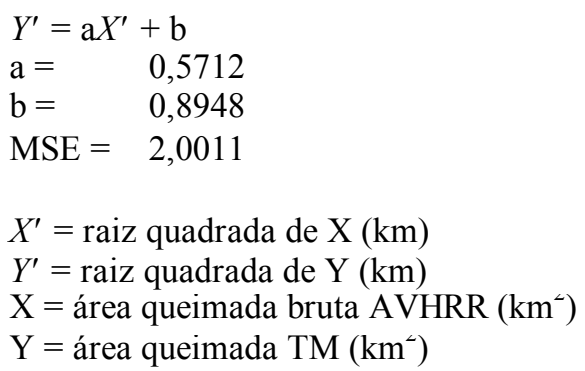


Em seguida, os dados foram colocados na forma gráfica e obtida a equação da reta de regressão linear. Da mesma forma, calculou-se: $Q S E$, EQM e analisou-se na forma gráfica, a dispersão dos $E P$ — Figuras 3.28 e 3.29.

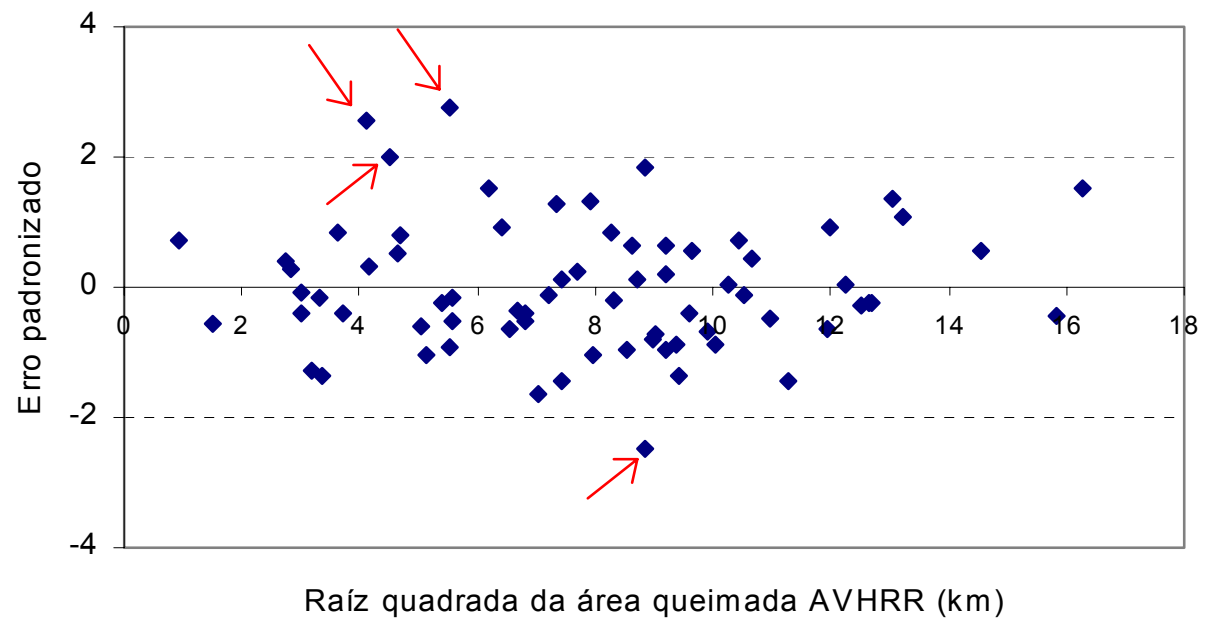

Figura 3.28 - Dispersão do erros padronizados para os dados transformados das regiões de Mato Grosso e Goiás (Cerrado 1); os outliers, posteriormente removidos, estão assinalados.

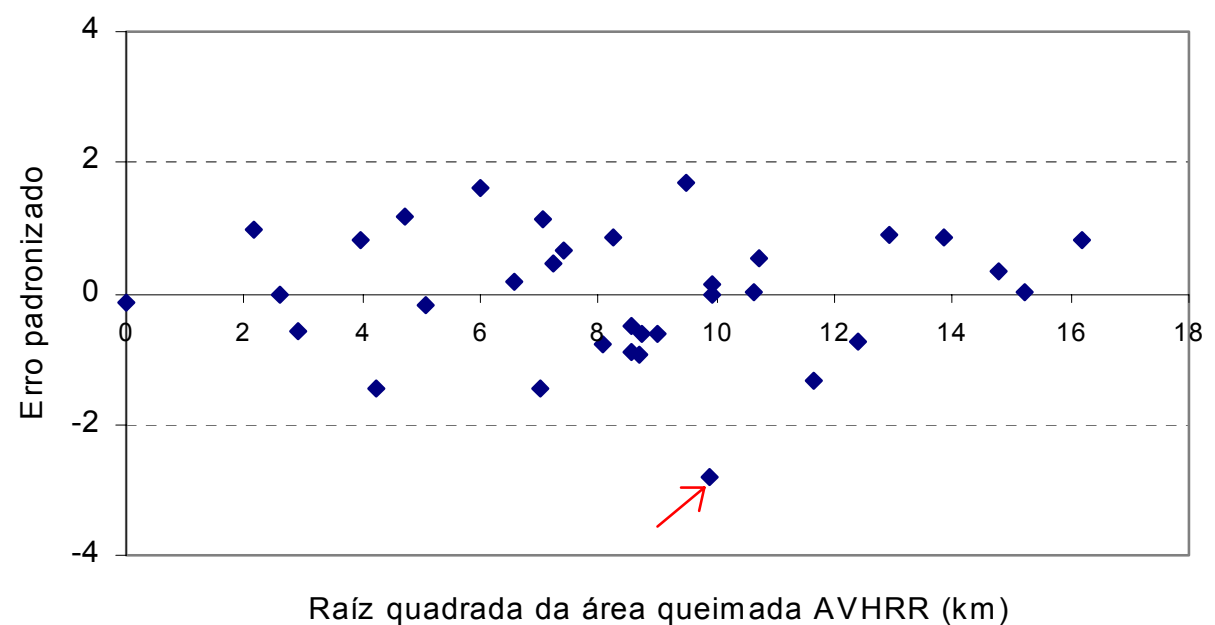

Figura 3.29 - Dispersão dos erros padronizados para os dados transformados da região da Bahia (Cerrado1); o outlier, posteriormente removido, está assinalado. 
A avaliação gráfica da distribuição dos $E P$, depois da transformação dos dados indicou que a variância dos erros tornou-se estável. Foi feita, então, a remoção de outliers (Netter e Wasserman, 1974): 04 na amostra correspondente aos dados de MT e GO e 01 na amostra da BA. Esses pontos corresponderam, nos dados originais Tabela 3.12 - às células de números 28 e 43 no Mato Grosso, 14 e 20 em Goiás e 04 na Bahia.

Dessa forma, o número de células válidas para a análise de regressão para as amostras 1 (MT e GO) e 2 (BA) foram, respectivamente:

$$
n_{1}=68 \quad \text { e } \quad n_{2}=33
$$

O $E M Q$, para esse novo conjunto de dados foi calculado em:

$$
\begin{aligned}
& E M Q_{1}=3,28 \\
& E M Q_{2}=2,06
\end{aligned}
$$

Os resultados obtidos na análise de regressão são apresentados nas Tabelas 3.15 a 3.22 e Figuras 3.30 e 3.31 .

Observou-se a região MT/GO fortes evidências de coerência da regressão linear proposta $\left(Y^{\prime}=0,995 X^{\prime}-0,834\right)$, já que a probabilidade de ocorrer um valor $\mathrm{F}$ tão grande quanto o encontrado $(246,51)$ é praticamente nula. Assim, esse valor é válido para qualquer nível de significância adotado. A seguir, testou-se a hipótese da reta passar pela origem, ou seja $b=0$, pelo teste t-student. Verificou-se que esse parâmetro ("b") pode realmente ser nulo, já que o teste indicou não haver diferença significativa a 5\% entre o verdadeiro valor de "b" e o zero, já que $\mathrm{P}(\mathrm{t}>0,834)>0,05$.

Em seguida, estimou-se novamente o coeficiente angular ("a") para o modelo de reta que passa pela origem. A regressão final para a região Cerrado 1 passou a ser:

$$
Y^{\prime}=0,9 X^{\prime}
$$

O coeficiente de determinação desta reta $\left(\mathrm{r}^{2}\right)$ foi estimado em 0,78 , indicando, portanto, que $78 \%$ da variação total é explicada quando se adota a regressão proposta. 
$\mathrm{Na}$ análise de regressão da amostra 2 (BA), encontraram-se resultados semelhantes, ou seja, a reta proposta $\left(Y^{\prime}=0,571 X^{\prime}+0,8948\right)$ é válida. Também nesse caso, verificou-se que reta de regressão pode passar pela origem. Então, estimou-se o coeficiente angular para $b=0$ e a regressão final para a região Cerrado 2 passou a ser:

$$
Y^{\prime}=0,7 X^{\prime}
$$

O coeficiente de determinação $\left(\mathrm{r}^{2}\right)$ foi estimado em 0,7 , indicando que $70 \%$ da variação total pode ser explicada quando adotado este modelo de regressão.

Tabela 3.15 - Análise de regressão para a região Cerrado 1 (MT/GO).

\begin{tabular}{cccccc}
\hline & Graus de liberdade & Soma dos quadrados & Quadrado médio & $F$ calculado & $\mathrm{P}\left(\mathrm{F}>\mathrm{F}_{\text {calc }}\right)$ \\
\hline Regressão & 1 & 796,394 & 796,395 & 246,509 & $5,69 * 10^{-24}$ \\
Erro & 66 & 213,226 & 3,231 & & \\
Total & 67 & 1009,621 & & & \\
\hline
\end{tabular}

Tabela 3.16 - Teste t-student para a região Cerrado 1 (MT/GO).

\begin{tabular}{cccc} 
& Coeficientes & $\mathrm{t}$-calculado & $\mathrm{P}\left(\mathrm{t}>\left|\mathrm{t}_{\text {calc }}\right|\right)$ \\
\hline A & 0.995 & 15,701 & $5,69 * 10^{-24}$ \\
B & $-0,834$ & $-1,516$ & 0,134
\end{tabular}

Tabela 3.17 - Análise de regressão para a região Cerrado 2 (BA).

\begin{tabular}{cccccc}
\hline & Graus de liberdade & Soma dos quadrados & Quadrado médio & $F$ calculado & $\mathrm{P}\left(\mathrm{F}>\mathrm{F}_{\text {calc }}\right)$ \\
\hline Regressão & 1 & 160,138 & 160,138 & 80,025 & $4,28 * 10^{-10}$ \\
Erro & 31 & 62,034 & 2,001 & & \\
Total & 32 & 222,172 & & & \\
\hline
\end{tabular}

Tabela 3.18 - Teste t-student para a região Cerrado 1 (BA).

\begin{tabular}{cccc} 
& Coeficientes & $\mathrm{t}$-calculado & $\mathrm{P}\left(\mathrm{t}>\left|\mathrm{t}_{\text {calc }}\right|\right)$ \\
\hline $\mathrm{a}$ & 0,571 & 8,946 & $4,28^{*} 10^{-10}$ \\
$\mathrm{~b}$ & 0,895 & 1,528 & 0,137 \\
\hline
\end{tabular}


Tabela 3.19 - Análise de regressão com reta passando pela origem, para a região Cerrado 1 (MT/GO).

\begin{tabular}{cccccc}
\hline & Graus de liberdade & Soma dos quadrados & Quadrado médio & $F$ calculado & $\mathrm{P}\left(\mathrm{F}>\mathrm{F}_{\text {calc }}\right)$ \\
\hline Regressão & 1 & 788,974 & 788,974 & 239,574 & $1,2 * 10^{-23}$ \\
Erro & 67 & 220,647 & 3,293 & & \\
Total & 68 & 1009,621 & & & \\
\hline
\end{tabular}

Tabela 3.20 - Teste t-student com reta passando pela origem, para a região Cerrado 1(MT/GO).

\begin{tabular}{cccc}
\hline & Coeficientes & t-calculado & $\mathrm{P}\left(\mathrm{t}>\left|\mathrm{t}_{\text {calc }}\right|\right)$ \\
\hline $\mathrm{A}$ & 0,907 & 35,795 & $2,18^{*} 10^{-45}$ \\
\hline
\end{tabular}

Tabela 3.21 - Análise de regressão com reta passando pela origem, para a região Cerrado 2 (BA).

\begin{tabular}{cccccc}
\hline & Graus de liberdade & Soma dos quadrados & Quadrado médio & $F$ calculado & $\mathrm{P}\left(\mathrm{F}>\mathrm{F}_{\text {calc }}\right)$ \\
\hline Regressão & 1 & 155,465 & 155,465 & 74,578 & $9,41 * 10-^{10}$ \\
Erro & 32 & 66,707 & 2,0846 & & \\
Total & 33 & 222,172 & & & \\
\hline
\end{tabular}

Tabela 3.22 - Teste t-student com reta passando pela origem, para a região Cerrado 2 (BA).

\begin{tabular}{cccc}
\hline & Coeficientes & $\mathrm{t}$-calculado & $\mathrm{P}\left(\mathrm{t}>\left|\mathrm{t}_{\text {calc }}\right|\right)$ \\
\hline $\mathrm{A}$ & 0,660 & 24,070 & $4,55^{*} 10^{-22}$ \\
\hline
\end{tabular}




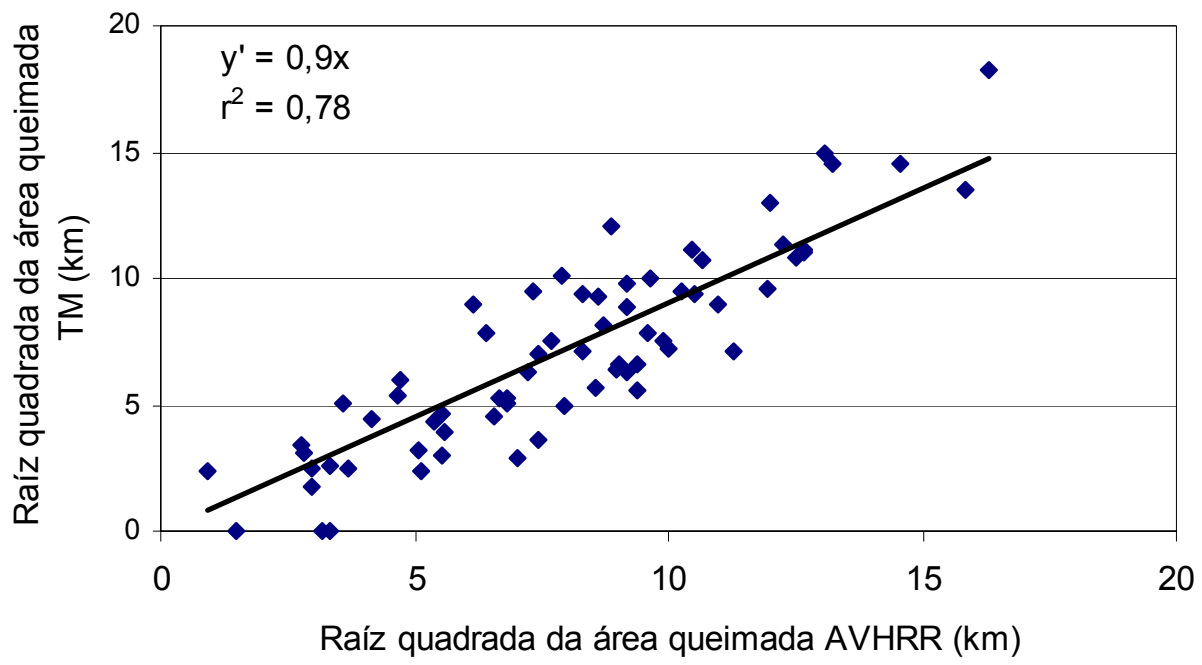

Figura 3.30 - Regressão linear com os dados transformados da área queimada nos mosaicos AVHRR $(\mathrm{km})$ e nas imagens TM $(\mathrm{km})$ nas regiões de Mato Grosso e Goiás - Cerrado 1.

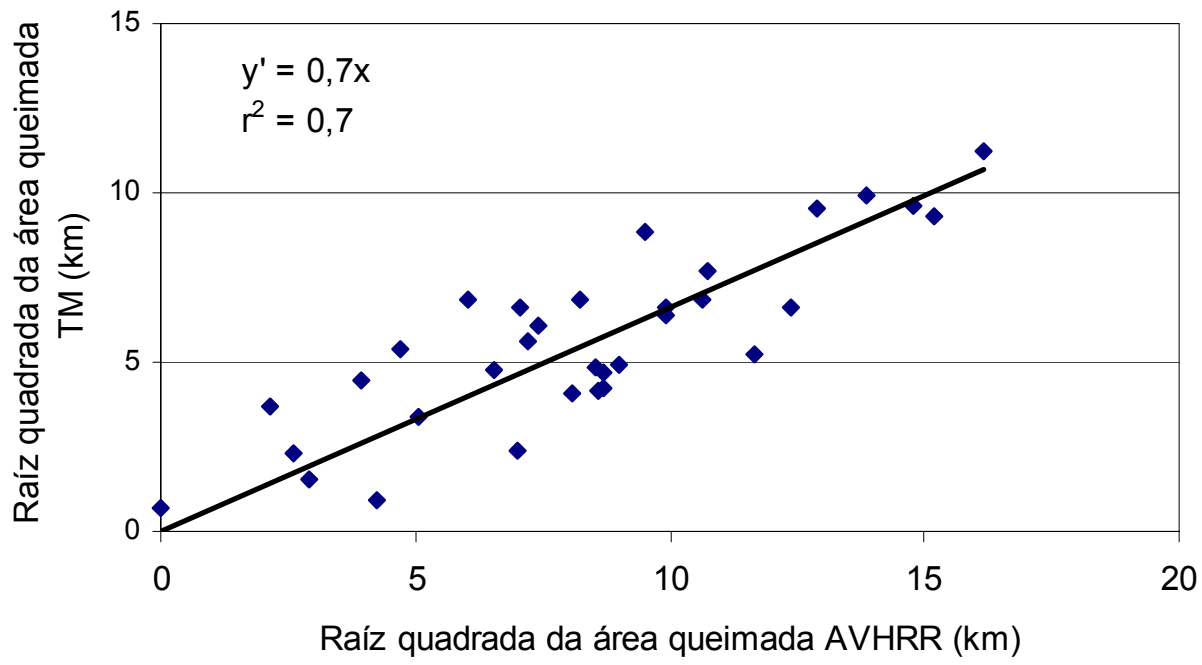

Figura 3.31 - Regressão linear com os dados transformados da área queimada nos mosaicos AVHRR $(\mathrm{km})$ e nas imagens TM $(\mathrm{km})$ na região da Bahia Cerrado 2. 
Em seguida, foram aplicados os testes de Bartlett e Kolmogorov-Smirnov para verificar se o modelo de regressão obtido atendia aos pressupostos relativos aos erros, ou seja, apresentarem variância constante e distribuição cumulativa normal.

$\mathrm{Na}$ aplicação do teste de Bartlett $(\alpha=0,05)$, na amostra 1 , correspondente a MT/GO, foram utilizados os seguintes valores:

$$
n_{T}=68, \quad r=4, \quad j=4, \quad n_{j}=17
$$

E, para a amostra 2, correspondente a BA,

$$
n_{T}=68, \quad r=3, \quad j=3, \quad n_{j}=11
$$

Calcularam-se, então, as seguintes estimativas de B:

$$
\begin{aligned}
& B_{1}=1,539568 \\
& B_{2}=1.564118
\end{aligned}
$$

Como em ambos os casos obteve-se $\mathrm{B} \leq \chi^{2}(1-\alpha ; \mathrm{r}-1)$, e aceitou-se a hipótese de que as variâncias no interior dos intervalos " $j "$ foram iguais entre si a 5\% de significância, ou seja, consideraram-se constantes as variâncias dos erros nas duas amostras analisadas.

O teste de Kolmogorov-Smirnov para uma amostra comparou a distribuição de freqüência acumulada dos EP com uma curva normal padrão. Obteve-se para as duas amostras $D_{t a b}>D_{o b s}$ - Tabela 3.23 - mostrando que a distribuição de freqüência acumulada dos erros para as duas amostras é uma normal padrão.

Tabela 3.23 - Resultados da aplicação do teste de Kolmogorov-Smirnov.

\begin{tabular}{c|c|c} 
& $\begin{array}{c}\text { Cerrado 1 } \\
\text { (MT e GO) }\end{array}$ & $\begin{array}{c}\text { Cerrado 2 } \\
\text { (BA) }\end{array}$ \\
\hline$D_{t a b}(5 \%)$ & 1,539568 & 0,236746 \\
$D_{o b s}$ & 0,673169 & 0,05908 \\
Resultado & $D_{t a b}>D_{o b s}$ & $D_{t a b}>D_{o b s}$
\end{tabular}


Foram então calculados os intervalos de confiança, cujos resultados estão apresentados nas Figuras 3.32 e 3.33.

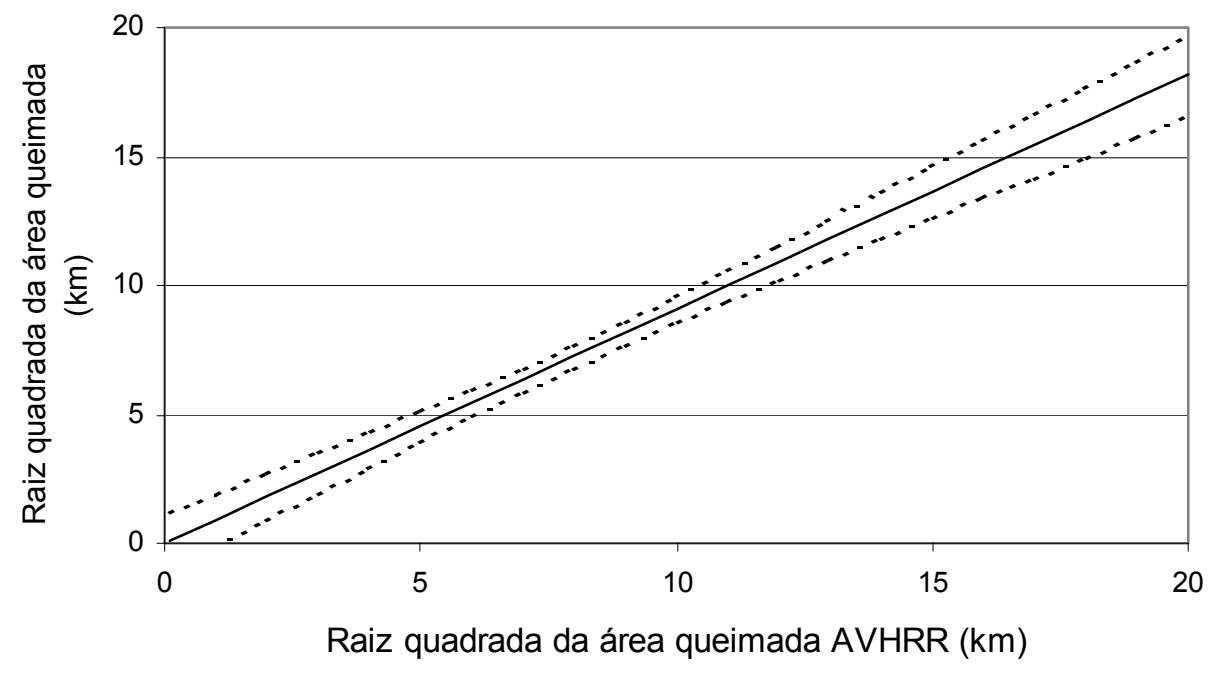

Figura 3.32 - Intervalo de confiança para os dados de regressão das regiões de Mato Grosso e Goiás - Cerrado 1.

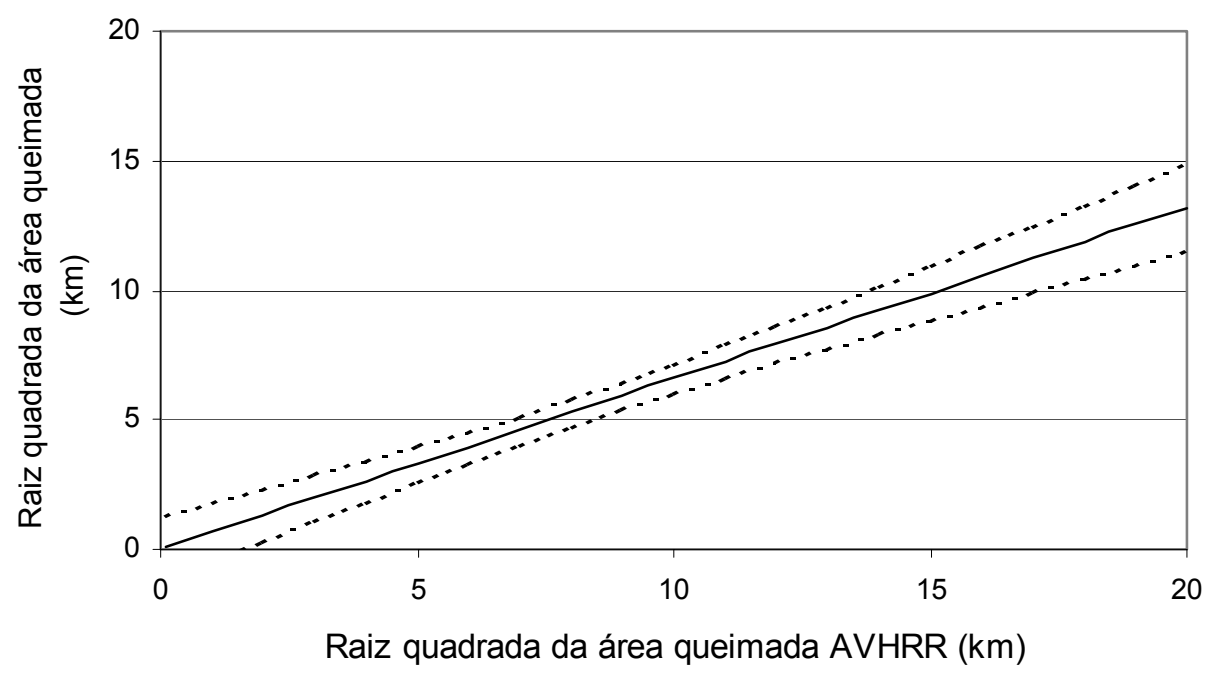

Figura 3.33 - Intervalo de confiança para os dados de regressão da Bahia - Cerrado 2. 
Finalmente, os dados foram elevados ao quadrado para retornar aos parâmetros originais de área, medida em $\mathrm{km}^{2}$; o mesmo foi feito em relação aos intervalos de confiança. Os resultado são mostrado nas Figuras 3.34 e 3.35.

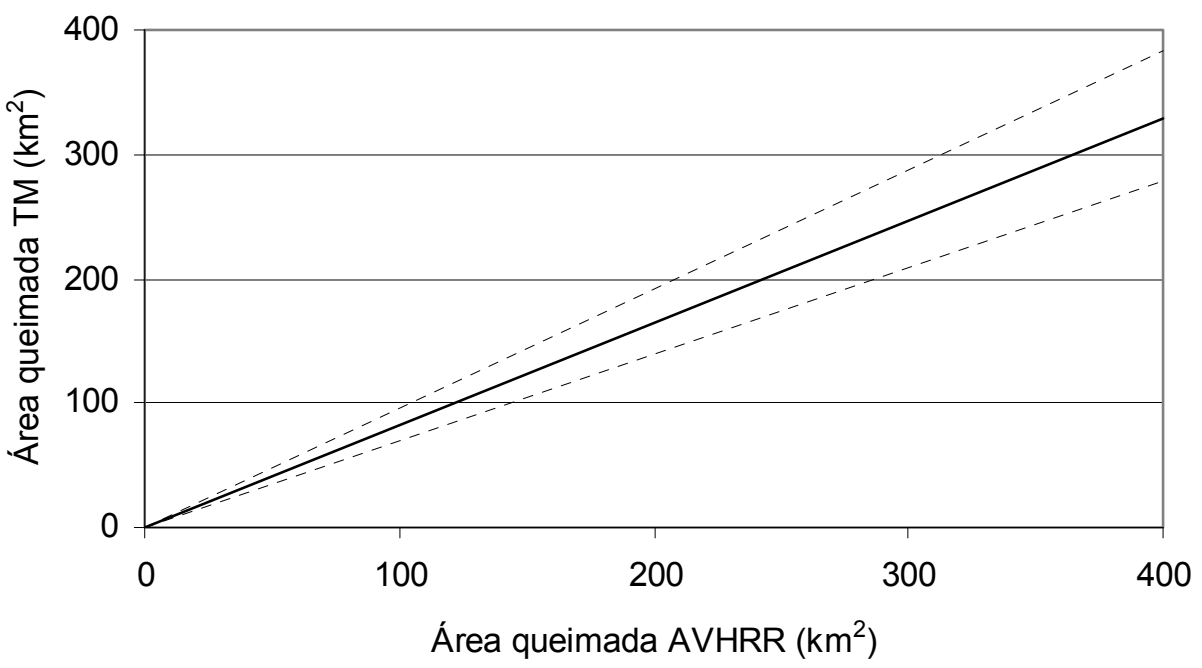

Figura 3.34 - Reta de regressão e intervalos de confiança para dados de área queimada do AVHRR e TM nas regiões de Mato Grosso e Goiás - Cerrado 1.

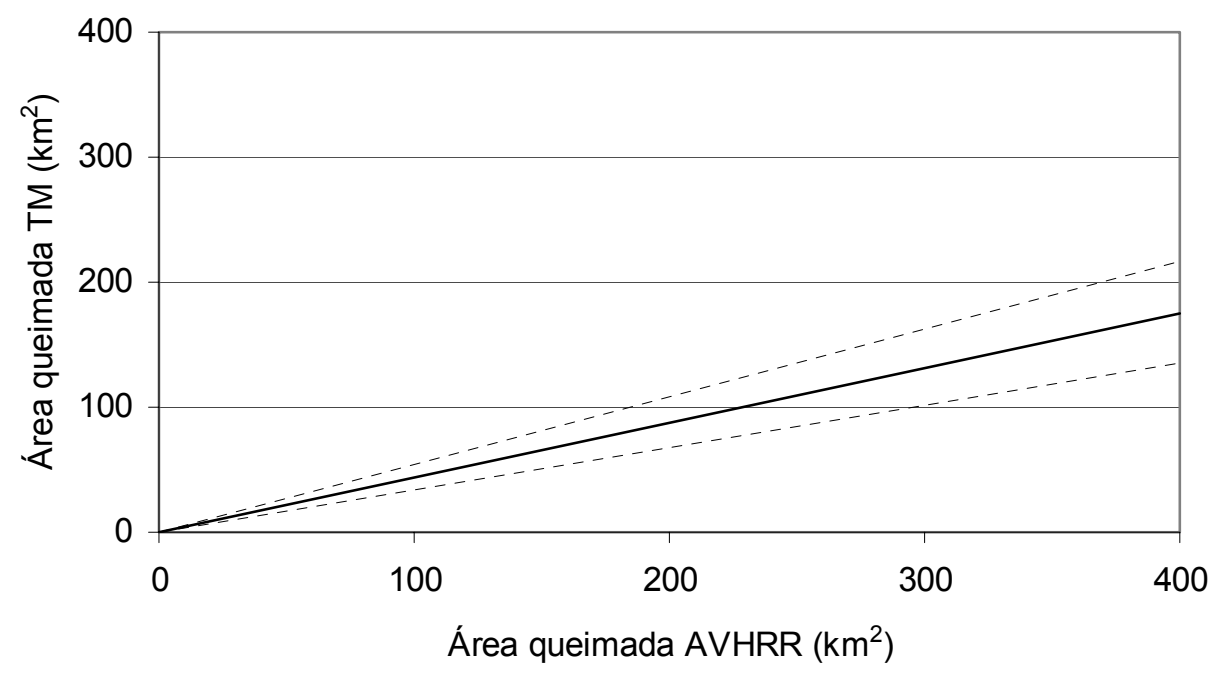

Figura 3.35 - Reta de regressão e intervalos de confiaça para dados de área queimada do AVHRR e TM na região da Bahia - Cerrado 2. 
As equações finais para obtenção dos intervalos de confiança foram:

$$
\begin{array}{ll}
Y_{h}^{\prime}=0,907 X_{h} \pm 2 \sqrt{3,34\left[\frac{1}{68}+\frac{\left(X_{h}-7,98\right)^{2}}{804,28}\right]} \quad \text { para Cerrado 1, e } \\
Y_{h}^{\prime}=0,660 X_{h} \pm 2,04 \sqrt{2,15\left[\frac{1}{34}+\frac{\left(X_{h}-8,32\right)^{2}}{490,87}\right]} \quad \text { para Cerrado 2. }
\end{array}
$$

\subsection{1 - Estimativas quinzenais de áreas queimadas no Cerrado}

A partir das equações obtidas na análise de regressão, foram estimadas para cada quinzena, os totais de área queimada nas áreas Cerrado 1 e Cerrado 2, no período de 15/maio/98 a 30/abril/99 — Tabela 3.24 — , conforme as equações 2.14 a 2.21 .

As áreas totais das regiões Cerrado 1 e 2 foram estimadas pelo SPRING em 1.764.000 $\mathrm{km}^{2}$ e $466.000 \mathrm{~km}^{2}$, respectivamente. A área total de Cerrado analisadas nesse trabalho foi, portanto, $2.230 .0000 \mathrm{~km}^{2}$.

Para construir um intervalo de confiança para a área total queimada $\left(Y_{\mathrm{t}}\right)$, ou seja, a soma $Y_{1}$ e $Y_{2}$, seria necessário conhecer a distribuição de $Y_{\mathrm{t}}$ que, no entanto, não é facilmente determinada (Yanasse, 1991). Mas, considera-se que $Y_{1}^{\prime}$ e $Y_{2}^{\prime}$ têm distribuição normal, pois supôs-se que o erro da regressão tinha distribuição normal com média zero e variância $\sigma^{2}$. Pode-se, então, através do método de Monte Carlo, simular dados com estas distribuições e calcular os limites de confiança dos dados transformados. Dessa forma, foram simulados 100 mil valores para $Y^{\prime}{ }_{1}$ e 100 mil valores para $Y_{2}$, para cada uma das quinzenas. Calculou-se então a média $\left(m Y_{t}\right)$ e os limites inferior e superior com 95\% de confiança - Tabela 3.25 .

Para estimar a área queimada de todo o período utilizou-se o resultado desta simulação e somou-se os valores para todas as quinzenas. A partir destes valores, calculou-se a média e os limites inferior e superior com $95 \%$ de confiança. A média calculada foi de $427.606 \mathrm{~km}^{2}$ com limites inferior e superior de $402.354 \mathrm{~km}^{2} \mathrm{e}$ $454.023 \mathrm{~km}^{2}$, respectivamente. No entanto, essa soma não incluiu a primeira quinzena de maio/ 88 . 
Tabela 3.24 - Estimativas quinzenais de $Y_{1}^{\prime}$ e $Y_{2}^{\prime}$ de todo o Cerrado no período de 15/maio/98 a 30/abril/99.

\begin{tabular}{|c|c|c|c|c|c|c|c|c|}
\hline Quinzena & $\begin{array}{c}A Q B_{1} \\
\left(\mathrm{~km}^{2}\right) \\
\end{array}$ & $\begin{array}{l}A Q B_{2} \\
\left(\mathrm{~km}^{2}\right) \\
\end{array}$ & $\begin{array}{c}A Q M_{1} \\
\left(\mathrm{~km}^{2}\right)\end{array}$ & $\begin{array}{c}A Q M_{2} \\
\left(\mathrm{~km}^{2}\right) \\
\end{array}$ & $\begin{array}{l}X^{\prime}{ }_{1} \\
(\mathrm{~km}) \\
\end{array}$ & $\begin{array}{l}X^{\prime}{ }_{2} \\
(\mathrm{~km})\end{array}$ & $\begin{array}{c}Y^{\prime}{ }_{1} \\
(\mathrm{~km}) \\
\end{array}$ & $\begin{array}{c}Y_{2}^{\prime} \\
(\mathrm{km})\end{array}$ \\
\hline Mai/98B & 1451 & 1714 & 8,24 & 36,47 & 2,87 & 6,04 & 2,60 & 3,98 \\
\hline Jun/98A & 2768 & 1496 & 15,73 & 31,83 & 3,97 & 5,64 & 3,60 & 3,72 \\
\hline Jun/98B & 3643 & 6819 & 20,70 & 145,09 & 4,55 & 12,05 & 4,13 & 7,95 \\
\hline $\mathrm{Jul} / 98 \mathrm{~A}$ & 6658 & 3445 & 37,83 & 73,30 & 6,15 & 8,56 & 5,58 & 5,65 \\
\hline $\mathrm{Jul} / 98 \mathrm{~B}$ & 27661 & 6819 & 157,16 & 145,09 & 12,54 & 12,05 & 11,37 & 7,95 \\
\hline Ago/98A & 24216 & 14257 & 137,59 & 303,34 & 11,73 & 17,42 & 10,64 & 11,49 \\
\hline Ago/98B & 119589 & 34918 & 679,48 & 742,94 & 26,07 & 27,26 & 23,64 & 17,98 \\
\hline Set/98A & 77498 & 39172 & 440,33 & 833,45 & 20,98 & 28,87 & 19,03 & 19,05 \\
\hline Set/98B & 53136 & 36803 & 301,91 & 783,04 & 17,38 & 27,98 & 15,76 & 18,46 \\
\hline Out/98A & 25854 & 24092 & 146,90 & 512,60 & 12,12 & 22,64 & 10,99 & 14,94 \\
\hline Out/98B & 15589 & 1156 & 88,57 & 24,60 & 9,41 & 4,96 & 8,54 & 3,27 \\
\hline Nov/98A & 5997 & 963 & 34,07 & 20,49 & 5,84 & 4,53 & 5,29 & 2,99 \\
\hline Nov/98B & 26960 & 1156 & 153,18 & 24,60 & 12,38 & 4,96 & 11,22 & 3,27 \\
\hline Dez/98A & 4682 & 2963 & 26,60 & 63,04 & 5,16 & 7,94 & 4,68 & 5,24 \\
\hline Dez/98B & 6224 & 144 & 35,36 & 3,06 & 5,95 & 1,75 & 5,39 & 1,15 \\
\hline Jan/99A & 1253 & 88 & 7,12 & 1,87 & 2,67 & 1,37 & 2,42 & 0,90 \\
\hline Jan/99B & 13240 & 1190 & 75,23 & 25,32 & 8,67 & 5,03 & 7,87 & 3,32 \\
\hline $\mathrm{Fev} / 99 \mathrm{~A}$ & 2777 & 151 & 15,78 & 3,21 & 3,97 & 1,79 & 3,60 & 1,18 \\
\hline Fev/99B & 2383 & 911 & 13,54 & 19,38 & 3,68 & 4,40 & 3,34 & 2,90 \\
\hline Mar/99A & 79 & 175 & 0,45 & 3,72 & 0,67 & 1,93 & 0,61 & 1,27 \\
\hline Mar/99B & 641 & 151 & 3,64 & 3,21 & 1,91 & 1,79 & 1,73 & 1,18 \\
\hline $\mathrm{Abr} / 99 \mathrm{~A}$ & 747 & 76 & 4,24 & 1,62 & 2,06 & 1,27 & 1,87 & 0,84 \\
\hline Abr/99B & 389 & 52 & 2,21 & 1,11 & 1,49 & 1,05 & 1,35 & 0,69 \\
\hline
\end{tabular}

Para estimar a área queimada no Cerrado na primeira quinzena de maio/98, foram utilizados os dados de focos de queimadas obtidos pelo sistema sensor AVHRR/NOAA-12, conforme equação 2.23 descrita no item 2.2.15, com os seguintes valores:

$$
F_{m_{a}}=461 \text { focos; } \quad F_{m_{b}}=715 \text { focos } \quad \text { e } A_{m_{b}}=1.969 \mathrm{~km}^{2}
$$

Obteve-se então, o seguinte valor de área queimada na primeira quinzena de maio/98:

$$
A_{m_{a}}=1.270 \mathrm{~km}^{2}
$$


Tabela 3.25 - Resultados da simulação de Monte Carlo para obtenção da área total quinzenal $\left(m Y_{t}\right)$.

\begin{tabular}{|c|c|c|c|c|c|c|c|c|c|c|}
\hline & $X^{\prime}{ }_{1}$ & $Y_{1}^{\prime}{ }_{1}$ & $v_{1}$ & $X_{2}^{\prime}$ & $Y_{2}^{\prime}$ & $\mathrm{V}_{2}$ & $m Y_{t}$ & $v Y_{t}$ & $\operatorname{Lim}_{\text {inf }}$ & im \\
\hline /98-B & 2,87 & 2,60 & 0,158 & 6,04 & 3,99 & 0,086 & 1969 & 144681 & 1296 & 2784 \\
\hline -A & 3,97 & 3,60 & 16 & 5,64 & 3,72 & 95 & 2958 & 9310 & 2136 & 3885 \\
\hline$-B$ & 4,55 & 4,13 & 98 & 2,05 & 7,95 & 124 & 595 & 77884 & 5003 & 7065 \\
\hline 3-A & 6,15 & 5,58 & 63 & 8,56 & 5,65 & 063 & 698 & 262451 & 6013 & 8027 \\
\hline $3-B$ &, 54 & 37 & 35 & 2,05 & 7,95 & 124 & 25773 & 240180 & 22909 & 28776 \\
\hline $8-A$ &, 73 & 64 & 108 & 17,42 & 11,50 & 426 & 26169 & 200 & 23445 & 29005 \\
\hline 98-B &, 07 & ,65 & 1,408 & 27,26 & 17,99 & 1,634 & 113943 & 102535000 & 94802 & 134507 \\
\hline 98-A &, 98 & 03 & 0,751 & 28,87 & 19,05 & 913 & 81016 & 832100 & 68967 & 93733 \\
\hline 98-B & , 38 & .76 & 0,416 & 27,98 & 18,47 & 756 & 59931 & 18126100 & 51805 & 68477 \\
\hline 98-A & 12,12 & 99 & 0,120 & 22,64 & 14,94 & 961 & 31830 & 810 & 28156 & 35706 \\
\hline & 9,41 & 8,53 & & 4,96 & 3,27 & 113 & 13 & & 11929 & 14795 \\
\hline & 5,84 & 5,30 & & 4,53 & 2,99 & & & & 4430 & 638 \\
\hline & 12,38 & 11,23 & & 4,96 & 3,27 & 3 & 22 & 00 & 19985 & 25573 \\
\hline & 16 & & & 7,94 & 5,24 & 064 & & & 4247 & 616 \\
\hline & 5,95 & 0 & & 1,75 & 16 & & & & 4278 & 62 \\
\hline & 2, & & & 1,37 & 90 & & & & 506 & 1881 \\
\hline & 7 & & & 5,03 & 32 & & 114 & & 10202 & 12692 \\
\hline & 3 & 3, & & 1,79 & 18 & & 2 & & 1580 & 3286 \\
\hline & 3,6 & 3, & & 4,4 & 2,90 & & 2386 & 184660 & 1606 & 3284 \\
\hline & 0,6 & & & 1,93 & 27 & & 20 & $6 / 2$ & 24 & 56 \\
\hline & 1, & & & 1,79 & 18 & & 64 & & 190 & 1294 \\
\hline & 2,0 & 1, & & 1,27 & 0,84 & 0 & 696 & 052 & 215 & 1366 \\
\hline 04/99-B & 1,49 & 1,35 & 0,22 & 1,05 & 0,69 & 0,295 & 397 & 11 & 57 & 95 \\
\hline & & & & & & & 606 & & & \\
\hline
\end{tabular}

Adicionou-se a à estimativa de área total queimada o valor calculado para a primeira quinzena de maio/98, ou seja, $1.270 \mathrm{~km}^{2}$. Esse valor foi somado à área total $\mathrm{e}$ aos limites do intervalo de confiança sob a forma de uma constante. Dessa forma, obteve-se a seguinte estimativa de área queimada (valores arredondados) para todo o Cerrado, no período 01/maio/98 a 30/abril/99: $429.000 \mathrm{~km}^{2}$, com limite inferior e superior de $404.000 \mathrm{~km}^{2}$ e $455.000 \mathrm{~km}^{2}$, respectivamente, correspondendo a $19 \% \mathrm{da}$ área de estudo (entre 18 e $20 \%$ ).

A Figura 3.36 mostra a variação temporal da área queimada no Cerrado. Notouse que os maiores valores concentraram-se nos meses de agosto e setembro, coincidindo com a elevação do número de focos de queimada obtidos pelo satélite NOAA-12, conforme Figura 1.1. A distribuição cumulativa das área queimadas — Figura 3.37 mostra o rápido crescimento das áreas queimadas no Cerrado nesse período. 
Conforme discutido anteriormente, na segunda quinzena de novembro/98, as queimadas foram super-estimadas pelo algoritmo por causa de reflexos em solo da banda 3 no sul de Goiás e norte de São Paulo, principalmente. Decidiu-se então, reclassificar essas áreas para solo, conforme interpretação visual da imagem. Dessa forma, a estimativa bruta de área queimada na segunda quinzena de novembro/98 foi $18.925,5 \mathrm{~km}^{2}$ no Cerrado 1. Refazendo-se os cálculos pelas equações de regressão, obteve-se a estimativa de $15.300 \mathrm{~km}^{2}$ queimados, ao invés do valor inicial de $22.700 \mathrm{~km}^{2}$. Essa foi, no entanto, a única quinzena em que os reflexos em solo provocaram discrepâncias grandes nos dados relativos ao Cerrado 1. Espera-se que os reflexos no solo, na região Nordeste, comumente confundidos com queimadas pelo algoritmo, não tenham provocado super-estimativa de área queimada na avaliação final, isto porque a reta de regressão obtida foi feita a partir de mosaico onde esse problema existiu e, portanto, deve ter sido compensado na comparação com os dados TM. Pereira (1992) obteve estimativa de $196.000 \mathrm{~km}^{2}$ de área queimada no Cerrado no período 08/junho a 12/setembro de 1988. Esse valor foi calculado por regressão dos dados de focos de queimadas de imagens AVHRR/NOAA-11, passagens vespertinas, com área queimada obtida de imagens TM (órbita ponto 223/69), abrangendo parte dos estados de Goiás, Tocantins e Mato Grosso. Para efeito de comparação entre os resultados, foram somadas as áreas queimadas obtidas dos mosaicos AVHRR no período de 01/junho a 14/setembro de 1998 ( $1^{\text {a }}$ quinzena de junho a $1^{\text {a }}$ quinzena de setembro de 1998) - Tab. 3.23 - e obteve-se o valor de $263.000 \mathrm{~km}^{2}$. Este valor é cerca de $34 \%$ superior àquele obtido por Pereira (1992). Esses dados no entanto, não podem ser comparados diretamente, pois apesar da área de estudo ser equivalente, há uma defazagem de dez anos entre eles.

Outras estimativas de áreas queimadas com base em imagens de baixa resolução não puderam ser comparadas com os resultados obtidos neste trabalho, pois não foram feitas especificamente para o Cerrado (Eva, 2000; Barbosa et al.; 1999; Pereira, 1999) 


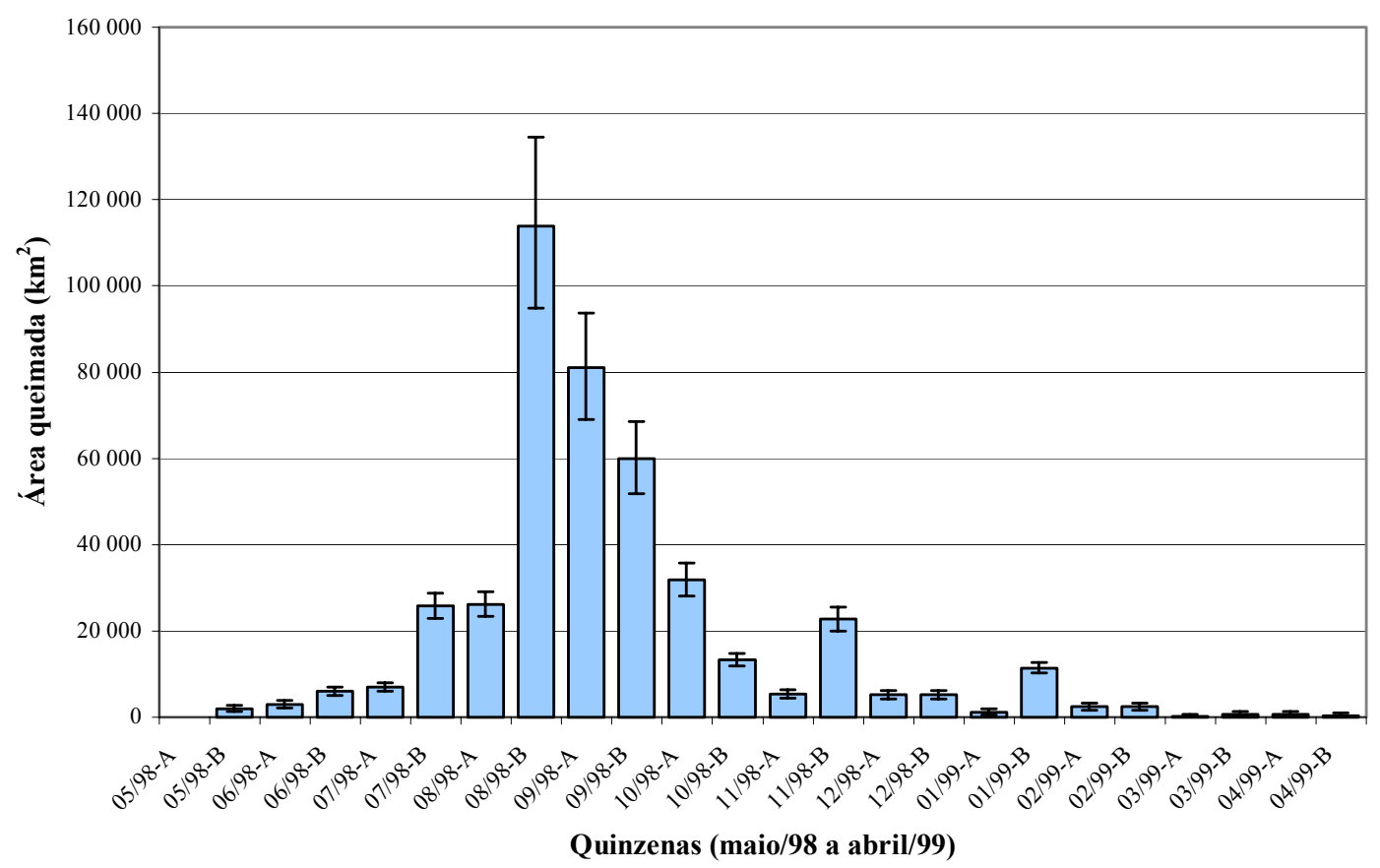

Figura 3.36 - Área queimada quinzenalmente no Cerrado no período de maio/98 a abril/99 estimada com os mosaicos AVHRR/NOAA-14.

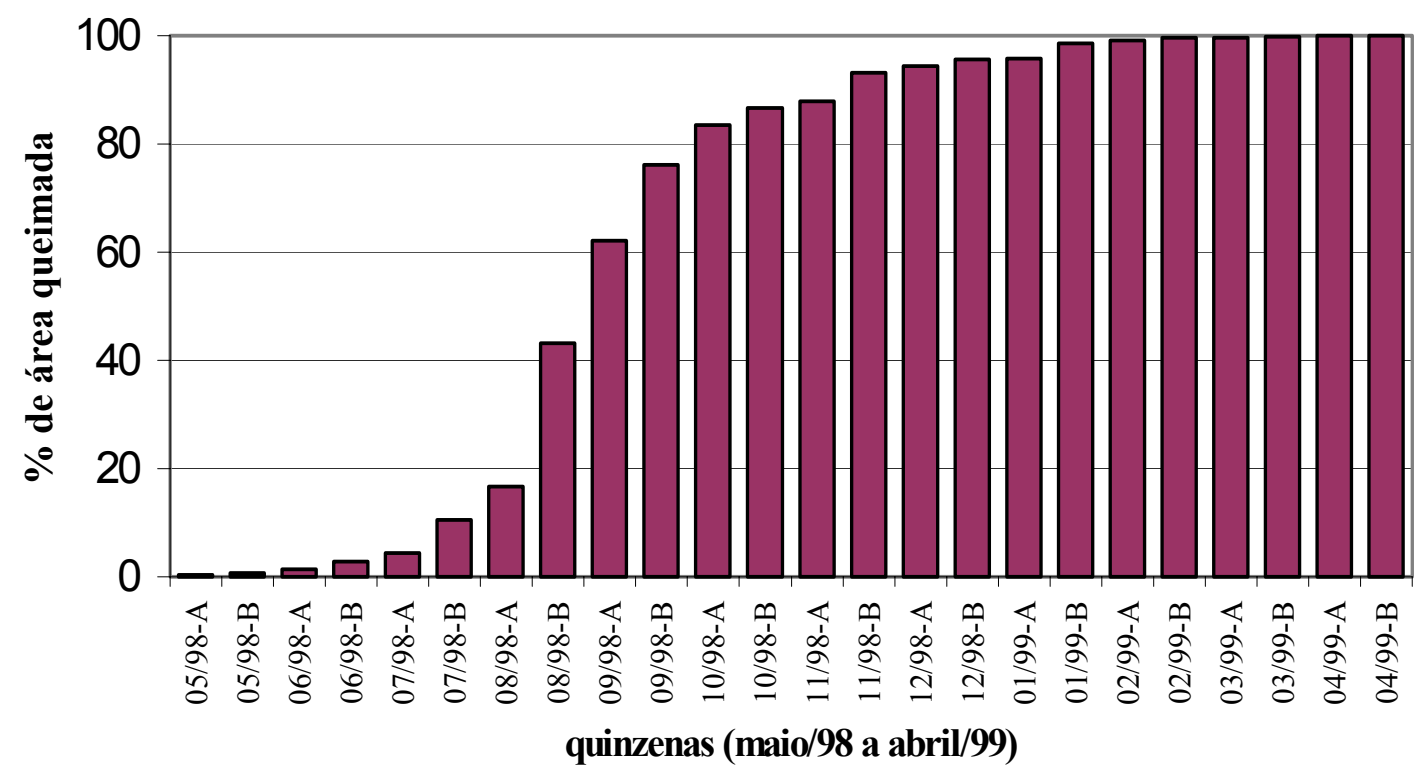

Figura 3.37 - Freqüência acumulada relativa da área queimada no Cerrado nas quinzenas do período de maio/98 a abril/99. 


\subsection{2 - Relação das estimativas de áreas queimadas obtidas nos mosaicos com focos de queimada do AVHRR-NOAA-12}

As grades numéricas contendo a soma dos focos de queimadas ativas detectados pelo AVHRR/NOAA-12 em períodos de 07 dias (ou menos, no caso do último período de cada mês) foram somadas entre si, de forma a coincidir exatamente com os períodos dos mosaicos AVHRR. As grades resultantes foram transferidas para o SPRING. Calculou-se a soma do número de focos de queimada ocorridos quinzenalmente no Cerrado no período de 01/ago/98 a 31/dez/98 - Tabela 3.26. Esses dados foram colocados na forma gráfica, adotando-se um modelo linear de regressão - Figura 3.38. O resultado indica forte relação entre os dados, porém o número de observações no período de maior ocorrência de queimadas ainda é insuficiente para uma análise estatística rigorosa. A equação da reta obtida, com $\mathrm{r}^{2}=0,93$ foi:

$$
Y=8,3 X+2810, \quad \text { onde }
$$

$Y=$ Estimativa de área queimada quinzenalmente no Cerrado calculada, pelos mosaicos AVHRR/NOAA-14.

$X=$ Número de focos de queimadas ativas, detectados quinzenalmente pelo AVHRR/NOAA-12.

Tabela 3.26 - Número de focos de queimada ativa detectados pelo AVHRR/NOAA-12 no Cerrado e área queimada estimada nos mosaicos AVHRR/NOAA-14.

\begin{tabular}{c|c|c}
$\begin{array}{c}\text { Mês_quinzena } \\
98\end{array}$ & $\begin{array}{c}\mathrm{N}^{\mathrm{o}} \text { focos de queimada } \\
\text { AVHRR/NOAA-12 }\end{array}$ & $\begin{array}{c}\text { Área queimada }\left(\mathrm{km}^{2}\right) \\
\text { AVHRR/NOAA-14 }\end{array}$ \\
\hline Ago_a & 2.435 & 26.100 \\
Ago_b & 11.617 & 113.500 \\
Set_a & 9.609 & 80.800 \\
Set-b & 8.217 & 60.700 \\
Out_a & 4.911 & 31.700 \\
Out-b & 2.565 & 13.300 \\
Nov_a & 423 & 5.400 \\
Nov_b & 488 & 22.700 \\
Dez_a & 240 & 5.100 \\
Dez_b & 127 & 5.200 \\
\hline
\end{tabular}




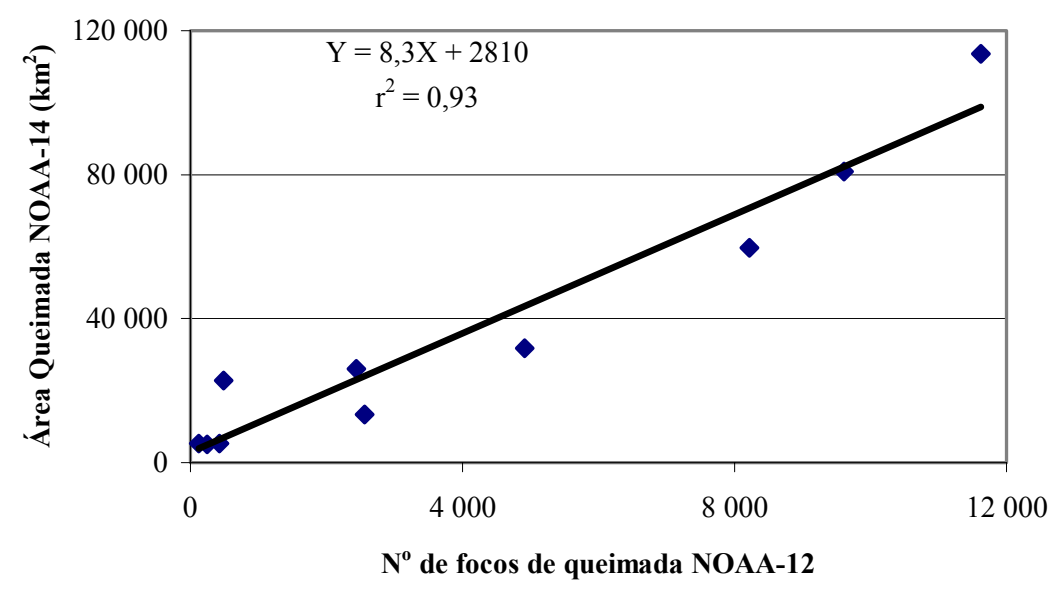

Figura 3.38 - Modelo linear de regressão entre focos de queimadas detectados pelo AVHRR/NOAA-12 e área queimada estimada nos mosaicos AVHRR/NOAA-14.

As considerações feitas a seguir supõem a existência de quantidade de observações adequadas, erros com variância constante e distribuição cumulativa normal, condições para que o modelo linear de regressão seja considerado adequado (Netter e Wasserman, 1974).

A partir do número de focos quinzenais do NOAA-12, detectados no período maio/99 a outubro/00, estimou-se a área queimada no Cerrado, conforme Tabela $3.27 \mathrm{e}$ Figura 3.39. Ressalta-se novamente, que esses resultados não puderam ser calculados com o rigor estatístico adequado pelos motivos expostos acima e, portanto, só podem ser interpretados como valores indicativos preliminares.

A soma dos dados de área queimada no período janeiro a dezembro/99 Tabelas 3.24 e 3.26 - é $470.000 \mathrm{~km}^{2}$, cerca de $21 \%$ do bioma. As três estimativas de área queimada no Cerrado, no mesmo período, apresentado por PNUD (2000), conforme apresentado no item 1.2 foram as seguintes: $315.545 \mathrm{~km}^{2}, 187.224 \mathrm{~km}^{2} \mathrm{e}$ $119.865 \mathrm{~km}^{2}$. Porém, indicou-se a segunda como a mais confiável. Não se pode, porém, comparar os dois resultados, pois:

a) os dados apresentados aqui, a partir de maio/99, são preliminares, já que não decorreram de análise estatística rigorosa conforme discutido anteriormente.

b) Não está indicada no trabalho de PNUD (2000), qual foi a área total de Cerrado analisada. 
Tabela 3.27 - Estimativa preliminar de área queimada no Cerrado a partir do número de focos de queimada detectados pelo AVHRR/NOAA-12.

\begin{tabular}{|c|c|c|}
\hline $\begin{array}{l}\text { Mês/Ano } \\
\text { Quinzena }\end{array}$ & $\begin{array}{c}\mathrm{N}^{\circ} \text { focos de } \\
\text { queimada } \\
\text { AVHRR/NOAA-12 }\end{array}$ & $\begin{array}{c}\text { Área queimada } \\
\left(\mathrm{km}^{2}\right)\end{array}$ \\
\hline Maio99a & 263 & 5000 \\
\hline Maio99b & 623 & 8000 \\
\hline Junho99a & 646 & 8000 \\
\hline Junho99b & 1065 & 12000 \\
\hline Julho99a & 1079 & 12000 \\
\hline Julho99b & 3087 & 28000 \\
\hline Ago99a & 4286 & 38000 \\
\hline Ago99b & 10300 & 88000 \\
\hline Set99a & 8426 & 73000 \\
\hline Set99b & 7879 & 68000 \\
\hline Out99a & 6239 & 54000 \\
\hline Out99b & 2885 & 27000 \\
\hline Nov99a & 653 & 8000 \\
\hline Nov99b & 1246 & 13000 \\
\hline Dez99a & 156 & 4000 \\
\hline Dez99b & 315 & 5000 \\
\hline Jan00a & 183 & 4000 \\
\hline Jan00b & 228 & 5000 \\
\hline Fev00a & 117 & 4000 \\
\hline Fev00b & 238 & 5000 \\
\hline Mar00a & 77 & 3000 \\
\hline Mar00b & 58 & 3000 \\
\hline Abr00a & 158 & 4000 \\
\hline Abr00b & 111 & 4000 \\
\hline Maio00a & 267 & 5000 \\
\hline Maio00b & 658 & 8000 \\
\hline Jun00a & 939 & 11000 \\
\hline Jun00b & 1694 & 17000 \\
\hline Jul00a & 951 & 11000 \\
\hline Jul00b & 1840 & 18000 \\
\hline Ago00a & 1259 & 13000 \\
\hline Ago00b & 6306 & 55000 \\
\hline Set00a & 3486 & 32000 \\
\hline Set00b & 6784 & 59000 \\
\hline Out00a & 4649 & 41000 \\
\hline Out00b & 3491 & 32000 \\
\hline
\end{tabular}




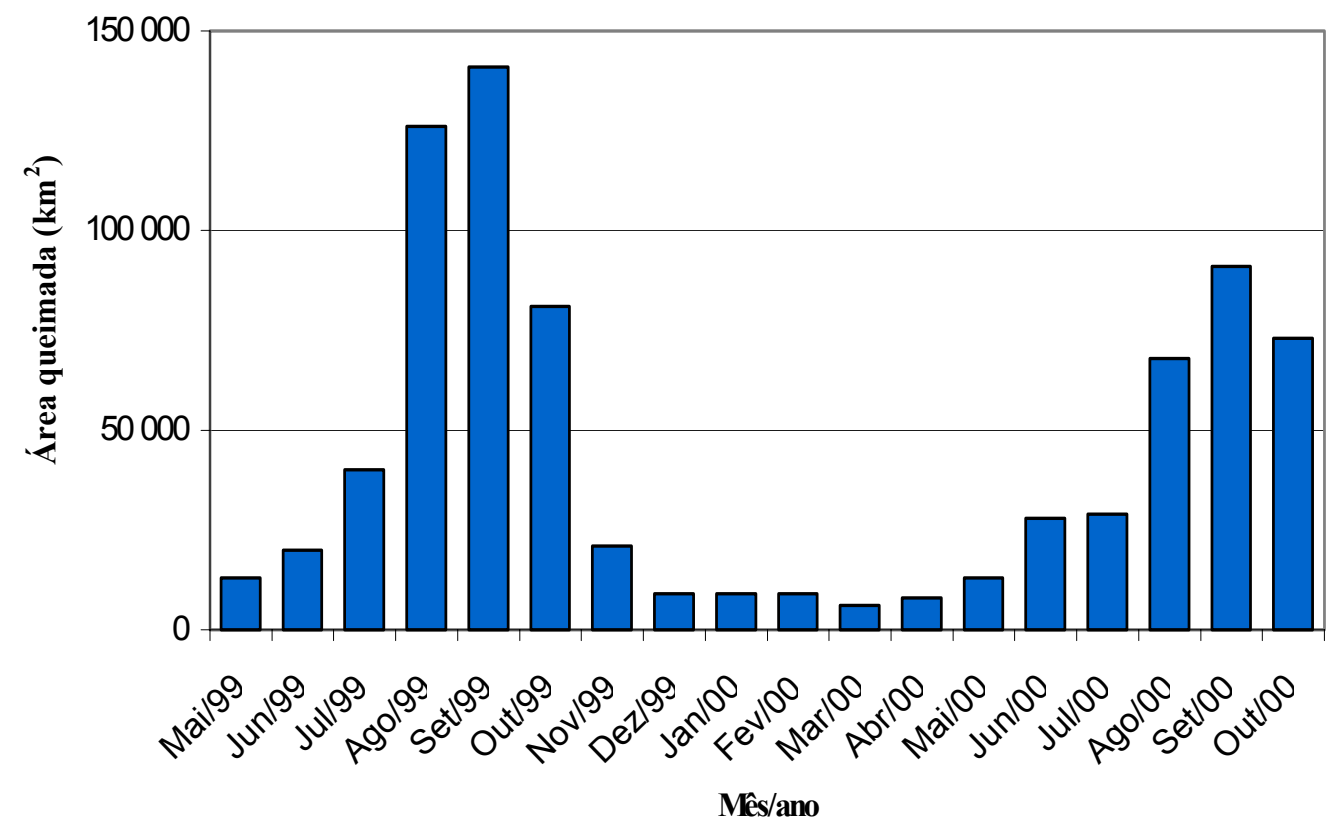

Figura 3.39 - Estimativas preliminares de área queimada no Cerrado no período maio/99 a outubro/00, obtidas dos dados AVHRR/NOAA-12. 


\section{4 - CONCLUSÕES}

\section{1 - Conclusões gerais}

Neste trabalho, o principal objetivo foi desenvolver uma metodologia para estimar quinzenalmente a superfície queimada no Cerrado utilizando imagens diárias do sensor AVHRR/NOAA, bandas 1 (0,58-0,68 $\mu \mathrm{m}), 2(0,725-1,0 \mu \mathrm{m}), 3(3,55-3,93 \mu \mathrm{m}) \mathrm{e}$ IVDN, e validá-la com dados TM/Landsat.

Acredita-se que este objetivo foi plenamente atingido, pois o algoritmo foi desenvolvido, podendo estimar a área queimada no Cerrado dentro de limites inferiores a $15 \%$ de erro e identificar $94 \%$ da área queimada. A aplicação da metodologia desenvolvida resultou em estimativas quinzenais de área queimada no Cerrado, no período de um ano (01/maio/98 a 30/abril/99). Obteve-se também uma equação relacionando a quantidade de focos de queimadas ativas no Cerrado obtida das imagens da banda 3 do AVHRR/NOAA-12, com a área queimada estimada pela metodologia desenvolvida nesse trabalho. Dessa forma, foi possível obter valores quinzenais preliminares de área queimada no período 01/maio/99 a 31/outubro/2000.

\section{2 - Conclusões específicas}

Quanto às características espectrais das cicatrizes das queimadas e da vegetação do Cerrado, observou-se que:

- os dados da banda 3 são os mais apropriados para a identificação de cicatrizes de queimadas, pois uma área recém-queimada sempre apresenta valores acentuadamente menores do que aqueles que antecederam a queimada; essa diminuição de valores, que resulta do aumento da temperatura da superfície em decorrência da remoção da cobertura vegetal pela ação do fogo, é claramente detectada nas imagens da banda 3 .

- reflexos em solos observados na banda 3 do AVHRR/NOAA-14, passíveis de classificação equivocada como queimada, só ocorreram em áreas 
agrícolas de cultivos anuais; nos demais casos, foi possível "filtrá-los" de forma automática.

- o IVDN não é um bom indicador de marcas de queimadas no Cerrado, pois apresenta valores baixos não só em áreas queimadas, mas também naquelas que não queimaram. Baixos valores de IVDN durante a estação seca, possivelmente se relacionam à senescência e queda de folhas.

- O IVDN é um bom indicador de áreas com cultivos agrícolas anuais, particularmente de soja, pois durante o período úmido, elas se apresentam com valores muito elevados desse índice.

- O IVDN pode ser utilizado para identificar corpos d'água que eventualmente causam reflexos na banda 3 , pois eles apresentam baixos valores desse índice ao longo de todo o ano; no entanto, não é um bom indicador de reflexos nas superfícies que alagam sazonalmente, como o Pantanal do Mato Grosso.

Quanto à caracterização da quantidade e dimensões das queimadas no Cerrado, a interpretação visual de 03 pares de imagens de alta resolução espacial (TM/Landsat), indicou que:

- mais de 50\% das queimadas que ocorrem no Cerrado, durante o período seco, são pequenas - menores que $0,5 \mathrm{~km}^{2}$ - e representam apenas $\sim 2,5 \%$ da área total queimada;

- queimadas grandes — maiores que $10 \mathrm{~km}^{2}$ — são pouco freqüentes, respondendo por cerca de $08 \%$ do número total de queimadas, mas são responsáveis por $\sim 74 \%$ da área queimada;

- entre 04 e $08 \%$ (média de 06\%) da superfície do Cerrado foi queimada num intervalo de apenas 16 dias durante a estação seca (agosto e setembro). 
Quanto aos resultados da aplicação do algoritmo de identificação de queimadas em mosaicos AVHRR e da análise de regressão com os dados TM:

- o algoritmo identificou 94\% da área queimada estimada pelo TM;

- o algoritmo AVHRR omitiu grande quantidade de queimadas, e destas, a maioria $(66 \%)$ correspondeu a queimadas pequenas, menores que $0,5 \mathrm{~km}^{2}$, mas o total de área omitida pelo algoritmo, no entanto, representou menos de $05 \%$ da área total queimada;

- os modelos de regressão linear utilizados resultaram em retas estatisticamente adequadas, e, portanto, puderam ser aplicados para estimar quinzenalmente a área queimada no Cerrado a partir de mosaicos quinzenais AVHRR.

Quanto aos dados de focos de queimadas obtidos pelo AVHRR/NOAA-12:

- a regressão entre os dados de focos de queimadas do AVHRR/NOAA-12 e a área queimada estimada nos mosaicos do AVHRR/NOAA-14 mostrou forte relação entre as duas variáveis, indicando a viabilidade de estimar área queimada no Cerrado a partir de números de focos ativos de fogo; no entanto, a quantidade de dados analisados neste trabalho foi insuficiente para análise estatística conclusiva.

Quanto às estimativas de área queimadas no Cerrado:

- a aplicação do modelo de regressão linear para todo o Cerrado forneceu estimativas quinzenais de áreas queimadas; a extensão das queimadas foi estimada em $429.000 \mathrm{~km}^{2}$ — de $404.000 \mathrm{~km}^{2}$ a $455.000 \mathrm{~km}^{2}$, com intervalo de confiança a $95 \%$ - no período de $01 /$ maio/98 a 30/abril/99, indicando que $\sim 19 \%$ da área do bioma queimou — com intervalos de confiança entre $18 \%$ e $20 \%$. 
As limitações constatadas para estimar área queimada em mosaicos AVHRR foram:

- existência de reflexos em solos e água nos dados da banda 3 que podem ser confundidos com queimadas;

- a resolução espacial grosseira que omite queimadas pequenas;

- a dificuldade de navegação das imagens que resultou em gasto de tempo excessivo para geração dos mosaicos AVHRR.

\section{3 - Recomendações e trabalhos futuros}

No sentido de dar continuidade ao trabalho aqui realizado, recomenda-se:

- aperfeiçoar e implantar um sistema operacional de monitoramento de áreas queimadas no Cerrado, disponibilizando os dados, através da Internet.

- aprofundar a análise da relação entre focos de queimada e área queimada, pois dela provavelmente resultará um método rápido e de baixo custo para avaliar a extensão das queimadas no Cerrado;

- fazer validações regulares dos dados com imagens de alta resolução e eventuais ajustes no algoritmo e nos modelos lineares de regressão obtidos;

- utilizar os produtos gerados pelo algoritmo nesse trabalho para análises de distribuição temporal e espacial das queimadas, indicando os locais e épocas com maior incidência de queimadas, bem como e apontar aquelas em que elas são menos freqüentes;

- cruzar, através de SIGs, as informações de localização e extensão de queimadas com mapas de vegetação, solos, geologia, atividades agropastoris, rios, estradas, cidades, etc.; a análise conjunta desses dados poderá auxiliar na compreensão do uso do fogo no Cerrado e, dessa forma, ser útil em planejamentos ambientais regionais, em estudos de ecologia, na adoção de planos de manejos e fiscalização do uso do fogo no Cerrado e também para estimar emissões resultantes de queima de vegetaçào no Cerrado. 
- direcionar pesquisas futuras para utilização dos dados do sensor MODIS (Moderate Resolution Imaging Spectroradiometer), a borda da plataforma Terra, pois eles fornecerão dados mais precisos e adequados para o monitoramento global e regular de queimadas. Esse sensor, em fase inicial de operação, tem bandas espectrais projetadas para a identificação de queimadas ativas, gerando imagens com 250 a $1.000 \mathrm{~m}$ de resolução espacial e freqüência temporal entre 01 e 03 dias, ou seja, possui características adequadas para o monitoramento preciso da extensão e localização das queimadas em nível global (NASA, 2000). 


\section{5 - REFERÊNCIAS BIBLIOGRÁFICAS}

Andreae, M.O. (1991). Biomass burning: its hitory, use, and distribution and its impact on environmental quality and global climate. In: Levine, J.S. (ed.). Global biomass burning: atmospheric, climatic, and biospheric implications. Cambridge/London, MIT Press, Cap. 1, pp. 3-21.

Andreae, M.O.; Chapius, A.; Cros, B.; Fontan, J,; Helas, G.; Justice, C.; Kaufman, Y.J.; Minga, A.; Nganga, D. (1992). Ozone and Aitken nuclei over Equatorial Africa: airbone observations during DECAFE 88. J. Geoph. Res. 97:6137-6148.

Andreae, M.O; Atlas, E.; Cachier, H.; Cofer, W.R.; Harris, G.W.; Helas, G.; Koppmann, R.; Lacaux, J.P.; Ward, D.E. (1996). Trace gas and aerosol emissions from savanna fires. In: Levine, J.S. (ed.). Biomass burning and global change. Cambridge, The MIT Press, Cap. 27, pp.278-295.

Aragão, L.T. (1990). Ocupação humana no cerrado de Brasília. In: Pinto, M.N.(org). Cerrado: caracterização, ocupação e perspectivas. Brasília, Ed. Univ. Brasília, Cap. 3, p. 163-180.

Arino, O; Piccolini, I.; Siegert, F.; Eva, H; Chuvieco, E.; Martin, P.; Li, Z.; Fraser, R.H.; Kasischke, E.; Roy, D.; Pereira, J.; Stroppiana, D. (2000). Burn scars mapping methods. In: Ahern F.; Grégorie, J.M.; Justice, C. Forest fire monitoring and mapping: a component of global observation of forest cover. European Commission Joint Research Centre, 256 p.

Artaxo, P.; Fernandes, E.T.; Martins, J.V.; Yamasoe, M.A.; Longo, K.M.; Hobbs, P.; Maenhaut, W. (1996a). Large scale elemental composition of atmospheric aerosols measured during SCAR-B. In: Kirchhoff, V.W.J.H. (ed.) Scar-B Proceedings. São José dos Campos, Transtec Editorial, p.9-14.

Artaxo, P.; Gerab, F.; Yamasoe, M.A.; Martins, J.V.; Longo, K.M.; Echalar, F. (1996b). Long term measurements of aerosol composition at three monitoring sites in the Amazon basin. In: Kirchhoff, V.W.J.H. (ed.) Scar-B Proceedings. São José dos Campos, Transtec Editorial, p.15-26.

Azevedo, L.G.; Adámoli, J. (1988). Avaliação agroecológica dos recursos naturais da região dos Cerrados. In: Marchetti; Machado. VI Simpósio sobre o Cerrado: uso e manejo. Brasília, Editerra, pp. 729-761.

Barbosa, P.M.; Grégoire, J.M.; Pereira, J.M.C. (1999) An algorithm for extracting burned areas from time series of AVHRR GAC data applied at a continental scale.

Remote Sensing of Environmental, 65:253-263.

Bruneau, M.; Toan, L.T. (1978) An interpretation of northern Thailand swiddening and multiple cropping systems using multidate Landsat images and computer campatible tapes. In: International Symposium on Remote sensing of Environment, 12. Ann Arbor, 20-26 April. Ann Arbor, ERIM, V.3, p. 1833-89.

Caetano, M.; Mertes, L.; Cadete, L.; Pereira, J. (1996) Assessment of AVHRR data for characterizing burned areas and post-fire vegetation recovery. EARsel Advances in Remote Sensing, 4(4):124-134. 
Chateerjee, S.; Price, B. (1977). Regression analysis by example. New York, Wiley $\&$ Sons, 228 p.

Chen, S.C.; Shimabukuro, Y.E.; Hernandez Filho, P. (1979) .The mapping of burned area in forest by IMAGE-100 system. São José dos Campos, INPE, 9p. (INPE 1431-RPE/009).

Chuvieco, E.; Congalton, R.G. (1988). Mapping and inventory of forest fires from digital processing of TM data. Geocarto International, 3(4):41-53.

Cochrane, T.T.; Porras, J.A.; Henão, M. (1988). Avaliação agroecológica dos recursos naturais da região dos Cerrados. In: Marchetti; Machado. VI Simpósio sobre o Cerrado: uso e manejo. Brasília, Editerra, pp. 229-242.

Coutinho, L.M. (1990a). Fire in the ecology of the Brazilian cerrado. In: Goldammer, J.G., ed. Fire in the tropical biota. New York, Springer-Verlag, Cap. 6, p. 82105. (Ecological Studies, 84).

Coutinho, L.M. (1990b). O cerrado e a ecologia do fogo. Ciência Hoje, 12(68):22-30.

CPTEC. (2000). < http://www.cptec.inpe.br/products/queimadas/queimap.html $>$. Acesso em out $/ 2000$.

Crutzen, P.J.; Andreae, M.O. (1990). Biomass burning in the tropics: impact on atmospheric chemistry and biogeochemical cycles. Science, 250, 1669-1678.

Deshler, W. (1974). An examination of the extent of fire in the grassland and savanna of Africa along the southern side of the Saara. In: International Symposium on Remote sensing of Environment, 9. Ann Arbor, 15-19 April , Ann Arbor, ERIM, V.1, p. 22-30.

Dias, B.F.S. (1990). A conservação da natureza. In: Pinto, M.N.(org) Cerrado: caracterização, ocupação e perspectivas. Brasília, Ed. Univ. Brasília, Cap. 21, p. 583-640.

Dias, B.F.S. (1996). Cerrados: uma caracterização. In: FUNATURA. Alternativas de desenvolvimento dos cerrados: manejo e conservação dos recursos naturais renováveis. Brasília, IBAMA. pp. 11-25.

DOLA (2000) < www.dola.wa.gov.au/home.nsf/(FrameNames)/Satellite+Images>, consulta em 10/2000.

Dozier, J. (1981). A method for satellite identification of surface temperature fields of subpixel resolution. Remote Sensing of Environment, 11:221-229.

DPI - Divisão de Processamento de Imagens do INPE (2000) $<$ www.dpi.inpe.br/spring/portugues/material.html>. Consulta feita em 07/2000.

DPI - Divisão de Processamento de Imagens do INPE. (1999). $<$ www.dpi.inpe.br/spring/>

Dwyer, E; Grégoire, J.M.; Malingreau, J.P. (1998). A global analysis of vegetation fires using satellites images: spatial and temporal dynamics. Ambio, 27(3): 175181.

Eck, T.F.; Holben, B.N.; Slutsker, I.; Setzer, A. (1998). Measurements of irradiance attenuation and estimation of aerosol single scattering albedo for biomass burning 
aerosols in Amazonia. Journal of Geophysical Research, 103 (D24): 31.86531878. (special section).

ESA - European Space Agency - (2000) http://shark1.esrin.esa.it/ionia/FIRE/BS/ATSR/

Eva, H. (2000) Monitoring of tropical fires and treir impact on land cover using remote sensing techniques. Dissertation doctorale, Universite Catholique de Louvain-Département de Géologie et de Géographie, $145 \mathrm{p}$.

Eva, H.; Lambin, E.F. (1998). Remote sensing of biomass burnig in tropical regions: sampling issues and multisensor approach. Remote Sensing of Environment, 64: 292:315.

Fernandez, A.; Illera, P.; Casanova, J.L. (1997). Automatic mapping of surfaces affected by forest fires in Spain using AVHRR NDVI composite image data. Remote Sensing of Environment, 60: 153-162.

Filgueiras, T.S.; Wechsler. (1996). Aproveitamento e manejo. In: FUNATURA. Alternativas de desenvolvimento dos cerrados: manejo e conservação dos recursos naturais renováveis. Brasília, IBAMA. pp. 47-49.

França, H. (1994). Um estudo fenológico com imagens AVHRR/NOAA nos cerrados do Parque Nacional das Emas, GO. (Dissertação de mestrado em Sensoriamento Remoto) - Instituto Nacional de Pesquisas Espaciais, São José dos Campos, 96 p. (INPE-6120-TDI/581

França, H.; Setzer, A. A história do fogo no Parque das Emas. (1999). Ciência Hoje 26(153): 69-73.

França, H.; Setzer, A.W. (1998). AVHRR temporal analysis of a savanna site in Brazil. International Journal of Remote Sensing, 19 (16): 3127-3140.

França, H.; Setzer, A.W. (2000). AVHRR analysis of a savanna site trough a fire season in Brazil. International Journal of Remote Sensing. (no prelo).

França. H.; Setzer, A. (1997). Regime de queimadas no Parque Nacional das Emas, GO: 1973-1995. Relatório de pesquisa apresentado à FAPESP (Proc. 95/2674/9). $85 \mathrm{p}$.

Hall, D.K.; Ormsby, J.P.; Johnson, L.;Brown, J. (1980). Landsat digital analysis of the initial recovery of burned tundra of Kokolik River, Alaska.. Remote Sensing of Environment, 10(1): 263-272.

Hao, W.M.; Liu, M.H.; Crutzen, J.P. (1990). Estimates of annual and regional releases of $\mathrm{Co} 2$ and other trace gases to the atmosphere from fires in the tropics, based on the FAO statistics for the period 1975-1980. In: Goldammer, J.G., ed. Fire in the tropical biota. New York, Springer-Verlag, Cap. 20, p. 440-462. (Ecological Studies, 84).

Haridasan, M. (1996). Impactos de processos ecológicos: estresse nutricional. In: FUNATURA. Alternativas de desenvolvimento dos cerrados: manejo e conservação dos recursos naturais renováveis. Brasília, IBAMA. pp. 27-30.

Holben, B.N.; Eck, T.F.; Setzer, A.; Slutsker, I.; Pereira, A.; Markham, B.; Castle, J.V. (1996a). Temporal and spatial variability of aerosol loading and properties during the Amazon, North American temperate and boreal forest burning seasons. In: 
Levine, J.S (ed). Biomass burning and global change. London, MIT Press, Cap. 60, p. 618-636. V. 2.

Holben, B.N.; Setzer, A.; Eck, T.F.; Pereira, A.; Slutsker, I. (1996b). Effect of dryseason biomass burning on Amazon basin aerosol concentrations and optical properties, 1992-1994. Journal of Geophysical Research, 101 (D4):19465-19481.

Hueter, G.F.; Goerke, H.W.; Berksan, N.A.; Liberti, A.; Ternisien, J. (1974). Air quality for photochemical oxidants and related hydrocarbons. Bruxelas, Comittee on the challenges of modern society north Atlantic treaty organization.

Iacobelis, S.F.; Frouim, R.; Razafimpanilo, H.; Somerville, R.C.J.; Piper, S.C. (1994). North African savanna fires and atmospheric carbon dioxide. Journal of Geophysical Research, 99(D4):8321-8334.

IBGE - Instituto Brasileiro de Geografia e Estatística. (1975). Censo agropecuário Brasil: 1970. Rio de Janeiro, IBGE.

IBGE - Instituto Brasileiro de Geografia e Estatística. (1984). IX Recenseamento geral do Brasil:1980 - Censo Agropecuário. Rio de Janeiro, IBGE.

IBGE - Instituto Brasileiro de Geografia e Estatística. (1987). Sinopse preliminar do censo agropecuário: região Centro-Oeste: 1985. Rio de Janeiro, IBGE.

IBGE - Instituto Brasileiro de Geografia e Estatística. (1988). Mapa de vegetação do Brasil, 1:5.000.000. Rio de Janeiro, IBGE.

IBGE - Instituto Brasileiro de Geografia e Estatística. (1993). Mapa de vegetação do Brasil, 1:5.000.000. Rio de Janeiro, IBGE.

IBGE - Instituto Brasileiro de Geografia e Estatística. (1998). <www.sidra.ibge.gov.br>

Jacobson, J.S.; Hill, A.C. (1970). Recognition of air pollution injury to vegetation: a pictorial atlas. Pittsburgh, Air Pollution Control Association.

Kasischke, E.S.; French, N.H.F. (1995). Locating and estimating the areal extent of wildfires in Alaskan boreal forest using multiple-season AVHRR NDVI composite data. Remote Sensing of Environment, 51:263-275.

Kasischke, E.S.; French, N.H.F.; Harrell, P.; Chistensen, N.L.; Ustin, S.L.; Barry, D. (1993). Monitoring of wildfires in boreal forests using large area AVHRR NDVI Composite image data. . Remote Sensing of Environment, 45:61-71.

Kaufman, Y.J.; Setzer, A.W.; Ward, D.; Tanre, D.; Holben, B.N.; Menzel, P.; Pereira, M.C.; Rasmussen, R. (1992). Biomass burning airbone and spaceborne experiment in the Amazonas (BASE-A). Journal of Geophysical Research , 97(D13): 14.58114.599 .

Kennedy, J.P.; Belward, A.; Grégoire J-M. (1994). An improved approach to fire monitoring in West Africa using AVHRR data. International Journal of Remote Sensing, 15(11):2235-2255.

Kidwell, K.B. (1998). NOAA polar orbits data: user guide: TIROS-N, NOAA-6 through NOAA-14. NOAA. National Climatic Data Center, Washington, D.C., http://perigee.ncdc.noaa.gov/docs/podug/.

Kidwell, K.B. (1995). NOAA polar orbits data: user guide: Tiros-N, NOAA-6, NOAA-7, NOAA-8, NOAA-9, NOAA-10, NOAA-11 AND NOAA-12. NOAA. National Climatic Data Center, Washington, D.C. 
Kirchhoff, V.W.J.H. (1991). Biomass burning in the Brazilian Amazon region: measurements of $\mathrm{CO}$ and $\mathrm{O}_{3}$. In: Levine, J.S. (ed.). Global biomass burning: atmospheric, climatic, and biospheric implications. Cambridge/London, MIT Press, Cap. 12, pp. 106-111.

Kirchhoff, V.W.J.H.; Oliveira, M.A.; Alvalá, P.C. (1996). Biomass burning effects on the distribution of atmospheric methane in Brazil. In: Levine, J.S. (ed.). Biomass burning and global change. Cambridge/London, MIT Press, Vol. 2, pp. 595-598.

Kirchhoff, V.W.J.H.; Pavão, H.G. (1996). The biomass burning sequence of the Brazilian cerrado and observations of atmospheric ozone. In: Levine, J.S. (ed.). Biomass burning and global change. Cambridge/London, MIT Press, Vol. 2, pp. 599-605.

Krupa, S.V.; Kickert, R.N. (1989). The greenhouse effect: impacts of ultraviolet-B (UV-B) radiation, carbon dioxide $\left(\mathrm{CO}_{2}\right)$, and ozone $\left(\mathrm{O}_{3}\right)$ on vegetation. Environmental Pollution, 61:263-393.(Special Issue).

Laboriau, M.L.S.; Casseti, V.; Vicentini, K.R.F.; Martin, L.; Soubiès, F.; Suguio, K.; Turcq, B. (1997). Late quatrnary and climatic changes in cerrado and palm swamp from central Brazil. Paleogeography, Paleoclimatology, Paleoecology, 128:215226.

Langaas, S. (1992). Temporal and spatial distribution of savanna fires in Senegal and the Gambia, West Africa, 1989-90, derived from multi-temporal AVHRR night images. Int. J. Wildland Fire, 2(1):21-36.

Lashof, D.A. (1996). The contribution of biomass burning to global warming: an integrated assessment. In: Levine, J.S. Global biomass burning. MIT Press, pp. $441-444$.

Lenoble, J. (1991). The particulate matter from biomass burning: a tutorial and critical review of its radioative imapct. In: Levine, J.S. (ed.). Global biomass burning: atmospheric, climatic, and biospheric implications. Cambridge/London, MIT Press, Cap. 46, pp. 381-386.

Malingreau, J.P. (1986) . Global vegetation dynamics: satellite observations over Asia. International. Journal of Remote Sensing, 7(9):1121-1146.

Malingreau, J.P.; Stephens, G.; Fellows, L. Remote sensing of forest fires: Kalimantan and North Borneo:1982-83. Ambio, 14(6): 314-321.

Mantovani, J.E.; Pereira, A. (1998). Estimativa da integridade da cobertura vegetal de cerrado através de dados TM/Landsat. IX Simpósio Brasileiro de Sensoriamento Remoto: Anais. São José dos Campos, INPE. (CD).

Matson M.; Holben, B. (1987). Satellite detection of tropical burning in Brazil. International Journal of Remote Sensing, 8(3):509-516.

Matson, M.; Dozier, J. (1981). Identification of subresolution high temperature sources using a thermal IR sensor. Photogr. Eng. Rem. Sens., 47:1311-1318.

Matson, M.; Schneider, S.R.; Aldridge, B.; Satchwell, B. (1984). Fire detection using the NOAA-series satellites. US Department of Commerce. National Oceanic and Atmospheric Administration, National Environmental Satellite, Data and Information Service, NOAA Technical Report NESDIS ,7. Washington, DC. 
Miranda, H.S.; Miranda, A.C. (2000). Queimadas e estoques de carbono no Cerrado. In: Moreira, A.G; Schwartzman (ed.). As mudanças climáticas globais e os ecossistemas brasileiros. Brasilia, IPAN, pp:75-81.

NASA. (2000). http://modarch.gsfc.nasa.gov/ MODIS/INSTRUMENT/MODIS specs.html

Netter, J; Wasserman, W. (1974). Applied linear statistical models: regression, analysis of variance, and experimental designs. Homewood, Irwin, $842 \mathrm{p}$.

Nimer, E; Brandão, A.M.P.M. (1989). Balanço hídrico e clima da região dos cerrados. Rio de Janeiro, IBGE, $166 \mathrm{p}$.

OESP. (1998). O Estado de São Paulo. 29/08/98 pg. A17.

Pavão, H.G. (1994). O gás carbônico atmosférico: variações e influências das queimadas em várias regiões do Brasil. São José dos Campos, INPE. (Tese de doutorado em Ciência Espacial - INPE-5673-TDI/563).

Pereira, A.C. (1992). Monitoramento de queimadas na região dos cerrados utilizando dados AVHRR/NOAA corrigidos por dados TM/LANDSAT. (Dissertação de mestrado em Sensoriamento Remoto) - Instituto Nacional de Pesquisas Espaciais, São José dos Campos, 187 p. (INPE-5490-TDI/507).

Pereira, A.C.; Setzer, A.W. (1996). Comparison of fire in savannas using AVHRR's Channel 3 and TM images. International Journal of Remote Sensing, 17(10):1925-1937.

Pereira, J.M.C. (1999). A comparative evaluation of NOAA/AVHRR vegetation indexes for burned surface detection and mapping. IEE Transactions on Geoscience and Remote Sensing, 35: 217-225.

Pereira, M.C. (1988). Detecção, monitoramento e análise de alguns efeitos ambientais de queimadas na Amazônia através da utilização de imagens dos satélites NOAA e Landsat, e dados de aeronave. (Dissertação de mestrado em Sensoriamento Remoto) - Instituto Nacional de Pesquisas Espaciais, São José dos Campos, 268 p. (INPE-4503-TDL/326).

Pereira, M.C.; Setzer, A.W. (1986). Detecção de queimadas e plumas de fumaça na Amazônia através de imagens dos satélites NOAA. In: Simpósio Brasileiro de Sensoriamento Remoto, 4., Gramado, RS, 1986. Anais. São José dos Campos, INPE, V. 1, p. 701-70.

Pereira, M.C.; Setzer, A.W. (1993). Spectral characteristics of deforestation fires in NOAA/AVHRR images. International Journal of Remote Sensing., 14(3):583597.

Piccolini, I.; Arino, O. (2000) Toward a global burned surface world atlas. Earth Observation Quaterly, 65: 14-18.

Pivello, V.R.; Coutinho, L.M. (1992). Transfer of macro-nutrients to the atmosphere during experimental burnings in an open cerrado (Brazilian savanna). Journal of Tropical Ecology, 8 (part 4):487-497.

PNUD. (2000). Estimativa da área total queimada no cerrado brasileiro em 1999, a partir de dados orbitais. Relatório PNUD BRA/95/G31. São José dos Campos, Nature. 
Ponzoni, F.J.; Lee, D.C.L.; Hernandez Filho, P. (1986). Avaliação da área queimada e da regeneração da vegetação afetada pelo fogo no Parque Nacional de Brasília através de dados do TM/Landsat. In: I Simpósio Brasileiro de Sensoriamento Remoto:Anais. Gramado, 10-15 Ago, 1986. Anais. São José dos Campos, INPE/SELPER/SBC, 1986, V. 1, p. 615-621.

Ramos-Neto, M.B. (2000). O Parque Nacional das Emas (GO) e o fogo: implicações para a conservação biológica. Tese de doutoramento, Instituto de Biociências da Universidade de São Paulo. São Paulo, 159 p.

Razafimpanilo, H.; Frouin, R.; Iacobellis, S.F.; Somerville, C.J. (1995). Methodology for estimating burned area from AVHRR reflectance data. Remote Sensing of Environment, 54(3): 273-289.

Reatto, A.; Correia, J.R.; Spera, S.T. (1998). Solos do bioma Cerrado: aspectos pedológicos. In: Sano, S.M.; Almeida, S.P. Cerrado: ambiente e flora. Planaltina, EMBRAPA, pp. 1-43.

Ribeiro, J.F.; Walter, B.M.T. (1998). Fitofisionomias do Bioma Cerrado. In: Sano, S.M.; Almeida, S.P. Cerrado: ambiente e flora. Planaltina, EMBRAPA, pp. 89166.

Robinson, J.M. (1991). Fire from space: global fire evaluation using infrared remote sensing. International Journal of Remote Sensing, 12(1):3-24.

Rodriguez, J.M.; Ko, M.K.W.; Sze, N.D.; Heisey, C.W. (1991). Impact of biomass burning on tropospheric $\mathrm{CO}$ and $\mathrm{OH}$ : a two-dimensional study. In: Levine, J.S. (ed.). Global biomass burning: atmospheric, climatic, and biospheric implications. Cambridge/London, MIT Press, Cap. 24, pp. 351-359.

Rudorff, B.F.T. (1993). Interactive effects of enhanced tropospheric ozone and carbon dioxide on wheat and corn. (Doctoral Dissertation) - Univ. of Maryland, Maryland, $192 \mathrm{p}$.

Santos, J.R.; Aoki, H. (1981). Monitoramento do Parque Nacional de Brasília, através de dados orbitais. (1981) In: Simpósio Brasileiro de Sensoriamento Remoto, 1. São José dos Campos, 27-29 Nov. 1978. Anais. São José dos Campos, INPE/CNPq, 1981, V. 1, p. 118-134.

Setzer, A.W. (1993). Operational satellite monitoring of fires in Brazil. International Forest Fire News, 9:8-11.

Setzer, A.W. (2000) . <www.cptec.inpe.br/products/queimadas $>$.

Setzer, A.W.; Malingreau, J.P. (1996). AVHRR monitoring of vegetation fires in the tropics: toward the development of a global product. In: Levine, J.S (ed). Biomass burning and global change. London, MIT Press, Cap. 3, p. 25-39. V. 1.

Setzer, A.W.; Pereira, M.C.; Pereira Jr., A.C. (1992). O uso de satélites NOAA na detecção de queimadas no Brasil. Climanálise, 7:10-53.

Setzer, A.W.; Pereira, M.C.; Pereira Jr., A.C. (1994). Satellite studies of biomass burning in Amazonia: some practical aspects. Remote Sensing Reviews, 10:91103. 
Setzer, A.W.; Verstraete, M.M. (1994). Fire and glint in AVHRR's ch. 3: a possible reason for the non saturation mystery. International Journal of Remote Sensing, 15(3):711-718.

Shimabukuro, Y.E.; Santos, J.R.; Lee, D.C.L.; Pereira, M.C. (1991). Dados sensoriados no monitoramento e avaliação de áreas queimadas: o caso do Parque Nacional das Emas. Pesquisa Agropecuária Brasileira, 26(10): 1589-98.

Silva, G.T.; Sato, M.N.; Miranda, H.S. (1996). Mortalidade de plantas lenhosas em campo sujo de cerrado submetido a queimadas prescritas. In: Miranda, H.S.; Saito, C.H.; Dias, B.F.S. Impactos de queimadas em áreas de cerrado e restinga. Brasília, ECL/UnB, p.193-101.

Sokal, R.R.; Rohlf, F.J. (1997). Biometry: the principles and practices of statistics in biological research. New York, Freeman, 887p.

Spiegel, S. (1977) Estatística não-paramétrica. São Paulo, McGraw-Hill, 350p.

Tanaka, S.; Kimura, H. ; Suga, Y. (1980). Preparation of a 1:25000 Landsat map for assessment of burnt area on Etajima Island. International Jounal of Remote. Sensing, 4(1):17-31.

Tucker, C.J. (1979). Red and photographic infrared linear combinations for monitoring vegetation. Remote Sensing of Environment, 8(2):127-150.

Vicentini, K.R.F.; Laboriau, M.L.S. (1996). Palynological analysis of a palm swamp in Central Brazil. Journal of South American Earth Science, 9 (3/4):209-219.

Watson, C.E.; Fishman, J.; Gregory, G.L.; Sachse, G.W. (1991). A comparison of wet and dry season ozone and $\mathrm{CO}$ over Brazil using in situ and satellite measurements. In: Levine, J.S. (ed.). Global biomass burning: atmospheric, climatic, and biospheric implications. Cambridge/London, MIT Press, Cap. 14, pp. 115-121.

Wightman, J.M. (1973). Detection, mapping and estimation of rate of spread of grass fires from southern African ERST-1 imagery. Symposium on Significant Results Obtained from the Earth Resources Technology Satellite-1. Maryland, 5-9 March 1973. Proceedings. Washington, NASA, V. 1, p. 593-601.

WWF - Fundo Mundial para a Natureza. (1998). De grão em grão, o Cerrado perde espaço. Brasilia, Procer, 66p.

Yanasse, C.C.F. (1991). Statistical analysis of synthetic aperture radar images and its applications to system analysis and change detection. University of Sheffield. (Thesis presented for the degree of doctor of Philosophy).

Zepp, R.G.; Miller, W.L.; Tarr, M.A.; Burke, R.A.; Parsons, D.A.B.; Scholes, M.C. (1996). Dynamics of carbon monoxide emissions from soil and vegetation in a Southern African savanna. In: Levine, J.S. (ed.). Biomass burning and global change. Cambridge, The MIT Press. Cap. 36 pp. 381-388.

Zherebtsov, G.; Kokourov, V.D.; Koshelev, V.V; Minko, N.P. (1996). Use of NOAA AVHRR data to detect forest fires. Earth Obs. Rem. Sens., 13:783-787 